\author{
Universidade de São Paulo \\ Instituto de Química de São Carlos \\ Departamento de Físico-Química \\ Grupo de Materiais Coloidais
}

\begin{abstract}
Natalia Sanchez Moreno
SÍNTESE DE NANOPARTÍCULAS DE MAGNETITA DOPADAS COM ÍONS TERRAS RARAS E AVALIAÇÃO DAS PROPRIEDADES MAGNETO-ÓPTICAS
\end{abstract}

São Carlos 
Natalia Sanchez Moreno

\title{
SÍNTESE DE NANOPARTÍCULAS DE MAGNETITA DOPADAS COM ÍONS TERRAS RARAS E AVALIAÇÃO DAS PROPRIEDADES MAGNETO-ÓPTICAS
}

\section{Exemplar revisado}

O exemplar original encontra-se em acervo reservado na Biblioteca do IQSC-USP

\begin{abstract}
Dissertação apresentada ao Instituto de Química de São Carlos da Universidade de São Paulo como parte dos requisitos para obtenção do título de mestre em química.
\end{abstract}

Área de concentração: Físico-Química

Orientador: Prof. Dr. Laudemir Carlos Varanda

São Carlos 
Dedico este trabalho aos meus pais, Marcos e Marisa, por não medirem esforços para que eu pudesse realizar mais este sonho. 


\section{Agradecimentos}

Ao Prof. Dr. Laudemir Carlos Varanda, pela oportunidade de realizar este trabaIho sob sua orientação, por todos os ensinamentos, confiança, paciência e amizade.

Aos meus pais, Marcos e Marisa, e irmão Rafael, pelo amor, incentivo e suporte que me permitiram chegar até aqui.

Ao Gonzo, pelo companheirismo, apoio, suporte técnico e paciência durante esses anos.

Aos companheiros do grupo de Materiais Coloidais, pela amizade dentro e fora do laboratório, pelo apoio, incentivo e por tornarem essa jornada mais divertida.

À Yolanda, pela amizade e confiança.

Aos meus amigos e família, que de alguma forma contribuíram para o desenvolvimento deste trabalho.

Ao Instituto de Química de São Carlos-USP, pela infraestrutura disponibilizada. Aos docentes do IQSC e IFSC e demais funcionários, pela qualidade do serviço prestado, contribuindo para o desenvolvimento deste trabalho.

Ao Prof. Dr. Daniel Reinaldo Cornejo, do Instituto de Física da USP e ao Prof. Dr. Fernando Aparecido Sigoli, do Instituto de Química da Universidade de Campinas, que gentilmente disponibilizaram equipamentos de caracterização necessários para a obtenção dos resultados apresentados e discutidos neste trabalho. Ao Prof. Dr. Danilo Manzani, pelo suporte com as análises de luminescência e pelo reagente gentilmente cedido.

Ao CNPq, pela bolsa concedida.

Ao CNPq, CAPES e FAPESP pelo apoio financeiro. 


\section{Resumo}

\section{SIINTESE DE NANOPARTÍCULAS DE MAGNETITA DOPADAS COM ÍONS TERRAS RARAS E AVALIAÇÃO DAS PROPRIEDADES MAGNETO-ÓPTICAS}

A combinação das propriedades dos lantanídeos (Ln) com as propriedades das ferritas por meio de dopagem tem sido de grande interesse nas últimas décadas, uma vez o processo de dopagem é capaz de melhorar as propriedades estruturais, elétricas e magnéticas das ferritas, podendo ampliar suas possíveis aplicações. Neste trabalho, o processo poliol foi utilizado para obtenção de nanopartículas (NP) de magnetita dopadas com neodímio e európio em etapa única. A metodologia empregada envolve a adição de acetilacetonato de ferro(III) e complexos de terras raras ao meio redutor de tetraetilenoglicol. Os complexos utilizando os ligantes tris(tenoiltrifluoroacetonato) $\left(\mathrm{Eu}(\mathrm{TTA})_{3}\right.$ e $\left.\mathrm{Nd}(\mathrm{TTA})_{3}\right)$ e acetilacetonato $\left(\mathrm{Eu}(\mathrm{acac})_{3}\right.$ e $\left.\mathrm{Nd}(\mathrm{acac})_{3}\right)$ foram preparados, caracterizados e empregados como precursores dos íons terras raras no meio de reação. Análises de difração de raios $X$ (DRX) e espectroscopia de infravermelho com transformada de Fourier (FTIR) confirmaram a formação da estrutura da magnetita e apresentaram indícios da substituição de íons $\mathrm{Fe}^{3+}$ por íons $\mathrm{Ln}^{3+}$. A microscopia eletrônica de transmissão (MET) mostrou nanopartículas esferoidais com distribuição de tamanho estreita e tamanho médio da ordem de $7 \mathrm{~nm}$. A presença dos elementos terras raras foi confirmada por espectroscopia de energia dispersiva de raios $\mathrm{X}$ (EDX) e por mapeamento utilizando a técnica STEM (scanning-transmission electron microscopy). Nossos resultados mostraram que o complexo TTA induz a formação de fases secundárias em todas as condições analisadas, o que não foi observado para o caso dos complexos com acetilacetonato. Ainda, foi possível determinar um tempo ótimo de reação para a dopagem de 3 horas, promovendo maior controle dos processos de nucleação e crescimento das NP e um valor crítico de dopagem ao redor de $15-20 \%$. As amostras apresentaram comportamento superparamagnético e efeito de exchange bias condizentes com o tamanho das NP e com efeitos de defeitos estruturais induzidos pela formação de fases hidroxiladas na superfície das NP e/ou da presença do dopante. Não foi possível promover uma caracterização estrutural mais aprofundada, no entanto, esta deverá ser realizada para confirmar esses resultados. Os valores de magnetização de saturação (Ms) são condizentes com a literatura tanto para as NP de magnetita dopadas quanto não dopadas. Este trabalho mostra que o precursor de íons de terras e as condições de síntese têm um grande impacto na formação de fases secundárias, assim como no tamanho das nanopartículas, dispersividade e propriedades magnéticas dos materiais. 


\section{Abstract}

SYNTHESIS OF RARE EARTH-DOPED MAGNETITE NANOPARTICLES AND EVALUATION OF MAGNETO-OPTICAL PROPERTIES

The combination of lanthanides' (Ln) and ferrites' properties through doping has been of great interest in recent decades since the doping process can improve the structural, electrical, and magnetic properties of ferrites, expanding their applications. In this work, the modified polyol process has been used to obtain neodymium and europium doped magnetite NP, in a one-pot reaction. The methodology employed involves adding iron(III) acetylacetonate and rare earth complexes to tetraethylene glycol reducing medium. The complexes using the tris(tenoyltrifluoroacetonate) ligands (Eu(TTA $)_{3}$ and $\left.\mathrm{Nd}(\mathrm{TTA})_{3}\right)$ and acetylacetonate $\left(\mathrm{Eu}(\mathrm{acac})_{3}\right.$ and $\left.\mathrm{Nd}(\mathrm{acac})_{3}\right)$ were prepared, characterized and used as precursors of rare-earth ions in the reaction medium. X-ray diffraction (XRD) and Fourier transform infrared (FTIR) spectroscopy confirmed the formation of the magnetite structure and showed evidence of $\mathrm{Fe}^{3+}$ ion replacement for $\mathrm{Ln}^{3+}$ ions. Transmission electron microscopy (TEM) showed spheroidal nanoparticles with narrow size distribution and an average size of $7 \mathrm{~nm}$. The presence of rare earth elements was confirmed by X-ray dispersive energy spectroscopy (EDX) and by mapping using the STEM (scanning-transmission electron microscopy) technique. Our results showed that the TTA complex induces the formation of secondary phases in all conditions analyzed, which was not observed for acetylacetonate complexes. Furthermore, it was possible to determine an optimal reaction time for doping of 3 hours, promoting greater control of the nucleation and growth processes of NP and a critical doping value of around $15-20 \%$. The samples showed superparamagnetic behavior and exchange bias effects consistent with the size of the NP and with the effects of structural defects induced by the formation of hydroxylated phases on the surface of the NP and/or the presence of the dopant. It was not possible to promote a more in-depth structural characterization, however, this should be done to confirm these results. The saturation magnetization values (Ms) are consistent with the literature for both doped and non-doped magnetite NP. This work shows that the precursor of rare-earth ions has a great impact on the formation of secondary phases, as well as on the size of the NP, dispersivity, and magnetic properties of the materials. 


\section{Lista de ilustrações}

Figura 1 - Escala comparativa entre as dimensões de um angstrom e um centímetro. . . . . . . . . . . . . . . . . . .

Figura 2 - Proporção de átomos presentes na superfície de NP de acordo com o tamanho da partícula. . . . . . . . . . . . . . . . . . . . . .

Figura 3 - Representação da estrutura de multidomínios magnéticos separados por paredes de domínios. . . . . . . . . . . . . . . . . . . . . . .

Figura 4 - Representação de curvas de magnetização em função do campo magnético $(\mathrm{Hb})$ aplicado para materiais ferromagnéticos $(\mathrm{a})$ e superparamagnéticos (b). São indicadas a magnetização de saturação (Ms), magnetização remanente (Mr) e coercividade $(\mathrm{Hc})$.

Figura 5 - Representação da curva de magnetização de um material ferromagnético sob efeito de exchange bias, onde Hc1 e Hc2 são os valores de coercividade e Heb indica o valor do deslocamento do centro da curva em relação à origem . . . . . . . . . . . . . . . . . . . . .

Figura 6 - Esquema do efeito de exchange bias na interface entre um material ferromagnético (FM) e um antiferromagnético (AFM), mostrando o ordenamento dos spins do sistema antes do resfriamento com campo magnético (a), etapas da curva de histerese e os respectivos ordenamentos de spins de acordo com a variação do campo magnético após o resfriamento (b) a (e). . . . . . . . . . . . . . . . . . . . . 18

Figura 7 - Posição dos elementos terras raras na tabela periódica. . . . . . . . 21

Figura 8 - Estratégias para multifuncionalização de nanopartículas. . . . . . . . 24

Figura 9 - Representação de uma cela unitária da estrutura cristalina espinélio mostrando os sítios tetraédricos (círculos vermelhos) e octaédricos (círculos verdes) ocupados pelos íons metálicos. Os círculos maiores representam átomos de oxigênio. . . . . . . . . . . . . . . . . .

Figura 10 - Microscopia eletrônica de transmissão de NPM preparadas por meio de coprecipitação (a), microemulsão (b) e decomposição térmica (c).

Figura 11 - Diagramas do modelo de La Mer para nucleação e crescimento de partículas. As concentrações de monômeros e núcleos estáveis em relação ao tempo são mostradas para processos com etapa de nucleação rápida (a) e lenta (b), assim como a distribuição de núcleos estáveis em ambos os processos(c). . . . . . . . . . . . . . . . . .

Figura 12 - Representação do aparato experimental utilizado (a), rampa de aquecimento (b) e fluxograma do procedimento experimental empregado na síntese das NPF. . . . . . . . . . . . . . . . . . . . . . . . . 
Figura 13 - Fluxograma do procedimento experimental empregado no preparo da solução de $\mathrm{EuCl}_{3} \ldots$. . . . . . . . . . . . . . . . . . . . . . .

Figura 14 - Fluxograma do procedimento experimental empregado na síntese do complexo $\mathrm{Eu}(\mathrm{TTA})_{3}$. . . . . . . . . . . . . . . . . . . . .

Figura 15 - Fluxograma do procedimento experimental empregado para a síntese de Eu(acac) $)_{3}$. . . . . . . . . . . . . . . . . . . . . .

Figura 16 - Fluxograma do procedimento experimental empregado na síntese das NPF dopadas com íons de terras raras em atmosfera de $\mathrm{N}_{2}$. . .

Figura 17 - Fluxograma do procedimento experimental empregado na síntese das NPF dopadas com íons de terras raras. . . . . . . . . . . . . . .

Figura 18 - Difratograma de raios X obtido para a amostra de ferrita sintetizada em comparação ao padrão JCPDF 19-629 da fase espinélio invertida de magnetita. . . . . . . . . . . . . . . . . . . . . . . .

Figura 19 - Espectro FTIR para a amostra de magnetita. A área em destaque apresenta bandas referentes à derivados da síntese ligados à superfície das NPF. . . . . . . . . . . . . . . . . . . . . . . . . . . . . .

Figura 20 - Curva de magnetização da amostra de magnetita. Região em destaque na figura mostra o deslocamento da curva devido ao efeito de exchange bias negativo. . . . . . . . . . . . . . . . . .

Figura 21 - Microscopia eletrônica de transmissão da amostra de ferrita de ferro e histograma de distribuição dos tamanhos das nanopartículas medidas.

Figura 22 - Espectros FTIR do Eu(TTA) ${ }_{3}$ sintetizado e de seus precursores $\mathrm{Eu}_{2} \mathrm{O}_{3}$ e TTA (a), estrutura molecular do complexo $\mathrm{Eu}(\mathrm{TTA})_{3}$ hidratado (b) e fotos da amostra sob irradiação de luz ultravioleta (365 nm) (c).

Figura 23 - Espectros FTIR do $\mathrm{Nd}(\mathrm{TTA})_{3}$ sintetizado e de seus precursores $\mathrm{Nd}_{2} \mathrm{O}_{3}$ e TTA . . . . . . . . . . . . . . . . . . . .

Figura 24 - Difratograma de raios $\mathrm{X}$ obtido para as amostras de magnetita dopadas com európio sintetizadas com tempos de refluxo iguais a $3 \mathrm{~h}$ (Eu:NPF_TTA_3), 6h (Eu:NPF_TTA_6), 8h (Eu:NPF_TTA_8), 10h (Eu: NPF_TTA_10), 12h (Eu:NPF_TTA_12), 14h (Eu:NPF_TTA_14), 16h (Eu:NPF_TTA_16), 18h (Eu:NPF_TTA_3), 20h (Eu:NPF_TTA_20) e 22h (Eu:NPF_TTA_22) em comparação ao padrão JCPDF 19-629 da fase espinélio invertida de magnetita. As linhas tracejadas indicam a presença de picos referentes a uma fase secundária. . . . . . . . . .

Figura 25 - Espectro FTIR da amostra Eu:NPF_TTA_3. A área em destaque apresenta bandas referentes à derivados da síntese ligados à superfície das NPF. 
Figura 26 - Microscopia eletrônica de transmissão das amostras de magnetita dopadas com európio Eu:NPF_TTA_22(a), Eu:NPF_TTA_20 (b), Eu: NPF_TTA_18(c), Eu:NPF_TTA_16(d), Eu:NPF_TTA_14 (e), Eu:NPF _TTA_12 (f), Eu:NPF_TTA_10 (g), Eu:NPF_TTA_8 (h), Eu:NPF_TTA 6 (i) e Eu:NPF_TTA_3 (j). . . . . . . . . . . . . . . . . . . . .

Figura 27 - Histogramas de distribuição de tamanho das NP de magnetita dopadas com európio (Eu:NPF). . . . . . . . . . . . . . . . . . . . . . .

Figura 28 - Mapeamento dos elementos Fe e Eu por STEM na amostra Eu:NPF_TTA_3. . . . . . . . . . . . . . . . . . . . .

Figura 29 - Curva de magnetização das amostras Eu:NPF_TTA_3, Eu:NPF_TTA_6, Eu:NPF_TTA_8, Eu:NPF_TTA_14 e Eu:NPF_TTA_22. Região em destaque na figura mostra o deslocamento das curvas de histerese devido ao efeito de exchange bias negativo. . . . . . . . . . . . . .

Figura 30 - Difratograma de raios $\mathrm{X}$ obtido para as amostras de magnetita dopadas com neodímio sintetizadas com tempos de refluxo iguais a 3h (Nd:NPF_TTA_3) e 6h (Nd:NPF_TTA_6), em comparação ao padrão JCPDF 19-629 da fase espinélio invertida de magnetita. As linhas tracejadas indicam a presença de picos referentes a uma fase secundária. . . . . . . . . . . . . . . . .

Figura 31 - Microscopia eletrônica de transmissão das amostras de magnetita dopadas com neodímio Nd:NPF_TTA_6 (a) e Nd:NPF_TTA_3 (b) e os respectivos histogramas de distribuição de tamanho das NP. . .

Figura 32 - Mapeamento dos elementos Fe e Nd por STEM na amostra Nd:NPF_TTA_6. . . . . . . . . . . . . . . . . .

Figura 33 - Curva de magnetização das amostras Nd:NPF_TTA_6 e Nd:NPF_TTA_3. Região em destaque na figura mostra o deslocamento das curvas de histerese devido ao efeito de exchange bias negativo. . .

Figura 34 - Curvas termogravimétricas (TG) e curvas de primeira derivada (DTG) dos complexos $\mathrm{Nd}(\mathrm{acac})_{3}$ e $\mathrm{Nd}(\mathrm{TTA})_{3}$ obtidas em atmosfera de ar sintético. . . . . . . . . . . . . . . .

Figura 35 - Difratograma de raios $\mathrm{X}$ obtido para as amostras de magnetita dopadas com $\mathrm{Nd}$ sintetizadas com tempos de refluxo iguais a $0,5 \mathrm{~h}$ (Nd:NPF_0,5), 1,0h (Nd:NPF_1), 1,5h (Nd:NPF_1,5), 2,0h (Nd:NPF_2), 2,5h (Nd:NPF_2,5), 3,0h (Nd:NPF_3), 3,5h (Nd:NPF_3,5) e 3,5 (Nd:NPF_4) em comparação à ferrita não dopada (NPF) e ao padrão JCPDF 19-629 da fase espinélio invertida de magnetita. . . . . . . . 
Figura 36 - Microscopias eletrônicas de transmissão das amostras sintetizadas com tempos de refluxo iguais a a) 0,5h (Nd:NPF_0,5), b) 1,0h (Nd: NPF_1), c) 1,5h (Nd:NPF_1,5), d) 2,0h (Nd:NPF_2), e) 2,5h (Nd:NPF_2,5), f) 3,0h (Nd:NPF_3), g) 3,5h (Nd:NPF_3,5) e h) 3,5 (Nd:NPF_4).

Figura 37 - Histogramas de distribuição dos tamanhos das nanopartículas medidas para as amostras (Nd:NPF_3), (Nd:NPF_3,5) e (Nd:NPF_4). . .

Figura 38 - Difratograma de raios $\mathrm{X}$ obtido para as amostras sintetizadas utilizando proporções de Nd/Fe iguais a 1/10 (Nd:NPF_10), 2/10 (Nd:NPF _20) e 3/10 (Nd:NPF_30) em comparação à ferrita não dopada (NPF) e ao padrão JCPDF 19-629 da fase espinélio invertida de magnetita.

Figura 39 - Imagens de MET obtidas para as amostras sintetizadas utilizando proporções de Nd/Fe iguais a 1/10 (Nd:NPF_10) (a), 2/10 (Nd:NPF_20) (b), 3/10 (Nd:NPF_30) (c) e histogramas de distribuição dos tamanhos das nanopartículas medidas $(\mathrm{d})$. . . . . . . . . . . . . . . .

Figura 40 - Espectros EDX das amostras Nd:NPF_20 e Nd:NPF_30 (a) e mapeamento por STEM dos elementos Fe e Nd na amostra Nd:NPF_10 (b). . . . . . . . . . . . . . . . . . . . . .

Figura 41 - Curva de magnetização das amostras de magnetita dopadas com neodímio (Nd:NPF) em diferentes proporções. Região em destaque na figura mostra o deslocamento das curvas de histerese devido ao efeito de exchange bias negativo. . . . . . . . . . . . . . . . . .

Figura 42 - Espectro FTIR do Eu(acac) $)_{3}$ sintetizado (a), estrutura molecular do acetilacetonato de európio (III) hidratado (b) e fotos da amostra sob irradiação de luz ultravioleta $(365 \mathrm{~nm})(\mathrm{c}) . .$. . . . . . . . . . . . . . .

Figura 43 - Curvas termogravimétricas (TG) e suas respectivas derivadas (DTG) dos complexos $\mathrm{Eu}(\mathrm{acac})_{3}$ e $\mathrm{Eu}(\mathrm{TTA})_{3}$ obtidas em atmosfera de ar sintético. . . . . . . . . . . . . . . . .

Figura 44 - Difratograma de raios $X$ obtido para as amostras sintetizadas utilizando proporções de Eu/Fe iguais a 1/10 (Eu:NPF_10), 2/10 (Eu:NPF_20), 3/10 (Eu:NPF_30) e 4/10 (Eu:NPF_40) em comparação à ferrita não dopada (NPF) e ao padrão JCPDF 19-629 da fase espinélio invertida de magnetita. . . . . . . . . . . . . . . . . . . . .

Figura 45 - Espectro FTIR da amostra Eu:NPF_20. A área em destaque apresenta bandas referentes à derivados da síntese ligados à superfície das NPF.

Figura 46 - Imagens de MET obtidas para as amostras sintetizadas utilizando proporções de Eu/Fe iguais a 1/10 (Eu:NPF_10) (a), 2/10 (Eu:NPF_20) (b), 3/10 (Eu:NPF_30) (c), 4/10 (Eu:NPF_40) (d) e histogramas de distribuição dos tamanhos das nanopartículas medidas (e). . . . 
Figura 47 - Espectro EDX das amostras Eu:NPF_10, Eu:NPF_20 e Eu:NPF_30. 76 Figura 48 - Curva de magnetização das amostras de magnetita dopadas com európio (Eu:NPF) em diferentes proporções. Região em destaque na figura mostra o deslocamento das curvas de histerese devido ao efeito de exchange bias negativo. . . . . . . . . . . . . . 76

Figura 49 - Espectros de excitação (monitorada em 615nm) (a) e emissão (b) das amostras dopadas com európio em diferentes proporções de Eu/Fe (excitadas a $280 \mathrm{~nm}$ ) 


\section{Lista de tabelas}

Tabela 1 - Comparação entre diferentes métodos de síntese de nanopartículas

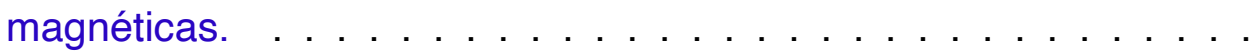

Tabela 2 - Variações nos parâmetros de reação empregados durante a síntese de NPF dopadas com terras raras em atmosfera de $\mathrm{N}_{2} \ldots \ldots \ldots$. .

Tabela 3 - Variações nos parâmetros de reação empregados durante a síntese de NPF dopadas com terras raras. . . . . . . . . . . . . . . .

Tabela 4 - Variações no tempo de refluxo empregado durante a síntese de NPF dopadas com terras raras em atmosfera de $\mathrm{N}_{2} \ldots \ldots \ldots \ldots$. . .

Tabela 5 - Comparação entre os valores de diâmetro médio (D) e tamanho de cristalito $\left(\mathrm{D}_{h k l}\right)$ para as amostras de magnetita dopadas com európio (Eu:NPF) em atmosfera de $\mathrm{N}_{2} \ldots \ldots \ldots \ldots \ldots \ldots$

Tabela 6 - Valores de magnetização de saturação (Ms), coercividade (Hc) e campo de exchange bias (Heb) das amostras de magnetita dopadas com európio (Eu:NPF) em atmosfera de $\mathrm{N}_{2} \ldots \ldots \ldots \ldots$. . .

Tabela 7 - Valores de magnetização de saturação (Ms), coercividade (Hc) e campo de exchange bias (Heb) das amostras de magnetita dopadas com neodímio (Nd:NPF) em atmosfera de $\mathrm{N}_{2} \ldots \ldots$. . . . .

Tabela 8 - Variações no tempo de refluxo empregado durante a síntese de NPF dopadas com neodímio (Nd:NPF). . . . . . . . . . . . . . .

Tabela 9 - Variações na proporção dos precursores utilizados na síntese de NPF dopadas com neodímio (Nd:NPF). . . . . . . . . . . . . .

Tabela 10 - Valores de magnetização de saturação (Ms), coercividade (Hc) e campo de exchange bias (Heb) das amostras de magnetita dopadas com neodímio (Nd:NPF). . . . . . . . . . . . . . . . . .

Tabela 11 - Variações na proporção dos precursores utilizados na síntese de NPF dopadas com európio (Eu:NPF). . . . . . . . . . . . . 72

Tabela 12 - Comparação entre os valores de diâmetro médio (D) e tamanho de cristalito $\left(\mathrm{D}_{h k l}\right)$ para as amostras de magnetita dopadas com európio (Eu:NPF). . . . . . . . . . . . . . . . .

Tabela 13 - Valores de magnetização de saturação (Ms), coercividade (Hc) e campo de exchange bias (Heb) das amostras de magnetita dopadas com európio (Eu:NPF). . . . . . . . . . . . . . . 


\section{Sumário}

INTRODUÇÃo . . . . . . . . . . . . . . . . . 13

$1.1 \quad$ Nanociência . . . . . . . . . . . . . . . . . . 13

$1.2 \quad$ Magnetismo em nanoescala . . . . . . . . . . . . . . . . 14

$1.2 .1 \quad$ Efeito de exchange bias $(\mathrm{EB}) \ldots \ldots \ldots \ldots$

$1.3 \quad$ Nanopartículas magnéticas (NPM) . . . . . . . . . . . . . . . . . . 19

$1.4 \quad$ Terras $\operatorname{raras}(\mathrm{TR}) \ldots \ldots \ldots \ldots \ldots$

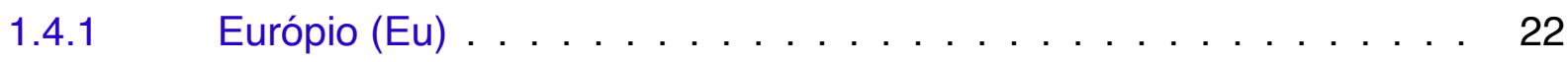

$1.4 .2 \quad$ Neodímio $(\mathrm{Nd}) \ldots \ldots \ldots \ldots$. . . . . . . . . . . . . . . . . . . . . . .

1.5 Multifuncionalização de nanopartículas . . . . . . . . . . . . . 23

1.5.1 Dopagem . . . . . . . . . . . . . . . . . 24

$1.6 \quad$ Método de síntese . . . . . . . . . . . . . . . . . 25

1.7 Justificativa do trabalho . . . . . . . . . . . . . . 28

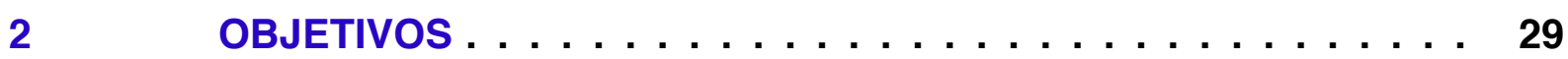

3 PROCEDIMENTO EXPERIMENTAL . . . . . . . . . . . . . . . 30

$3.1 \quad$ Síntese da ferrita de ferro (magnetita) . . . . . . . . . . . . . . 30

3.2 Preparo das soluções de cloreto de európio $\left(\mathrm{EuCl}_{3}\right)$ e cloreto de neodímio $\left(\mathrm{NdCl}_{3}\right) \ldots \ldots \ldots . \ldots . \ldots 31$

3.2.1 Preparo da solução sólida de 3\% de alaranjado de xilenol . . . . . . 32

3.2.2 Preparo da solução de tampão acetato com $\mathrm{pH}=5,8 \ldots \ldots$. . . . . . . 32

3.2.3 Preparo e padronização da solução de EDTA . . . . . . . . . . . . . 33

3.2.3.1 Preparo da solução de $\mathrm{CaCO}_{3} \ldots \ldots \ldots$. . . . . . . . . . . . . . 33

3.2.3.2 Preparo da solução do indicador preto de eriocromo T . . . . . . . . . . . 33

3.2.3.3 Preparo da solução tampão hidróxido de amônio/cloreto de amônio $\mathrm{pH}=10 \quad 33$

3.3 Síntese dos complexos tris(tenoiltrifluoroacetonato) de európio(III) $\left(\mathrm{Eu}(\mathrm{TTA})_{3}\right)$ e tris(tenoiltrifluoroacetonato) de neodímio(III) $\left(\mathrm{Nd}(\mathrm{TTA})_{3}\right) \ldots \ldots \ldots \ldots$

3.4 Síntese e purificação do complexo acetilacetonato de európio(III) $\mathrm{Eu}(\mathbf{a c a c})_{3} \ldots \ldots \ldots . \ldots \ldots$

3.5 Síntese das NPF dopadas com íons terras raras em atmosfera de $\mathrm{N}_{2} \ldots \ldots \ldots \ldots$. . . . . . . . . . . . . . 36

3.6 Síntese das NPF dopadas com íons terras raras utilizando acetilacetonato de $\mathbf{T R}(\mathrm{III}) \ldots \ldots . \ldots 38$

$3.7 \quad$ Caracterização . . . . . . . . . . . . . . . . . . . . . . . . . 39

3.7.1 Difratometria de raios X $(\mathrm{DRX}) \ldots \ldots \ldots \ldots$

3.7.2 Microscopia eletrônica de transmissão (MET) . . . . . . . . . . . . . 40

3.7.3 Espectroscopia de energia dispersiva de raios X (EDX) . . . . . . . 40 
3.7.4 Espectroscopia no infravermelho com transformada de Fourier (FTIR) 40

3.7.5 Espectroscopia de fluorescência . . . . . . . . . . . 41

3.7.6 Análise termogravimétrica $(\mathrm{TG}) \ldots \ldots \ldots \ldots . \ldots 41$

3.7.7 Magnetometria de Amostra Vibrante (VSM) $\ldots \ldots \ldots \ldots$

$4 \quad$ RESULTADOS E DISCUSSÃo $\ldots \ldots \ldots \ldots \ldots \ldots \ldots \ldots$

$4.1 \quad$ Síntese da ferrita de ferro (magnetita) $\ldots \ldots \ldots \ldots \ldots$

4.2 Síntese dos complexos $\mathrm{Eu}(\mathrm{TTA})_{3}$ e $\mathrm{Nd}(\mathrm{TTA})_{3} \ldots \ldots . \ldots 46$

4.3 Síntese de magnetitas dopadas com íons terras raras em atmosfera de $\mathbf{N}_{2} \ldots \ldots \ldots \ldots \ldots \ldots \ldots$

4.3.1 Síntese de magnetita dopada com európio (Eu:NPF) . . . . . . 48

4.3.2 Síntese de magnetita dopada com neodímio (Nd:NPF) . . . . . . 56

4.4 Síntese de magnetita dopada com neodímio utilizando $\mathrm{Nd}(\mathrm{acac})_{3}$ como precursor de TR . . . . . . . . . . . . . . . . 61

4.4.1 Estudo do impacto do tempo de refluxo na síntese de magnetita dopada com neodímio . . . . . . . . . . . . . . . . . . 62

4.4.2 Síntese de magnetita dopada com neodímio em diferentes proporções 65

4.5 Síntese do complexo $\mathrm{Eu}(\mathrm{acac})_{3} \ldots \ldots \ldots \ldots$

4.6 Síntese de magnetita dopada com európio utilizando $\mathrm{Eu}(\mathrm{acac})_{3}$ como precursor de TR . . . . . . . . . . . . 71

$5 \quad$ CONCLUSÃo $\ldots \ldots \ldots \ldots \ldots \ldots \ldots$

6 PERSPECTIVAS PARA TRABALHOS FUTUROS $\ldots \ldots \ldots . .81$

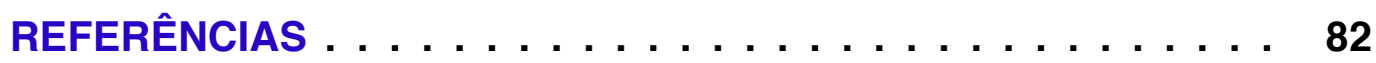




\section{Introdução}

\subsection{Nanociência}

Nanociência é o estudo de materiais em nanoescala, cujas propriedades diferem significativamente daquelas de seu material constituinte em escala macroscópica (bulk) ou mesmo microscópica (átomos e moléculas). (1, 2, 3) A nanoescala, baseada no nanômetro $(\mathrm{nm})$, existe especificamente entre 1 e $100 \mathrm{~nm}$ e é ilustrada na Figura 1. De forma geral, os materiais com pelo menos uma de suas dimensões na nanoescala são considerados nanomateriais.(3)

Figura 1 - Escala comparativa entre as dimensões de um angstrom e um centímetro.

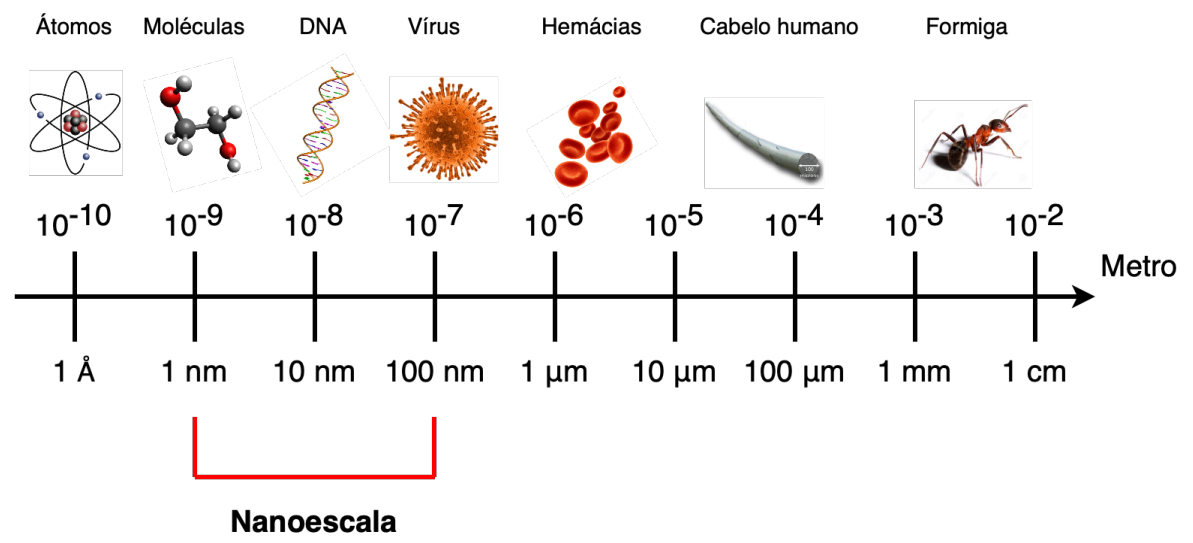

Fonte: Autoria própria.

Existem dois conceitos-chave de nanociência: a relação área de superfície/ volume (S/V) e o confinamento quântico. Com o aumento da S/V nos nanomateriais, mais átomos ficam expostos ao meio e um número maior das chamadas "ligações pendentes" tornam-se disponíveis na superfície, o que torna a partícula mais ativa quimicamente. $(1,2,3,4)$ Conforme mostrado na Figura 2, em partículas de diâmetro em torno de $10 \mathrm{~nm}, 10 \%$ dos átomos estão localizados na superfície, já em partículas de $3 \mathrm{~nm}$ diâmetro, a fração de átomos expostos na superfície é de $30-40 \% .(1,5)$ As propriedades dos nanomateriais estão diretamente relacionadas não só à composição química, mas também à forma e ao tamanho das nanopartículas (NP), devido à $\mathrm{S} / \mathrm{V}$, por isso existe a necessidade de controlar esses fatores quando se deseja uma nanomaterial com uma resposta específica. 
Figura 2 - Proporção de átomos presentes na superfície de NP de acordo com o tamanho da partícula.

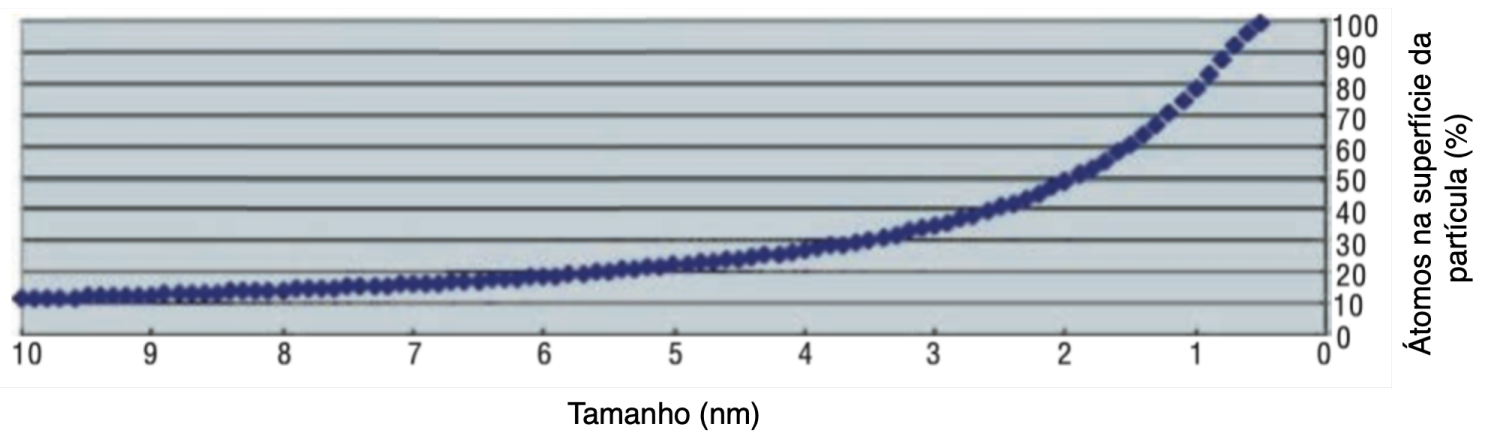

Fonte: Adaptado de Binns, C. Introduction to Nanoscience and Nanotechnology. Wiley, 2010. 301p.(5)

A restrição do movimento dos elétrons é denominada confinamento quântico e é decorrente da redução do tamanho do material, fazendo com que as funções de onda eletrônica sejam mais estreitamente confinadas, resultando em mudanças nas propriedades eletrônicas do nanomaterial.(3) Um menor tamanho de partícula resulta em um confinamento mais forte, que dá origem ao aumento do gap e modifica a estrutura da banda do material. Isso resulta em mudanças na mobilidade do elétron, na massa efetiva, constante dielétrica relativa, propriedades ópticas, entre outros.(1) Devido ao confinamento quântico, as nanopartículas apresentam propriedades interessantes, como variações na cor das suspensões coloidais com a alteração do tamanho das partículas, fotoluminescência aprimorada, entre outras. $(1,3)$

\subsection{Magnetismo em nanoescala}

O magnetismo de nanopartículas apresenta importantes diferenças em comparação ao magnetismo de sólidos estendidos. Essas diferenças podem ser explicadas pela maior proporção de átomos de superfície, quebra de simetria de translação, presença de sítios com número de coordenação reduzido e dimensões comparáveis entre o tamanho das nanopartículas magnéticas e o tamanho limite de monodomínios magnéticos. $(6,7)$ Em partículas grandes, existe uma estrutura denominada multidomínios magnéticos, onde regiões de magnetização uniformes são separadas por paredes de domínio (Figura 3). A formação destas paredes é um processo direcionado pelo equilíbrio entre a energia magnetostática, que aumenta proporcionalmente com o volume dos materiais, e a energia das paredes de domínio, que aumenta proporcionalmente com a área de interface entre os domínios.(7) 
Figura 3 - Representação da estrutura de multidomínios magnéticos separados por paredes de domínios.

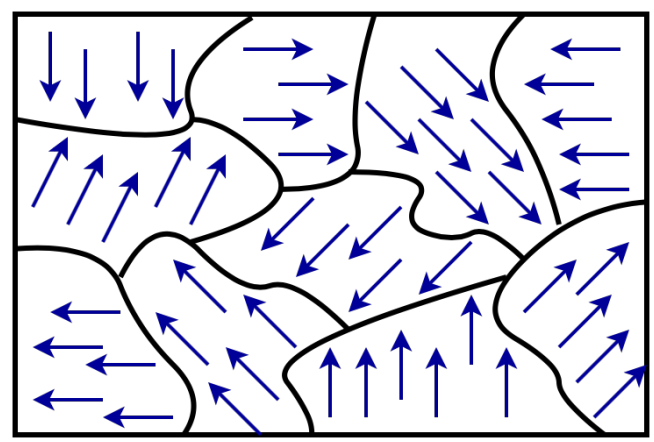

Fonte: Autoria própria

Em partículas nanométricas, há um diâmetro crítico (Dc) abaixo do qual é necessária mais energia para criar paredes de domínio do que para suportar a energia magnetoestática de um estado de monodomínio (SD, do inglês single domain). Desta forma, abaixo de Dc, os monodomínios se apresentam como a configuração mais favorável para as partículas.(8) O valor do diâmetro crítico é característico de cada material e encontra-se, geralmente, na escala de nanômetros.(7)

Nanopartículas constituídas por um único domínio magnético possuem alta constante de momento magnético e se comportam como um grande átomo paramagnético, apresentando rápida resposta a um campo magnético aplicado, com remanência (Mr) (magnetismo residual que permanece no circuito após a remoção do campo externo aplicado) e coercividade (Hc) (campo que deve ser aplicado para que não haja magnetização remanente) insignificantes, sendo classificadas como superparamagnéticas.(8) A ausência de remanência e coercividade ampliam as possíveis aplicações das nanopartículas magnéticas em sistemas biológicos, uma vez que a resposta magnética restrita a aplicação de campo externo reduz efeitos de aglomeração por interações de acoplamento magnético, aumentando a estabilidade coloidal das NP em meio fisiológico.(7)

O comportamento magnético de nanopartículas pode ser analisado por meio de uma curva de histerese, que apresenta a variação da magnetização da amostra conforme o campo magnético aplicado $(\mathrm{Hb})$. Como mostrado na Figura 4, na ausência do campo externo (ponto 0 ), os domínios magnéticos são orientados aleatoriamente e a amostra apresenta magnetização total igual a zero. Com a aplicação do campo magnético, os domínios vão sendo alinhados ao campo até que ele seja suficientemente forte para que o máximo de momentos magnéticos estejam alinhados, atingindo então a magnetização de saturação (Ms). Com a redução do campo externo, ocorre o desalinhamento dos momentos magnéticos das partículas devido aos processos de relaxa- 
ção, causando a diminuição da magnetização da amostra. Partículas ferromagnéticas (Figura 4a) apresentam uma magnetização residual denominada como remanência quando o campo atinge valor zero. Para que essas partículas sejam completamente desmagnetizadas, é necessário aplicar um campo magnético invertido. $\mathrm{O}$ valor de $\mathrm{Hb}$ necessário para que a magnetização seja nula é denominado coercividade. No caso de partículas superparamagnéticas (Figura 4b), os momentos magnéticos se desalinham rapidamente com a remoção do campo, resultando em valores de remanência e coercividade nulos.(9)

Figura 4 - Representação de curvas de magnetização em função do campo magnético $(\mathrm{Hb})$ aplicado para materiais ferromagnéticos (a) e superparamagnéticos (b). São indicadas a magnetização de saturação (Ms), magnetização remanente (Mr) e coercividade (Hc).

a)

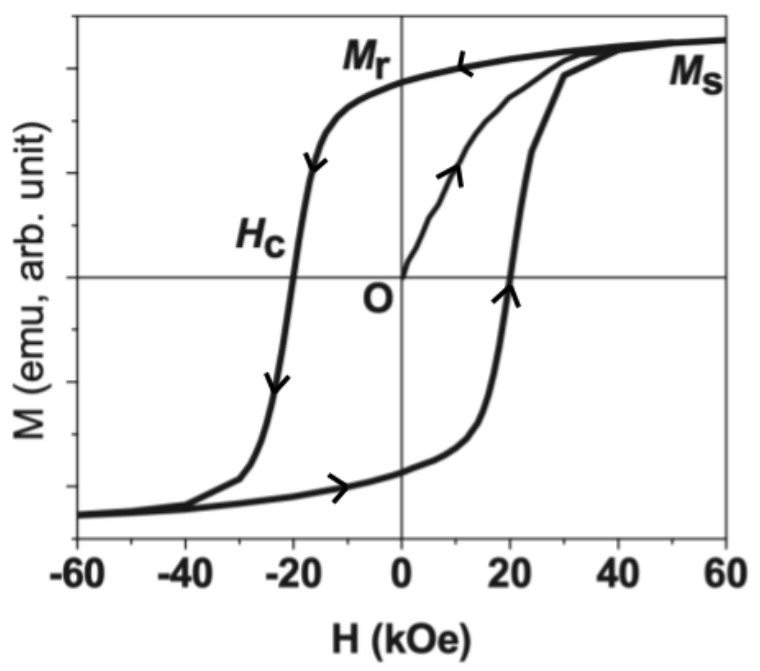

b)

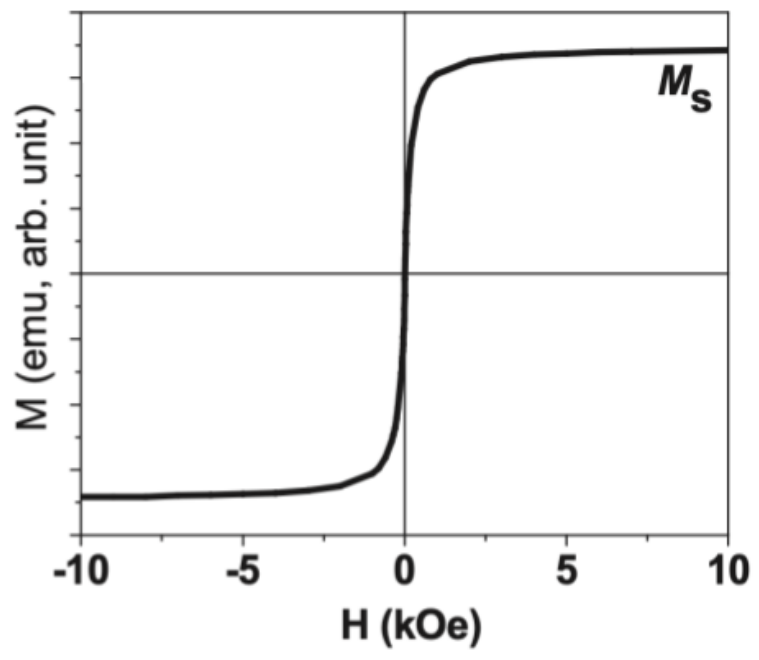

Fonte: Adaptado de SUN, S. Recent Advances in Chemical Synthesis, Self-Assembly, and Applications of FePt Nanoparticles. Advanced Materials, v. 18, p. 393-403, 2006.(9)

O comportamento magnético de sistemas nanoestruturados depende das propriedades intrínsecas das NP e das interações entre elas. A distribuição de forma, tamanho e defeitos de superfície, assim como a pureza de fase, influenciam nas propriedades magnéticas.(7) Dessa forma, a síntese de nanopartículas monodispersas, com composição controlada, forma bem definida e estabilidade química é altamente necessária para a aplicação dessas NP.

\subsubsection{Efeito de exchange bias (EB)}

O fenômeno conhecido como exchange bias foi descrito inicialmente por Meiklejohn e Bean em 1956(10) e é caracterizado pelo deslocamento horizontal da curva de histerese, podendo ser acompanhado de um aumento na coercividade (Figura 5). (7, 
$11,12,13,14) O$ valor do deslocamento do centro da curva de histerese em relação à origem é definido como campo de exchange bias (Heb). O EB é um efeito causado pelo acoplamento magnético entre os spins presentes na interface de dois materiais ordenados magneticamente $(11,14,15)$ e resulta em uma nova anisotropia magnética unidirecional na interface. $(11,16,17)$

Figura 5 - Representação da curva de magnetização de um material ferromagnético sob efeito de exchange bias, onde Hc1 e Hc2 são os valores de coercividade e Heb indica o valor do deslocamento do centro da curva em relação à origem

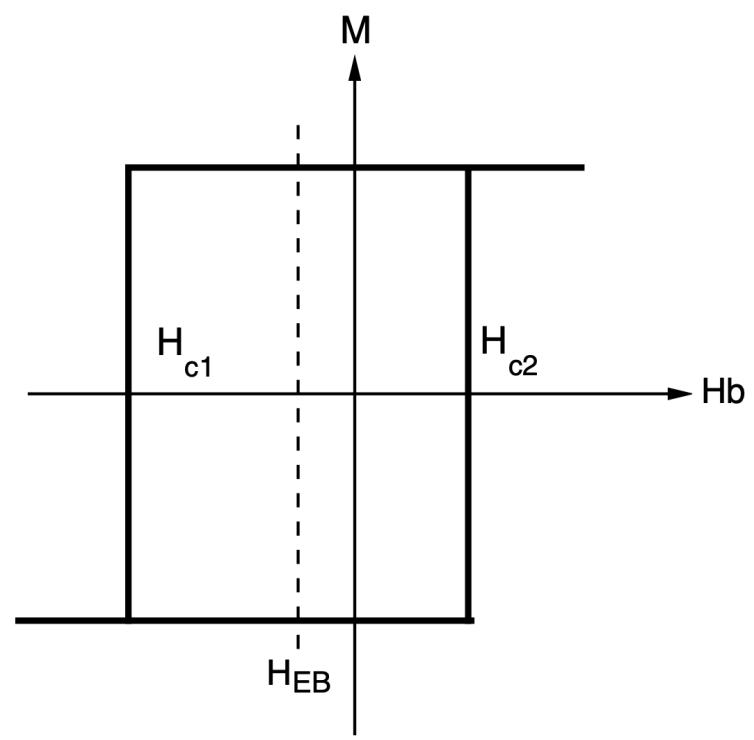

Fonte: Adaptado de STAMPS, R. L. Mechanisms for exchange bias. Journal of Physics D: Applied Physics, v. 33, p. 247-268, 2000.(17)

O modelo do mecanismo de EB é baseado no resfriamento de uma interface entre materiais ferromagnéticos (FM) e antiferromagnéticos (AFM) sob aplicação de um campo magnético. Se um campo magnético grande o suficiente é aplicado a uma temperatura T intermediária à temperatura de Néel (TN) (temperatura na qual um material AFM se torna paramagnético (PM)) e à temperatura de Curie (TC) (na qual os materiais FM passam a exibir comportamento paramagnético) todos os spins no FM estarão alinhados paralelamente a $\mathrm{Hb}$, ou seja, o FM estará saturado. Enquanto isso, os spins no AFM permanecerão ordenados aleatoriamente, pois T>TN (Figura 6a). (11, 15)

Quando o par FM-AFM é resfriado a uma temperatura inferior à TN, os momentos magnéticos do AFM presentes na interface se ordenam em relação aos momentos da camada FM, que está saturada na direção do campo. Após o resfriamento, os spins no FM e no AFM estão paralelos entre si na interface (Figura 6b). Quando o campo magnético é invertido, os spins no FM começam a girar. No entanto, se a anisotropia do AFM for grande o suficiente, os spins no AFM permanecerão fixos e, devido ao acoplamento da interface, exercerão um torque nos spins do FM, tentando mantê-los 
em sua posição original (Figura 6c). Assim, um campo magnético extra será necessário para superar o torque exercido pelos spins no AFM. Como resultado, o campo coercitivo negativo aumenta (Figura 6d). Quando o campo magnético é revertido para valores positivos, a rotação dos spins no FM será mais fácil do que em um FM desacoplado, ou seja, o AFM irá exercer um torque na mesma direção que o campo magnético aplicado (Figura 6e). Dessa forma, o campo coercitivo positivo será reduzido. O efeito resultante é uma mudança na curva de histerese ao longo do eixo do campo magnético e a existência de apenas uma configuração estável (ou seja, anisotropia unidirecional) para os spins do FM. $(11,15)$

Figura 6 - Esquema do efeito de exchange bias na interface entre um material ferromagnético (FM) e um antiferromagnético (AFM), mostrando o ordenamento dos spins do sistema antes do resfriamento com campo magnético (a), etapas da curva de histerese e os respectivos ordenamentos de spins de acordo com a variação do campo magnético após o resfriamento (b) a (e).

a)

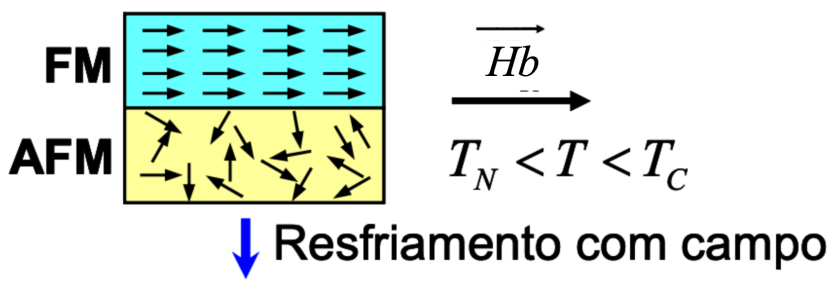

b)

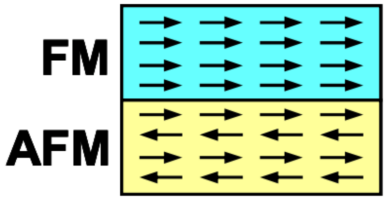

$$
T<T_{N}
$$

c)

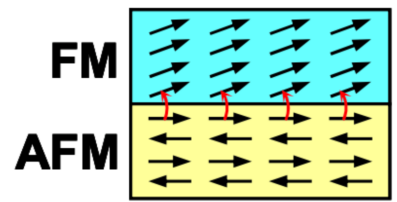

d)

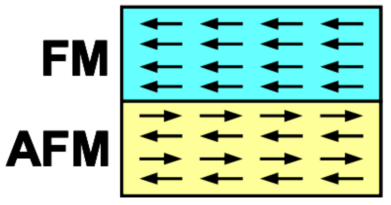

e)
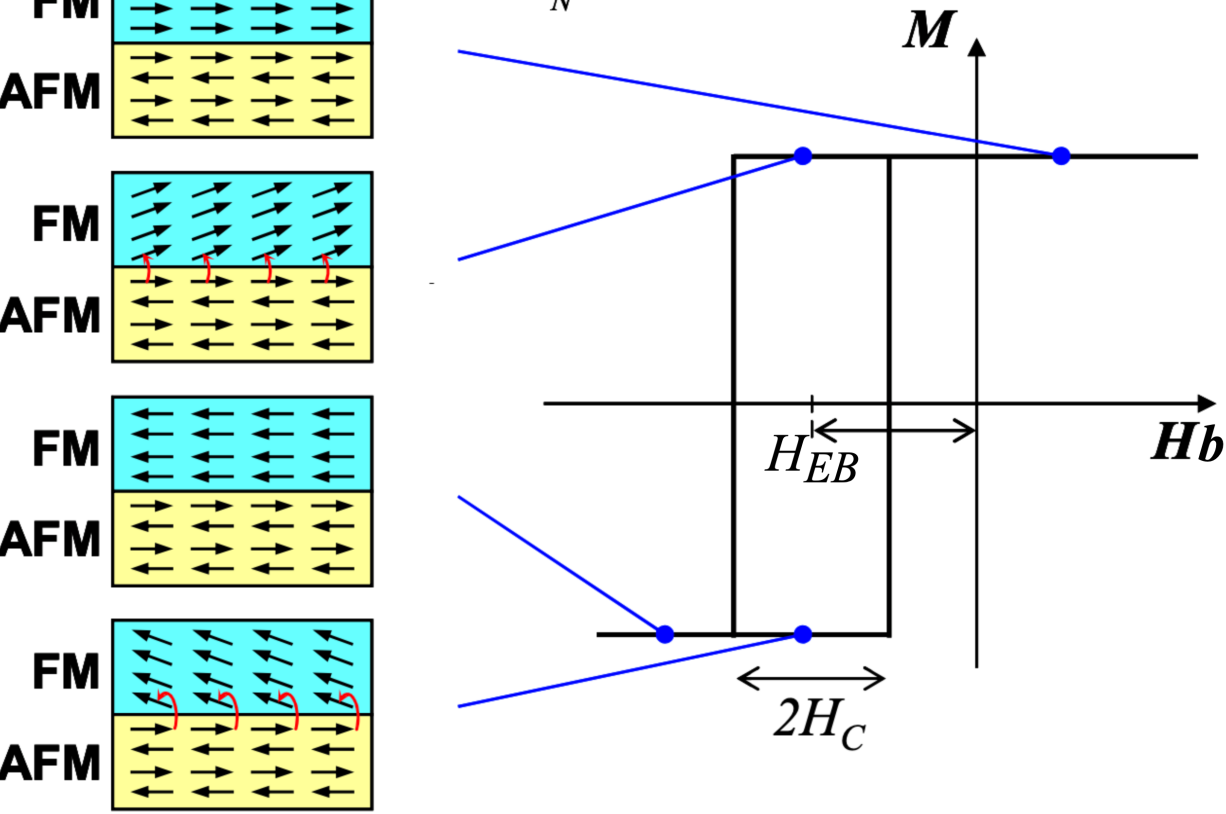

Fonte: Adaptado de SOARES, M. M. Observação de vórtices magnéticos em calotas tridimensionais submicrométricas. 2008. 149 f. Dissertação (Mestrado) - Curso de Física, Instituto de Física "Gleb Wataghin", Universidade Estadual de Campinas, Campinas, 2008.(18)

O efeito de EB descrito pelo modelo acima envolve o deslocamento da curva de histerese para valores negativos em relação ao campo aplicado.(11, 15) A esse 
efeito é dado o nome de exchange bias negativo. Embora menos comum, o efeito de EB positivo, no qual a curva de histerese é deslocada para valores positivos de $\mathrm{Hb}$, também pode ocorrer, tendo sido reportado pela primeira vez por Nogués et. al. em 1996.(19) Pouco é compreendido sobre o mecanismo de EB positivo, mas estudos indicam que uma condição necessária para a ocorrência deste efeito é o acoplamento do tipo antiferromagnético entre as interfaces. $(19,20,21,22)$

Embora seja comumente descrito para interfaces do tipo FM/AFM, o EB também ocorre em interfaces de materiais ferrimagnéticos (FI)/FM, FI/AFM, FI/FI, FM/FM, entre outras.(15) Além disso, o efeito também pode ser encontrado em nanopartículas magnéticas de componente único devido a presença de defeitos na superfície, que fazem com que o núcleo e a superfície das partículas apresentem diferentes coordenações dos átomos, causando um ordenamento diferente dos spins e levando à diferentes comportamentos magnéticos. $(7,11,12,15) \mathrm{A}$ diminuição do tamanho das partículas de modo que anisotropia de superfície seja maior que a do bulk em muitas ordens de magnitude também acarreta na ocorrência de EB.(12) Em NP, as propriedades do material, o tamanho e a estrutura atômica da interface são determinantes para a existência e a força do EB. (23) O efeito de exchange bias em nanopartículas pode ocorrer espontaneamente sem resfriamento na presença de campo magnético, dependendo apenas do alinhamento magnético decorrente da estrutura cristalina do material.(22)

O estudo de materiais que apresentam EB é uma área com crescente interesse visto que o mecanismo do fenômeno nas mais diversas interfaces ainda não é completamente compreendido e esses materiais possuem uma ampla gama de aplicações tecnológicas, que vão desde a gravação magnética, spintrônica, até biomedicina, como sensores para detecção de biomarcadores, imageamento por ressonância magnética nuclear (MRI), entre outros. $(11,12,15,22)$

\subsection{Nanopartículas magnéticas (NPM)}

Nanopartículas magnéticas são de grande interesse para pesquisas devido à vasta gama de aplicações desses materiais, como aplicações em gravação magnética, fluidos magnéticos, spintrônica, sensores de gás e biotecnologia.(24) Na área de biomedicina, suas aplicações incluem agente de contraste em imagem de ressonância magnética, entrega de fármacos assistida por força magnética, magnetohipertermia para tratamento de câncer, reparo de tecidos e isolamento de proteínas. $(25,26)$ Para cada aplicação, a resposta das nanopartículas ao campo magnético é fortemente afetada por sua composição, estrutura, forma e tamanho, motivando o estudo de sínteses de materiais homogêneos. $(26,27,28)$

Dentre os diferentes tipos de nanopartículas magnéticas e, mais recentemente, 
nanopartículas magnéticas multifuncionais, as nanopartículas de óxido de ferro são são as NP inorgânicas mais representativas para aplicações biomédicas.(25, 26, 29) Essas aplicações são baseadas nas propriedades básicas das ferritas: significativa magnetização de saturação, alta resistividade elétrica, baixas perdas elétricas e estabilidade química.(29) Combinar o comportamento magnético das ferritas com funcionalizações de superfície(25) ou com propriedades eletrônicas de outros materiais por meio de dopagem(24, 30, 31), expande as possíveis aplicações dessas nanopartículas e torna seus nanomateriais multifuncionalizados fortes ferramentas biomédicas para uso em campos de detecção, diagnóstico ou terapia. $(24,25)$

\subsection{Terras raras $(\mathrm{TR})$}

A combinação de materiais com propriedades ópticas e magnéticas tornou-se de grande interesse devido às aplicações biomédicas dessas nanopartículas, como marcação e rastreamento celular, $(32,33,34,35,36)$ liberação direcionada de fármacos, $(33,34)$ imageamento multimodal, $(33,34,37,38)$ novas abordagens combinadas de imagem e terapia, $(33,34,39,40)$ entre outros. Durante as últimas décadas, várias sondas luminescentes, como Quantum Dots (QD) e corantes orgânicos, foram combinadas com nanopartículas magnéticas para produzir nanopartículas bifuncionais.(33, 41) A utilização de QD superou as limitações apresentadas pelos corantes orgânicos, como baixa estabilidade fotoquímica,(33, 34, 41), bandas largas de emissão e faixa de absorção estreita. $(34,39)$ No entanto, a potencial toxicidade dos QD limita suas aplicações em sistemas biológicos.(33, 39)

Nesse cenário, nanopartículas baseadas em terras raras são um tipo promissor de agente luminescente, exibindo propriedades vantajosas como luminescência com maior tempo de vida,(34, 39, 41, 42, 43) bandas de emissão mais estreitas e nítidas,(33, $35,39,41,42)$ maior estabilidade fotoquímica, $(33,35,39,41)$ alto rendimento quântico (33) e menor toxicidade.(44)

O conjunto de elementos denominados como terras raras inclui a série dos lantanídeos (Ln), assim como o escândio e o ítrio, conforme mostra a Figura 7. As terras raras diferem dos demais elementos devido à natureza dos orbitais $4 \mathrm{f}$, que são protegidos do ambiente de coordenação pela presença de elétrons nos orbitais $5 s^{2}$ e $5 p^{6}$.(45) Esses elementos podem apresentar estado de oxidação 2+, 3+ e 4+, no entanto, são mais estáveis no estado de oxidação $3+.(46,47)$ 
Figura 7 - Posição dos elementos terras raras na tabela periódica.

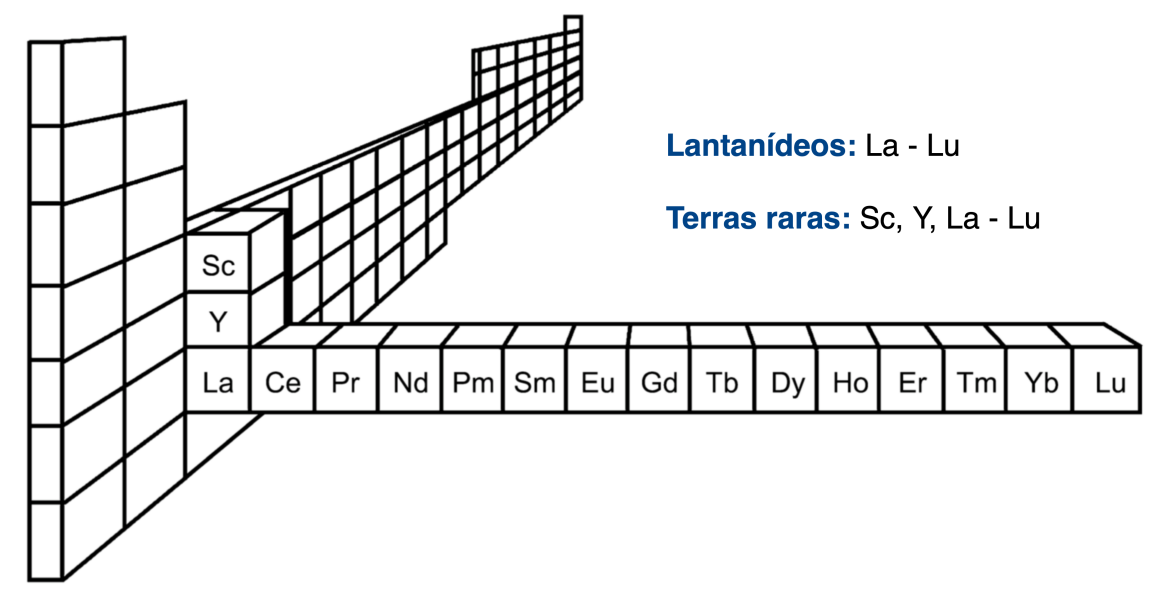

Fonte: Adaptado de WEN, H.; WANG, F. Lanthanide-Doped Nanoparticles: synthesis, property, and application. Nanocrystalline Materials. 2 ed. Elsevier, 2014. p. 121-160. (48)

Os átomos neutros possuem em comum a configuração eletrônica $6 s^{2}$ e uma ocupação variável do nível $4 f$. Como consequência da camada $4 f$ parcialmente preenchida, os íons terras raras apresentam grande número de níveis de energia, podendo gerar bandas de emissão desde o infravermelho até o ultravioleta, dependendo da matriz onde são incorporados. $(46,47)$ A interação com campo cristalino externo leva ao aumento da degenerescência e ao aparecimento de níveis não degenerados de energia, devido às interações elétron-elétron e acoplamento spin-órbita, influenciando as propriedades espectroscópicas e magnéticas desses elementos.(46)

Devido às propriedades luminescentes e magnéticas, os elementos terras raras têm sido extensivamente estudados em sistemas biológicos como sondas espectroscópicas e também como agentes de contraste em MRI. Em relação às propriedades luminescentes, os íons mais utilizados são $\mathrm{Eu}(\mathrm{III})$ e $\mathrm{Tb}(\mathrm{III})$, devido às suas características emissões de vermelho e verde, respectivamente.(47) O Eu(II) é o íon lantanídeo não trivalente de maior destaque em razão de sua emissão no azul, decorrente das transições d-f.(45, 47) Na região de infravermelho-próximo, Yb, Er e Nd são os lantanídeos com maior potencial de aplicação como sondas luminescentes. $(45,49,50)$

A luminescência dos elementos terras raras é observada tanto para íons dopados em matrizes cristalinas, quanto para complexos de TRs com ligantes orgânicos. Devido às transições $f-f$ estreitas, a sensibilização da luminescência dos íons terras raras pode ser alcançada através do efeito antena, no qual os ligantes atuam como uma antena para absorver e transferir a energia de excitação para os níveis de energia mais elevados dos íons, a partir do qual os níveis excitados emissores podem ser populados. $(51,52)$ 
Em relação às propriedades magnéticas, com exceção dos íons Y(III), La(III) e Lu(III), os íons Ln(III) são aplicados como agentes de contraste por apresentarem caráter paramagnético. O íon $\mathrm{Gd}(\mathrm{III})$ é o mais utilizado devido ao fato de possuir um momento magnético muito alto, seguido por $\mathrm{Nd}(\mathrm{III})$, que também possui diversas aplicações como ímã permanente. $(47,53)$

O presente trabalho emprega os elementos európio e neodímio como agentes luminescentes e moduladores de propriedades magnéticas em ferritas de ferro por meio de dopagem.

\subsubsection{Európio (Eu)}

Dentre os elementos terras raras, o európio é o de maior destaque em termos de luminescência, principalmente no estado de oxidação 3+. O íon Eu(III) é conhecido pela sua forte luminescência na região espectral vermelha e seus compostos apresentam diversas propriedades e aplicações importantes.(45) Atualmente, a maioria das lâmpadas fluorescentes e dispositivos emissores de luz (LEDs, do inglês light emitting devices) têm como base fósforos contendo íons $\mathrm{Eu}(\mathrm{III})$, como $\mathrm{Y}_{2} \mathrm{O}_{3}: \mathrm{Eu}^{3+}$. $\mathrm{Na}$ biomedicina, os complexos de európio(III) têm importante atuação como sondas luminescentes. $(47,52,54)$

As linhas dos espectros de emissão do Eu(III) são nítidas e dependentes do campo cristalino ao redor do íon.(51) O número de linhas observadas no espectro de luminescência ou no espectro de absorção permite determinar a simetria do sítio do $E$ u(III).(52) O espectro de emissão visível do $E u(I I I)$ é composto pelas transições ${ }^{5} \mathrm{D}_{0} \rightarrow{ }^{7} \mathrm{~F}_{\mathrm{J}}(\mathrm{J}=0-6)$, sendo ${ }^{5} \mathrm{D}_{0} \rightarrow{ }^{7} \mathrm{~F}_{2},{ }^{5} \mathrm{D}_{0} \rightarrow{ }^{7} \mathrm{~F}_{1}$ e ${ }^{5} \mathrm{D}_{0} \rightarrow{ }^{7} \mathrm{~F}_{0}$ as principais. $(52,54) \mathrm{A}$ transição ${ }^{5} \mathrm{D}_{0} \rightarrow{ }^{7} \mathrm{~F}_{2}$ é denominada uma transição hipersensível, ou seja, é uma transição sensível a mudanças na esfera de coordenação, cuja intensidade é influenciada pela simetria local do íon Eu(III) e pela natureza dos ligantes. $(45,52) A$ transição ${ }^{5} D_{0} \rightarrow{ }^{7} F_{2}$, encontrada em torno de $615 \mathrm{~nm}$, é responsável pela luminescência vermelha característica de fósforos de európio (III) e sua intensidade é frequentemente utilizada como uma medida para a assimetria do sítio $\mathrm{Eu}(\mathrm{III})$.(52) A intensidade da transição dipolo magnética, ${ }^{5} D_{0} \rightarrow{ }^{7} F_{1}$, é independente do ambiente químico e é frequentemente considerada constante, sendo utilizada para calibrar os espectros de luminescência do íon Eu(III). $(52,54) A$ transição ${ }^{5} D_{0} \rightarrow{ }^{7} F_{0}$ é observada apenas para certas simetrias e é uma indicação de que o íon Eu(III) ocupa um local com simetria $\mathrm{C}_{n v}, \mathrm{C}_{n}$ ou $\mathrm{C}_{s}$. $\mathrm{A}$ observação de mais de uma banda na região espectroscópica dessa transição indica que mais de um sítio ou espécie de Eu(III) está presente.(52)

Estas características das transições do európio fazem com que ele atue como sonda estrutural, podendo ser utilizado na determinação da simetria e geometria de 
espécies complexas e em estruturas contendo outros elementos, quando dopadas com európio. $(51,52)$

\subsubsection{Neodímio (Nd)}

O interesse em íons lantanídeos com luminescência na região do infravermelhopróximo tem se desenvolvido nas últimas décadas devido à aptidão desses íons a atuarem em sistemas biológicos. O íon $\mathrm{Nd}$ (III) tem se destacado em aplicações biomédicas por apresentar excitação e emissão na denominada "janela biológica" (BW, do inglês biological window), uma região espectral onde os tecidos são parcialmente transparentes, o que permite uma maior penetração da luz devido ao menor espalhamento.(50, 55) A primeira janela biológica (I-BW) se encontra na região de 700 a $950 \mathrm{~nm}$, enquanto a segunda janela biológica (II-BW) se estende de 1000 a $1400 \mathrm{~nm}$.(55) O espectro do íon $\mathrm{Nd}(\mathrm{III})$ é rico em bandas em três regiões espectrais referentes às

transições ${ }^{4} \mathrm{~F}_{3 / 2} \rightarrow{ }^{4} \mathrm{I}_{9 / 2},{ }^{4} \mathrm{~F}_{3 / 2} \rightarrow{ }^{4} \mathrm{I}_{11 / 2}$ e ${ }^{4} \mathrm{~F}_{3 / 2} \rightarrow{ }^{4} \mathrm{I}_{13 / 2}$ em torno de 910, 1050 e $1330 \mathrm{~nm}$, respectivamente. $(55,56,57)$ Em decorrência de suas emissões tanto na I-BW quanto na II-BW, o $\mathrm{Nd}$ (III) tem sido amplamente utilizado no desenvolvimento de lasers de estado sólido para sistemas de imageamento. $(47,53)$

Os elementos terras raras também são amplamente utilizados na tecnologia de ímãs devido ao seu grande momento magnético atômico intrínseco e estão entre as principais fontes magnéticas da indústria moderna. $(58,59)$ As propriedades magnéticas das terras raras são dominadas principalmente pelo spin, momento angular orbital e interações de seus elétrons f.(59) Atualmente, o neodímio é a base dos ímãs fortes, permanentes e leves. Ímãs de neodímio, ferro e boro (NdFeB) são os ímãs permanentes mais utilizados e podem ser encontrados em telefones celulares, discos rígidos, eletrodomésticos, carros híbridos, satélites, geradores de turbinas eólicas, equipamentos de ressonância magnética nuclear (RMN), entre outros. $(47,58,59)$

\subsection{Multifuncionalização de nanopartículas}

Nas últimas décadas um grande número de pesquisas a respeito de nanopartículas com múltiplas funcionalidades vêm sendo realizadas e diversas estratégias de multifuncionalização vem sendo estudadas, como mostra a Figura 8.(32, 41, 60) A combinação de materiais com propriedades ópticas e magnéticas tornou-se de grande interesse devido às aplicações biomédicas dessas nanopartículas, como marcação e rastreamento celular, $(32,33,34,35,36)$ liberação direcionada de fármacos,(33, 34) imageamento multimodal, $(33,34,37,38)$ novas abordagens combinadas de imagem e terapia, $(33,34,39,40)$ entre outros. 
Figura 8 - Estratégias para multifuncionalização de nanopartículas.

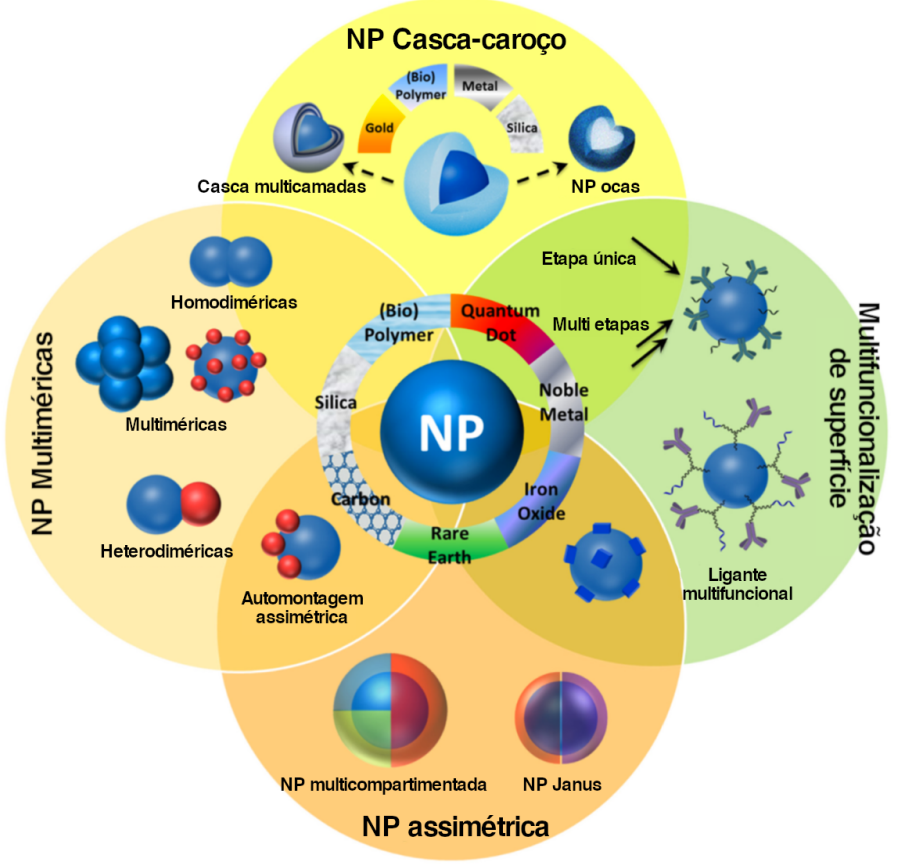

Fonte: Adaptado de CROZALS, G. et al. Nanoparticles with multiple properties for biomedical applications: A strategic guide. Nano Today, v. 11, p.435-463, 2016.(60)

\subsubsection{Dopagem}

Uma das possíveis estratégias de multifuncionalização de NP é a dopagem de materiais. A dopagem é um processo amplamente aplicado na ciência de materiais e envolve a incorporação de átomos ou íons de elementos apropriados na rede cristalina de um determinado material, a fim de produzir materiais com propriedades e funções desejáveis.(42) Este processo pode causar pequena desordem estrutural, alteração no tamanho da partícula, redistribuição de cátions, bem como afetar propriedades físicas e químicas. $(24,28,42)$ É de fundamental importância para modificar propriedades eletrônicas, modular o magnetismo, assim como ajustar propriedades de emissão. $(34,42)$

As propriedades estruturais, elétricas e magnéticas da ferrita com estrutura espinélio (Figura 9) são dependentes da natureza dos cátions, seus estados de oxidação e sua distribuição entre os sítios tetraédricos e octaédricos. $(24,28,30,61,62,63,64,65)$ O comportamento magnético das ferritas é governado pela interação Fe-Fe (acoplamento do spin dos elétrons $3 d) .(30,64)$ A introdução de íons lantanídeos (Ln) em uma rede cristalina do tipo espinélio, leva ao aparecimento da interação Ln-Fe (acoplamento $3 d-4 f)$, que determina a anisotropia magnetocristalina da ferrita e pode melhorar as propriedades elétricas e magnéticas, causando alterações na temperatura de Curie e nas propriedades de magnetização.(24, 30, 31, 64) 
Figura 9 - Representação de uma cela unitária da estrutura cristalina espinélio mostrando os sítios tetraédricos (círculos vermelhos) e octaédricos (círculos verdes) ocupados pelos íons metálicos. Os círculos maiores representam átomos de oxigênio.
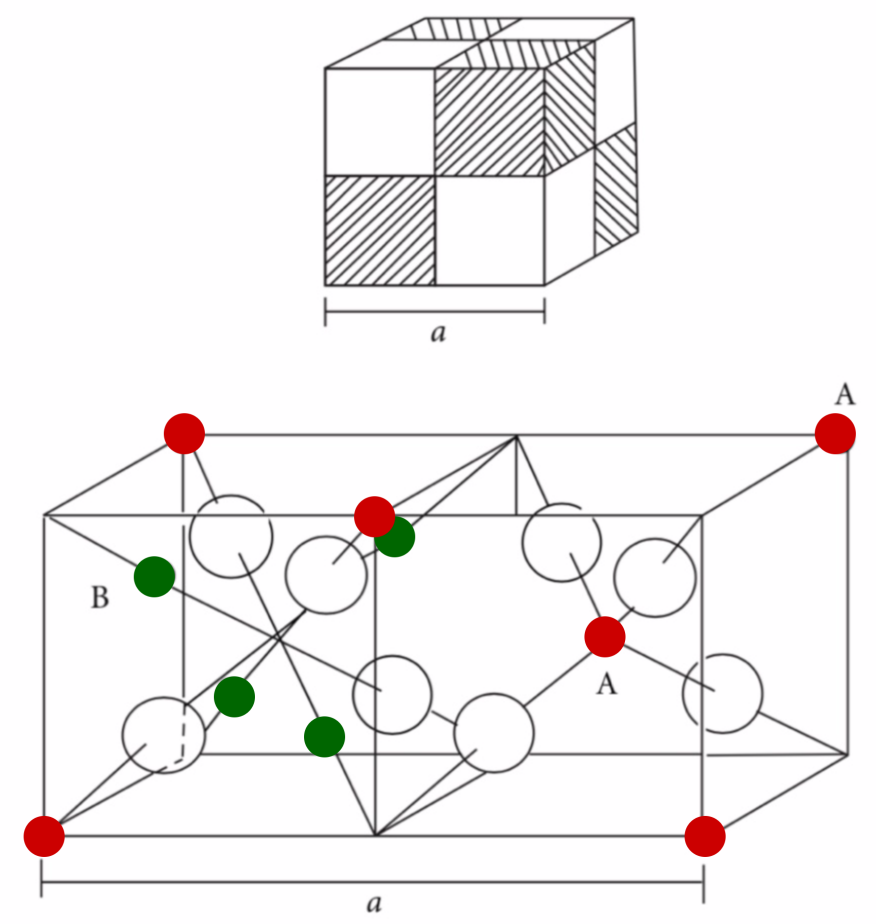

Fonte: Adaptado de VALENZUELA, R. Novel aplications of ferrites. Physics Research International, v. 2012, p.1-9, 2012.(29)

\subsection{Método de síntese}

Nos últimos anos, diversas rotas de síntese para a obtenção de nanopartículas de magnetita com tamanho, morfologia, composição química e estrutural controlados vêm sendo propostas na literatura. Diversas metodologias baseadas em abordagens físicas e químicas têm sido desenvolvidas, cada uma apresentando vantagens e desvantagens específicas, como mostra a Tabela 1.(25, 66) Embora os métodos físicos possibilitem a escalabilidade, eles não apresentam controle de forma e tamanho, enquanto os métodos químicos fornecem alto controle sobre o processo, mas uma pequena quantidade de material.(25) As rotas sintéticas mais utilizadas são os métodos de coprecipitação, síntese hidrotérmica e solvotérmica, microemulsão, métodos aerosol/vapor e decomposição térmica. $(7,25,60)$ A maioria das NP descritas na literatura até o momento foram preparadas usando variações do método de coprecipitação. Esse método apresenta como vantagem a utilização de água como solvente, o que diminui o custo do processo. No entanto, proporciona um baixo controle de forma e tamanho das NP, como pode ser observado na comparação entre magnetitas obtidas por diferentes métodos de síntese na Figura 10.(25) 
Tabela 1 - Comparação entre diferentes métodos de síntese de nanopartículas magnéticas.

\begin{tabular}{lllllllll}
\hline Método de síntese & Condiçães & Temperatura & Duração & Solvente & Agentes de superfície & Distribuição de tamanho & Controle de forma \\
\hline Coprecipitação & $\begin{array}{l}\text { Simples } \\
\text { Condição amb. }\end{array}$ & $20-90{ }^{\circ} \mathrm{C}$ & Minutos & Água & Sim, após a reação & Relativamente estreita & Ruim \\
\hline $\begin{array}{l}\text { Decomposição } \\
\text { térmica }\end{array}$ & $\begin{array}{l}\text { Complicada } \\
\text { Atm. inerte }\end{array}$ & $100-330{ }^{\circ} \mathrm{C}$ & Horas & Orgânico & Sim, durante a reação & Muito estreita & Muito bom \\
\hline Microemulsão & $\begin{array}{l}\text { Complicada } \\
\text { Condição amb. }\end{array}$ & $20-70{ }^{\circ} \mathrm{C}$ & Horas/dias & Orgânico/água & Sim, durante a reação & Estreita & \multirow{2}{*}{ Bom } \\
\hline Síntese hidrotérmica & $\begin{array}{l}\text { Simples } \\
\text { Alta pressão }\end{array}$ & $>100{ }^{\circ} \mathrm{C}$ & Horas/dias & Orgânico/água & Sim, durante a reação & Estreita & \multirow{2}{*}{ Bom } \\
\hline
\end{tabular}

Fonte: Adaptado de VARANDA, L. C.; JAFELICCI, M.; BECK, W. Magnetic and Multifunctional Magnetic Nanoparticles in Nanomedicine: Challenges and Trends in Synthesis and Surface Engineering for Diagnostic and Therapy Applications. Biomedical Engineering, Trends in Materials Science. Intech, 2011. p. 397-424. (25)

Figura 10 - Microscopia eletrônica de transmissão de NPM preparadas por meio de coprecipitação (a), microemulsão (b) e decomposição térmica (c).
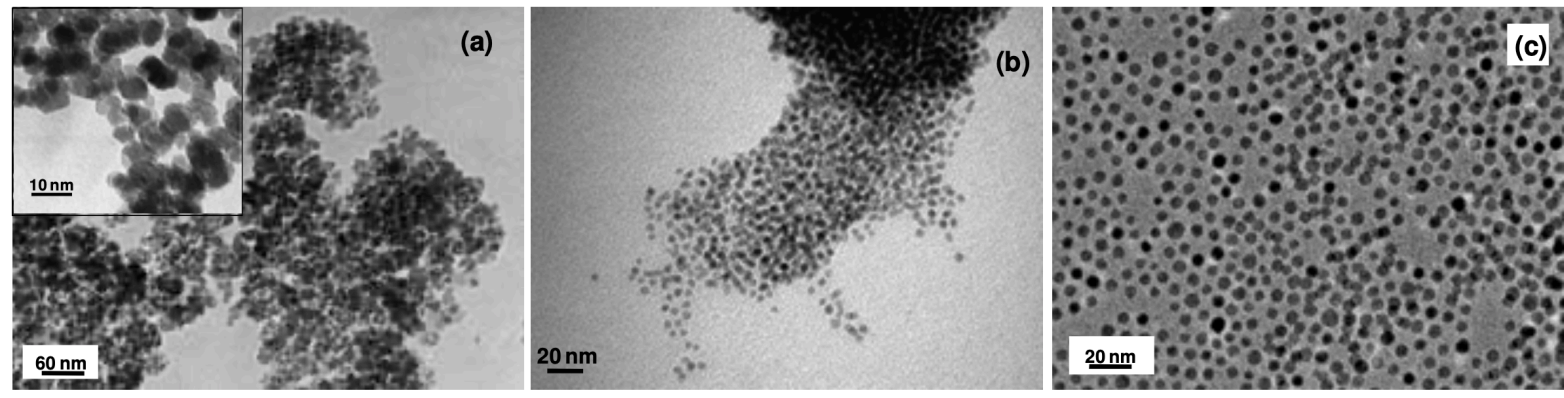

Fonte: VARANDA, L. C.; JAFELICCI, M.; BECK, W. Magnetic and Multifunctional Magnetic Nanoparticles in Nanomedicine: Challenges and Trends in Synthesis and Surface Engineering for Diagnostic and Therapy Applications. Biomedical Engineering, Trends in Materials Science. Intech, 2011. p. 397-424. (25)

Para este trabalho, foi selecionado o método poliol, também conhecido por decomposição térmica, para síntese de nanopartículas de magnetita dopadas com íons terras raras. Este método de síntese se destaca pelo maior controle de forma e tamanho das nanopartículas. Esse processo foi inicialmente proposto por Fiévet et al. $(67,68)$, utilizando etilenoglicol para a síntese de nanopartículas metálicas através da redução de íons em altas temperaturas, mas foi modificado e amplamente difundido por Sun et al. $(9,69)$ Atualmente existem muitas variantes do método poliol e suas modificações consistem principalmente na substituição dos precursores metálicos carbonílicos por precursores de menor toxicidade, como a modificação proposta por Varanda et al. $(66,70)$, que substitui o ferro pentacarbonil por acetilacetonato de ferro(III), apresentando vantagens como a solubilidade em solventes orgânicos, maior controle composicional e menor custo.(70)

O diferencial do método poliol é o uso de solventes de alto ponto de ebulição e precursores organometálicos na presença ou ausência de surfactantes que podem favorecer o controle do tamanho das nanopartículas. $(26,66)$ Os compostos usados como precursores geralmente têm boa solubilidade no solvente de síntese e estabili- 
dade térmica relativamente alta. Quando o sistema atinge a temperatura adequada, o precursor se decompõe de forma rápida e homogênea em toda a solução bulk e a concentração de monômeros aumenta drasticamente no meio de reação. $(26,68)$ Além disso, tanto o solvente quanto os surfactantes presentes no meio de reação podem atuar como agentes de coordenação, melhorando a disponibilidade e a dispersibilidade dos íons metálicos em solução, estreitando a faixa de temperatura em que ocorre a decomposição térmica.(26)

O controle e a separação das fases de nucleação (formação inicial dos clusters atômicos de forma homogênea) e crescimento pelo processo poliol são fatores determinantes para a obtenção de sistemas monodispersos. $(25,68)$ O crescimento de partículas monodispersas é geralmente explicado pelo modelo de nucleação e crescimento de La Mer e Dinegar (Figura 11).(71) Segundo este modelo, a monodispersividade de um sistema é obtida quando a nucleação ocorre rapidamente através de uma solução supersaturada, seguida de uma etapa de crescimento lenta sem que ocorra novamente uma nucleação significativa. $(26,68)$ Múltiplos processos de nucleação favorecem a formação de nanopartículas maiores por meio do processo conhecido como envelhecimento de Ostwald. Neste processo, as partículas menores se dissolvem no meio e são redepositadas sobre a superfície das partículas maiores. $(7,72)$ Dessa forma, de modo a evitar a ocorrência de processos de envelhecimento e agregação de partículas, é imprescindível controlar o tempo e demais condições de síntese, evitando-se assim a polidispersividade do sistema.

Figura 11 - Diagramas do modelo de La Mer para nucleação e crescimento de partículas. As concentrações de monômeros e núcleos estáveis em relação ao tempo são mostradas para processos com etapa de nucleação rápida (a) e lenta (b), assim como a distribuição de núcleos estáveis em ambos os processos(c).

a)

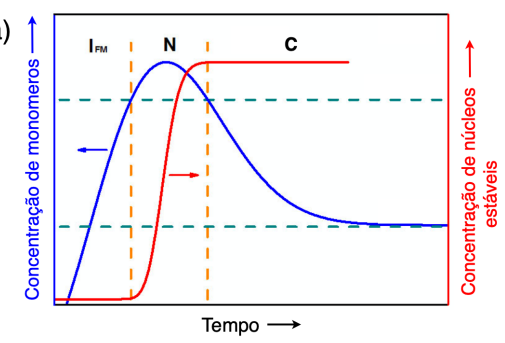

b)

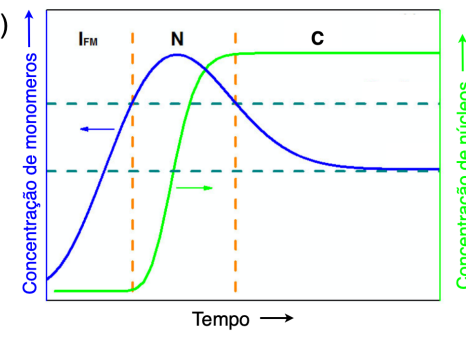

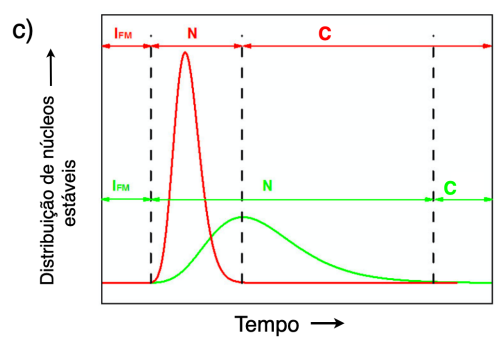

Fonte: Adaptado de VARANDA, L. C. et al. Size and shape-controlled nanomaterials based on modified polyol and thermal decomposition approaches. A brief review. Anais da Academia Brasileira de Ciências, v. 91, p. 1-32, 2019.(26) 


\subsection{Justificativa do trabalho}

O objetivo deste trabalho está em buscar o desenvolvimento de um material bi ou multifuncional através da dopagem da magnetita com íons TRs. Numa etapa futura, essas nanopartículas serão investigadas quanto às suas propriedades magnéticas como agentes de contrastes duplo $\left(\mathrm{T}_{1}\right.$ e $\left.\mathrm{T}_{2}\right)$ nanoparticulados, assim como suas propriedades para possíveis tratamentos por hipertermia magnética. Nesta etapa, se pretende avaliar os melhores parâmetros de síntese do método poliol para que esses materiais possuam as características necessárias para serem aplicados em sistemas biológicos.

Este trabalho também pretende, não como foco principal, avaliar um ponto recentemente reportado na literatura por alguns trabalhos que indicam a coexistência das propriedades ópticas (luminescentes) e magnéticas nesse tipo de material.(73, 74 , $75,76)$. A experiência do nosso Grupo de Pesquisa em se trabalhar com os denominados materiais luminomagnéticos, tem demonstrado que a propriedade luminescente é suprimida pelo contato direto com materiais magnéticos (magnetic quenching) e esse fenômeno foi, portanto, avaliado. 


\section{Objetivos}

Este trabalho tem como objetivo sintetizar nanopartículas de $F e_{(3-x)} T R_{x} O_{4}$ (TR= $\mathrm{Nd}$ e Eu) com estrutura espinélio e estudar suas propriedades ópticas e magnéticas para avaliar seu possível uso em aplicações biomédicas.

Em mais detalhes, os objetivos são:

i Adequar a metodologia de síntese do processo poliol modificado para obtenção da fase espinélio de ferrita de ferro (magnetita)

ii Ajustar as condições experimentais para utilizar os diferentes dopantes ( $\mathrm{TR}=\mathrm{Nd}$ e Eu), buscando obter as ferritas dopadas com terras raras

iii Otimizar as condições para obtenção de sistemas com controle de forma e tamanho, visando sistemas monodispersos

iv Caracterizar os diferentes materiais obtidos quanto a composição, estrutura cristalina e propriedades ópticas e magnéticas 


\section{Procedimento Experimental}

A seguir serão descritos os procedimentos experimentais utilizados para a síntese da ferrita pura e das ferritas dopadas, assim como dos compostos de európio utilizados para síntese. Todos os reagentes utilizados são de grau analítico e foram empregados sem tratamento prévio.

\subsection{Síntese da ferrita de ferro (magnetita)}

As sínteses foram realizadas utilizando o aparato experimental representado na Figura 12a. Em um balão de três bocas foram adicionados $0,1 \mathrm{mmol}$ de acetilacetonato de ferro(III) $\left(\mathrm{Fe}(\mathrm{acac})_{3}\right.$ ) (Sigma-Aldrich, 99\%) e $10 \mathrm{~mL}$ de tetraetileno glicol (TTEG) (Sigma-Aldrich, 99\%). O balão foi acoplado a um condensador de Graham conectado a um circulador de água, e foi apoiado em uma manta de aquecimento sobre um agitador magnético, que manteve o sistema sob agitação durante todo o tempo de reação. $A$ manta de aquecimento, assim como um termopar imerso no meio de reação, foram acoplados a um controlador de temperatura, onde foram programadas as etapas de aquecimento.

A síntese ocorreu aquecendo a mistura até $130^{\circ} \mathrm{C}$ a uma taxa de $10^{\circ} \mathrm{C} / \mathrm{min}$, agitando durante 10 minutos nessa temperatura, aquecendo novamente a $288^{\circ} \mathrm{C}\left(3^{\circ} \mathrm{C} / \mathrm{min}\right)$ e mantendo o sistema em refluxo durante 3 horas. A rampa de aquecimento utilizada encontra-se retratada na Figura 12b. Após resfriamento até temperatura ambiente, as nanopartículas foram lavadas utilizando uma mistura de isopropanol (Synth, P.A.) e etanol (Synth, P.A.) (2:1) e separadas por meio de centrifugação a $9000 \mathrm{rpm}$ por 5 minutos. Esse processo de lavagem e centrifugação foi repetido por três vezes e as nanopartículas resultantes foram estocadas em hexano. O procedimento empregado é representado de forma geral na Figura 12c. 
Figura 12 - Representação do aparato experimental utilizado (a), rampa de aquecimento (b) e fluxograma do procedimento experimental empregado na síntese das NPF.

a)

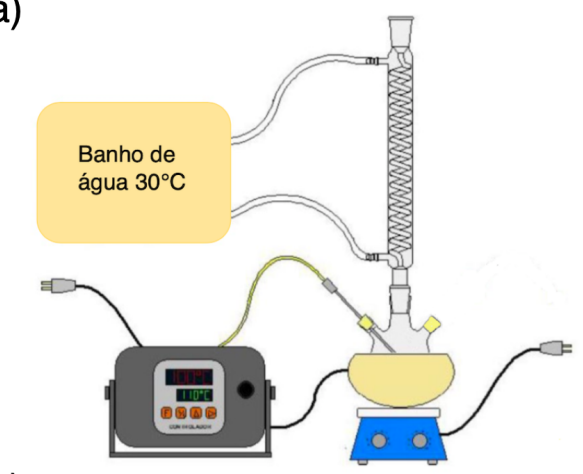

b)

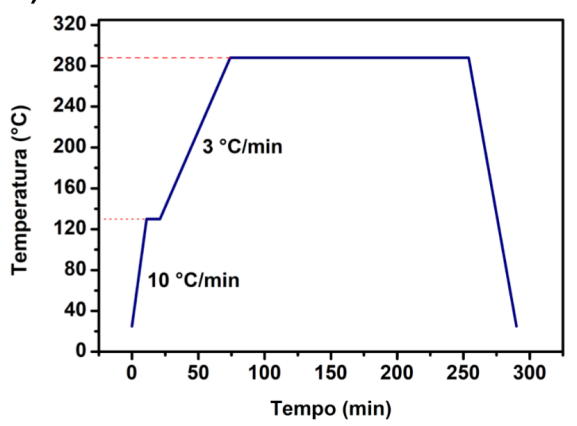

c)

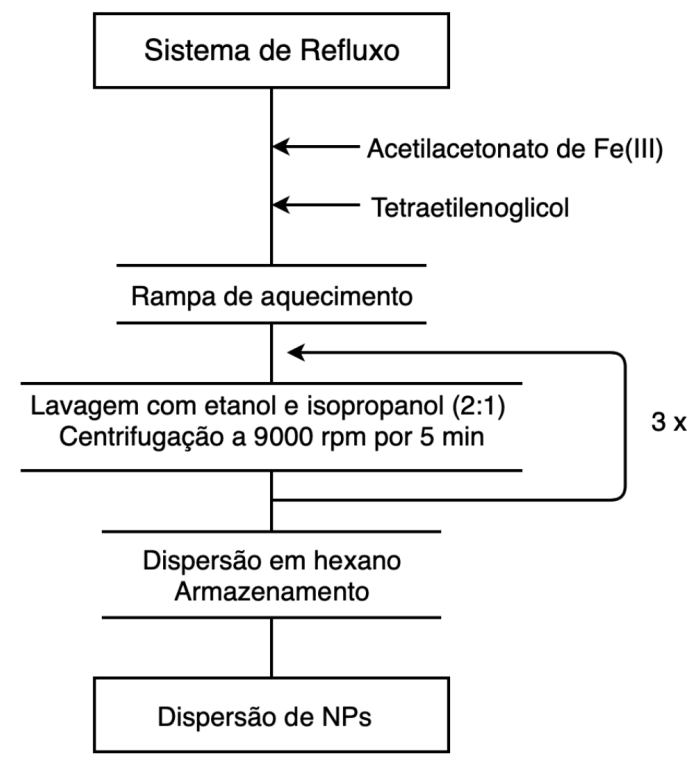

Fonte: Autoria própria.

\subsection{Preparo das soluções de cloreto de európio $\left(\mathrm{EuCl}_{3}\right)$ e cloreto de neodímio $\left(\mathrm{NdCl}_{3}\right)$}

Em um béquer de $100 \mathrm{~mL}$ foram adicionados $0,002 \mathrm{~mol}$ de óxido do lantanídeo de interesse e $30 \mathrm{~mL}$ de água destilada. Sob constante agitação, ácido clorídrico foi adicionado até completa dissolução do sólido. $\mathrm{O}$ pH da solução foi ajustado para 4,5 com adição de hidróxido de amônio e então ela foi aquecida para que o volume fosse reduzido. Foram realizados quatro ciclos de adição de água destilada e evaporação para remover o excesso de ácido por arraste a vapor. A solução final foi transferida para um balão volumétrico e o volume foi completado com água destilada.

A concentração das soluções de cloreto de európio e cloreto de neodímio foi determinada a partir da titulação realizada em triplicata com uma solução previamente padronizada de EDTA (sal dissódico de ácido etilenodiamino tetracético). Em um erlenmeyer de $25 \mathrm{~mL}$ foram adicionados $2 \mathrm{~mL}$ da solução de $\left(\mathrm{EuCl}_{3}\right)$ ou $\left(\mathrm{NdCl}_{3}\right), 10 \mathrm{~mL}$ de tampão acetato $\mathrm{pH}=5,8$ e $5 \mathrm{mg}$ de solução sólida $3 \%$ do indicador alaranjado de xilenol. A titulação foi realizada até que a coloração da solução fosse do rosa ao amarelo e o cálculo da concentração foi realizado utilizando a média dos volumes de EDTA utilizados na titulação. O procedimento é representado de forma geral na Figura 13. 
Figura 13 - Fluxograma do procedimento experimental empregado no preparo da solução de $\mathrm{EuCl}_{3}$.

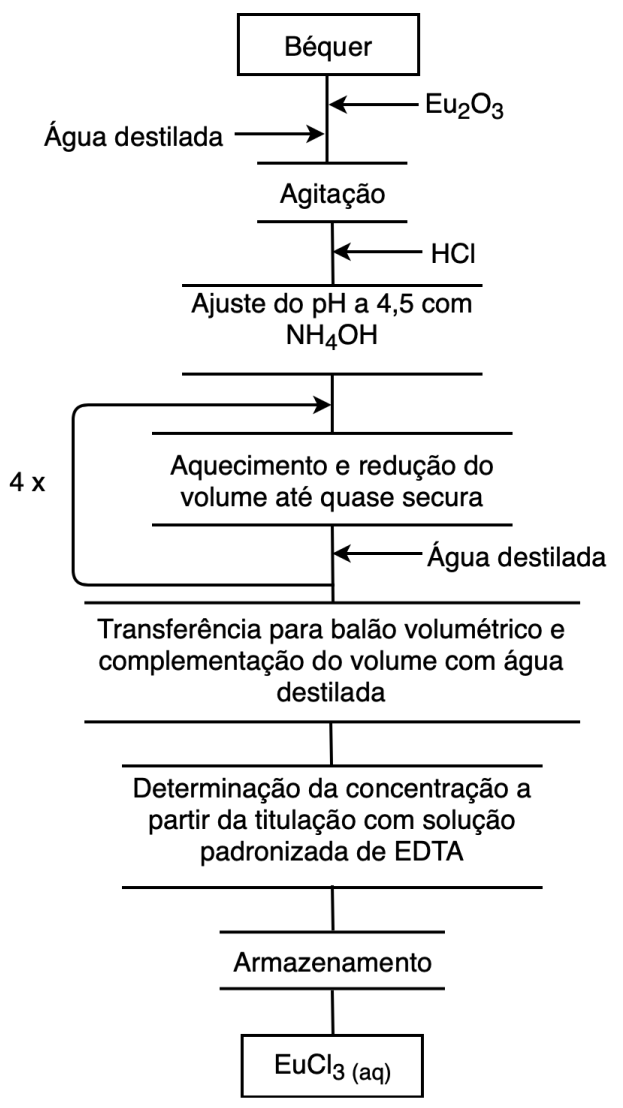

Fonte: Autoria própria.

\subsubsection{Preparo da solução sólida de 3\% de alaranjado de xilenol}

Foram pesados $0,097 \mathrm{~g}$ de brometo de potássio (KBr) (Acros) e $0,003 \mathrm{~g}$ de alaranjado de xilenol (Dinâmica). Os sólidos foram macerados e misturados utilizando almofariz e pistilo.

\subsubsection{Preparo da solução de tampão acetato com $\mathrm{pH}=5,8$}

Em um balão volumétrico de $250 \mathrm{~mL}$ contendo $100 \mathrm{~mL}$ de água destilada, foram adicionados 1,43 $\mathrm{mL}$ de ácido acético glacial (J.T. Baker, 99,9\%) e 22,95 mL de solução $1 \mathrm{~mol} / \mathrm{L}$ de hidróxido de sódio. O volume foi completado com água destilada e o $\mathrm{pH}$ da solução foi aferido utilizando um pHmetro. 


\subsubsection{Preparo e padronização da solução de EDTA}

Uma massa equivalente a 0,0025mol de EDTA (Sigma-Aldrich, 99,9\%), previamente seco em estufa a vácuo por 12 horas, foi pesada e dissolvida em um pequeno volume de água destilada. Essa solução foi transferida a um balão volumétrico de 250 $\mathrm{mL}$ e o volume foi completado com água destilada.

A concentração da solução de EDTA foi determinada a partir da titulação com uma solução de $0,01 \mathrm{~mol} / \mathrm{L}$ de carbonato de cálcio $\left(\mathrm{CaCO}_{3}\right)$. Em um erlenmeyer de $125 \mathrm{~mL}$ foram adicionados $5 \mathrm{~mL}$ da solução de $\mathrm{CaCO}_{3}, 50 \mathrm{~mL}$ de água destilada, $4 \mathrm{~mL}$ de tampão hidróxido de amônio/cloreto de amônio com pH = 5,8 e 15 gotas de solução do indicador preto de eriocromo T. O processo foi realizado três vezes até que a coloração da solução fosse do roxo ao azul e o cálculo da concentração foi realizado utilizando a média dos volumes de EDTA utilizados na titulação. Detalhes acerca dos preparos das soluções do indicador, de $\mathrm{CaCO}_{3}$ e da solução tampão utilizada serão descritos a seguir.

\subsubsection{Preparo da solução de $\mathrm{CaCO}_{3}$}

Uma massa referente à $0,0025 \mathrm{~mol}$ de $\mathrm{CaCO}_{3}$ (Synth, P.A.), previamente seco em estufa a vácuo por 12 horas, foi pesada e adicionada a um béquer contendo uma pequena quantidade de água destilada. Foram adicionadas 20 gotas de $\mathrm{HCl}$ e após a completa dissolução, a solução foi transferida a um balão volumétrico de $250 \mathrm{~mL}$ e o volume foi completado com água destilada.

\subsubsection{Preparo da solução do indicador preto de eriocromo T}

Foram pesados $0,1 \mathrm{~g}$ de preto de eriocromo $\mathrm{T}$ (Merck) e $20 \mathrm{~g}$ de cloreto de sódio ( $\mathrm{NaCl})$ (J.T. Baker, 99,9\%). Utilizando almofariz e pistilo, os sólidos foram macerados e então foram dissolvidos parcialmente em uma solução contendo $5 \mathrm{~mL}$ de etanol e 15 $\mathrm{mL}$ de água destilada. A mistura foi filtrada por meio de filtração simples e a solução resultante foi armazenada em frasco de vidro na geladeira.

\subsubsection{Preparo da solução tampão hidróxido de amônio/cloreto de amônio pH=10}

Em um balão volumétrico de $100 \mathrm{~mL}$ contendo $30 \mathrm{~mL}$ de água destilada, foram adicionados 1,34 $\mathrm{mL}$ de hidróxido de amônio e 1,50 $\mathrm{mL}$ de solução de ácido clorídrico $1,0 \mathrm{~mol} / \mathrm{L}$. O volume foi completado com água destilada e o $\mathrm{pH}$ da solução foi aferido utilizando um pHmetro. 


\subsection{Síntese dos complexos tris(tenoiltrifluoroacetonato) de európio(III) (Eu(TTA) $)_{3}$ ) e tris (tenoiltrifluoroacetonato) de neodímio(III) $\left(\mathrm{Nd}(\mathrm{TTA})_{3}\right)$}

A síntese dos complexos $\mathrm{Eu}(\mathrm{TTA})_{3}$ e $\mathrm{Nd}(\mathrm{TTA})_{3}$ seguiu procedimento descrito por Charles e Ohlmann(77), representado pelo fluxograma na Figura 14. Em um erlenmeyer de $50 \mathrm{~mL}$ foram adicionados $3 \mathrm{mmol}$ de TTA (2-Tenoiltrifluoracetona) (SigmaAldrich, 99\%), gentilmente cedido pelo Prof. Dr. Danilo Manzani, 7,5 mL de etanol e 3 $\mathrm{mL}$ de solução $1 \mathrm{~mol} / \mathrm{L}$ de $\mathrm{NH}_{4} \mathrm{OH}$. Em seguida foram adicionados $1 \mathrm{mmol}$ da solução de $\mathrm{EuCl}_{3}$ ou $\mathrm{NdCl}_{3}$ previamente preparadas e a mistura foi deixada em repouso por 4 horas. O sólido obtido foi filtrado a vácuo e lavado com água destilada gelada. Então foi seco em estufa a vácuo por 12 horas e em seguida foi recristalizado, sendo dissolvido em $5 \mathrm{~mL}$ de acetona, filtrado e reprecipitado em água destilada gelada. $O$ sólido então foi filtrado a vácuo e seco em estufa a vácuo por 12 horas.

Figura 14 - Fluxograma do procedimento experimental empregado na síntese do complexo $\mathrm{Eu}(\mathrm{TTA})_{3}$.

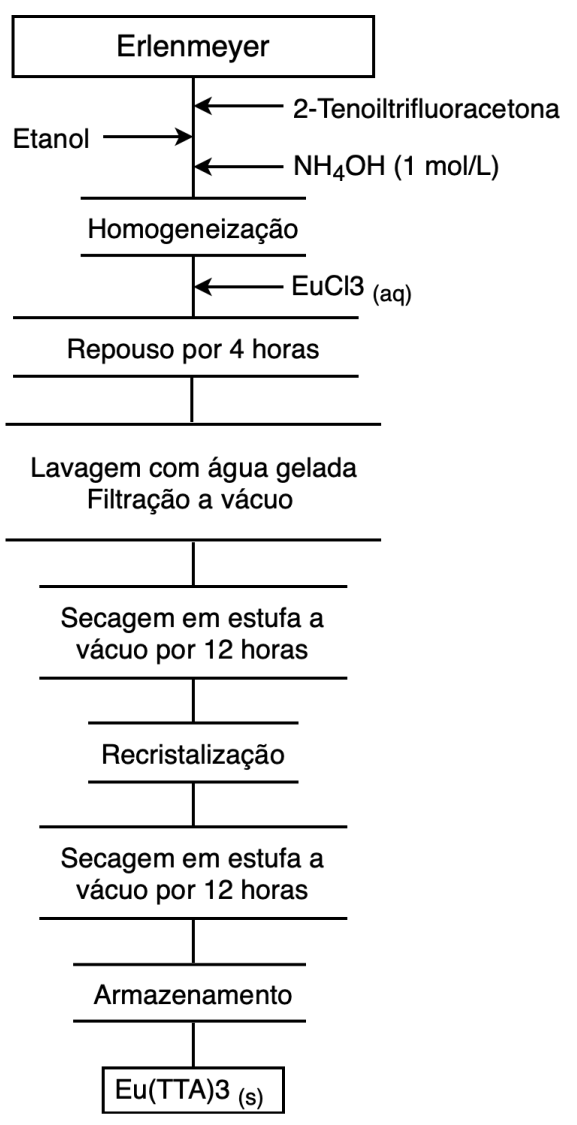

Fonte: Autoria própria. 


\subsection{Síntese e purificação do complexo acetilacetonato de európio(III) $\mathrm{Eu}(\mathrm{acac})_{3}$}

A síntese do acetilacetonato de európio(III) seguiu procedimento descrito por Stites, McCarty e Quill(78), representado pelo fluxograma na Figura 15. Foram preparadas duas soluções: (i) em um erlenmeyer foram dissolvidos $1 \mathrm{mmol}$ de óxido de európio (Sigma-Aldrich, 99,9\%) em uma quantidade mínima de ácido clorídrico $(\mathrm{HCl})$ (Panreac, 37\%). O pH dessa solução foi ajustado com adição de hidróxido de amônio $\left(\mathrm{NH}_{4} \mathrm{OH}\right)$ (J.T. Baker, 28-30\%) até $\mathrm{pH}$ 5. (ii) a solução foi preparada utilizando $0,9 \mathrm{~mL}$ de acetilacetona (Sigma-Aldrich, 99\%) $1 \mathrm{~mL}$ de hidróxido de amônio e $10 \mathrm{~mL}$ de água destilada, e então foi adicionada à solução (i) vagarosamente, sob agitação. A mistura final teve seu $\mathrm{pH}$ ajustado a 6,5 utilizando $\mathrm{HCl}$ e $\mathrm{NH}_{4} \mathrm{OH}$ e foi mantida sob agitação por 12 horas. Após o término da reação, o precipitado foi separado por meio de filtração a vácuo, sendo lavados com água destilada gelada e então secos em estufa a vácuo por 24 horas.

O produto obtido foi submetido a dois processos de purificação consecutivos: recristalização com etanol (Synth, 99,5\%) e precipitação, dissolvendo o sólido em clorofórmio (Sigma-Aldrich, 99,8\%) e gotejando hexano (Synth, 98,5\%) até a precipitação. O produto desses processos foi seco em estufa a vácuo por 24 horas e armazenado em recipiente fechado. 
Figura 15 - Fluxograma do procedimento experimental empregado para a síntese de $\mathrm{Eu}(\mathrm{acac})_{3}$.

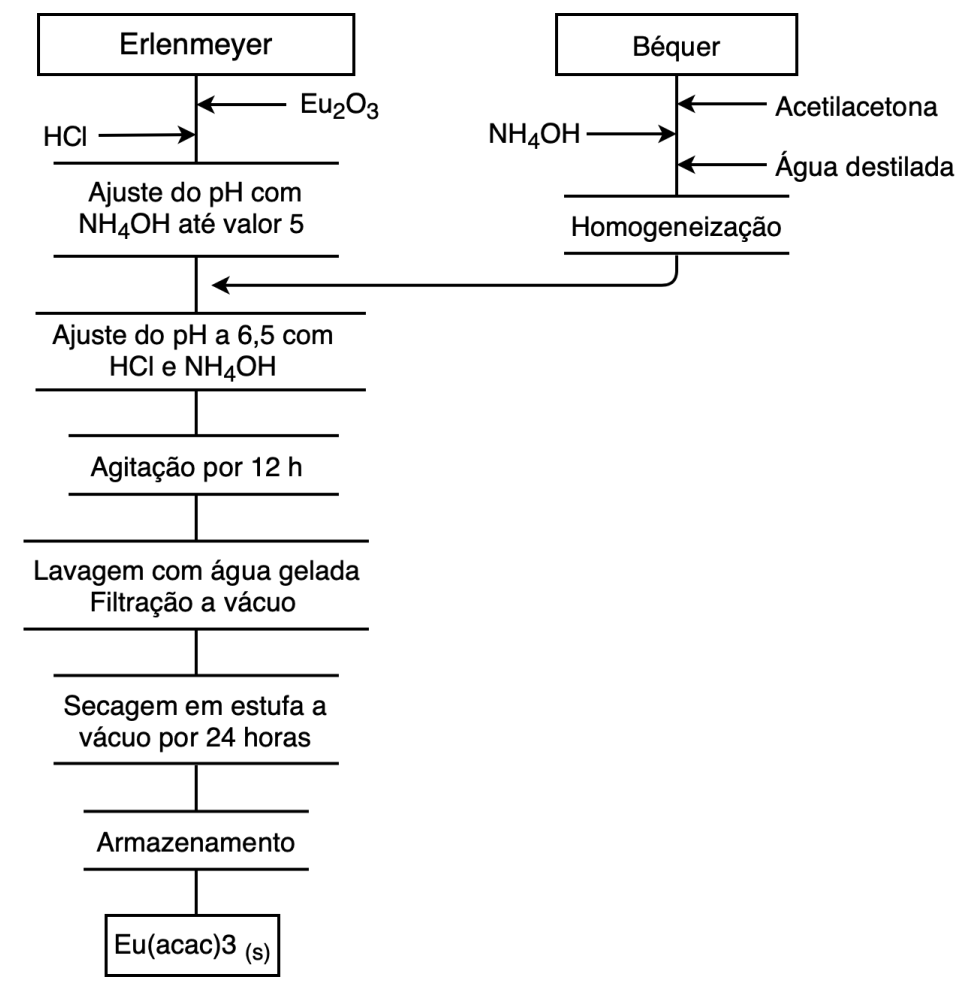

Fonte: Autoria própria.

\subsection{Síntese das NPF dopadas com íons terras raras em atmosfera de $\mathrm{N}_{2}$}

A fim de avaliar o efeito da atmosfera de $\mathrm{N}_{2}$ na síntese das NPF dopadas, foram realizados experimentos utilizando quantidades fixas dos precursores e tempos de refluxo variados, conforme mostra a Tabela 2. As ferritas são denominadas por Nd:NPF e Eu:NPF quando dopadas por neodímio e európio, respectivamente. O procedimento experimental empregado é o mesmo descrito para a magnetita, precedido por uma etapa de agitação a temperatura ambiente sob fluxo constante de $\mathrm{N}_{2}$ durante 20 minutos. Durante o período de refluxo, o sistema experimental é fechado, mantendo a atmosfera de $\mathrm{N}_{2}$. O procedimento é representado de forma geral na Figura 16. 
Tabela 2 - Variações nos parâmetros de reação empregados durante a síntese de NPF dopadas com terras raras em atmosfera de $\mathrm{N}_{2}$.

\begin{tabular}{|c|c|c|c|c|c|}
\hline \multirow{2}{*}{ Amostra } & \multicolumn{2}{|c|}{ Precursor de TR } & \multicolumn{2}{|c|}{ Precursor de Fe } & \multirow{2}{*}{ Tempo de Refluxo (h) } \\
\hline & Tipo & Qtde (mmol) & Tipo & Qtde (mmol) & \\
\hline Eu:NPF_TTA_22 & $\mathrm{Eu}(\mathrm{TTA})_{3}$ & 0,02 & $\mathrm{Fe}(\mathrm{acac})_{3}$ & 0,1 & 22 \\
\hline Eu:NPF_TTA_20 & $\mathrm{Eu}(\mathrm{TTA})_{3}$ & 0,02 & $\mathrm{Fe}(\mathrm{acac})_{3}$ & 0,1 & 20 \\
\hline Eu:NPF_TTA_18 & $\mathrm{Eu}(\mathrm{TTA})_{3}$ & 0,02 & $\mathrm{Fe}(\mathrm{acac})_{3}$ & 0,1 & 18 \\
\hline Eu:NPF_TTA_16 & $\mathrm{Eu}(\mathrm{TTA})_{3}$ & 0,02 & $\mathrm{Fe}(\mathrm{acac})_{3}$ & 0,1 & 16 \\
\hline Eu:NPF_TTA_14 & $\mathrm{Eu}(\mathrm{TTA})_{3}$ & 0,02 & $\mathrm{Fe}(\mathrm{acac})_{3}$ & 0,1 & 14 \\
\hline Eu:NPF_TTA_12 & $\mathrm{Eu}(\mathrm{TTA})_{3}$ & 0,02 & $\mathrm{Fe}(\mathrm{acac})_{3}$ & 0,1 & 12 \\
\hline Eu:NPF_TTA_10 & $\mathrm{Eu}(\mathrm{TTA})_{3}$ & 0,02 & $\mathrm{Fe}(\mathrm{acac})_{3}$ & 0,1 & 10 \\
\hline Eu:NPF_TTA_8 & $\mathrm{Eu}(\mathrm{TTA})_{3}$ & 0,02 & $\mathrm{Fe}(\mathrm{acac})_{3}$ & 0,1 & 8 \\
\hline Eu:NPF_TTA_6 & $\mathrm{Eu}(\mathrm{TTA})_{3}$ & 0,02 & $\mathrm{Fe}(\mathrm{acac})_{3}$ & 0,1 & 6 \\
\hline Eu:NPF_TTA_3 & $\mathrm{Eu}(\mathrm{TTA})_{3}$ & 0,02 & $\mathrm{Fe}(\mathrm{acac})_{3}$ & 0,1 & 3 \\
\hline Nd:NPF_TTA_6 & $\overline{\mathrm{Nd}(\mathrm{TTA})_{3}}$ & 0,02 & $\mathrm{Fe}(\mathrm{acac})_{3}$ & 0,1 & 6 \\
\hline Nd:NPF_TTA_3 & $\overline{\mathrm{Nd}(\mathrm{TTA})_{3}}$ & 0,02 & $\mathrm{Fe}(\mathrm{acac})_{3}$ & 0,1 & 3 \\
\hline
\end{tabular}

Fonte: Autoria própria.

Figura 16 - Fluxograma do procedimento experimental empregado na síntese das NPF dopadas com íons de terras raras em atmosfera de $\mathrm{N}_{2}$.

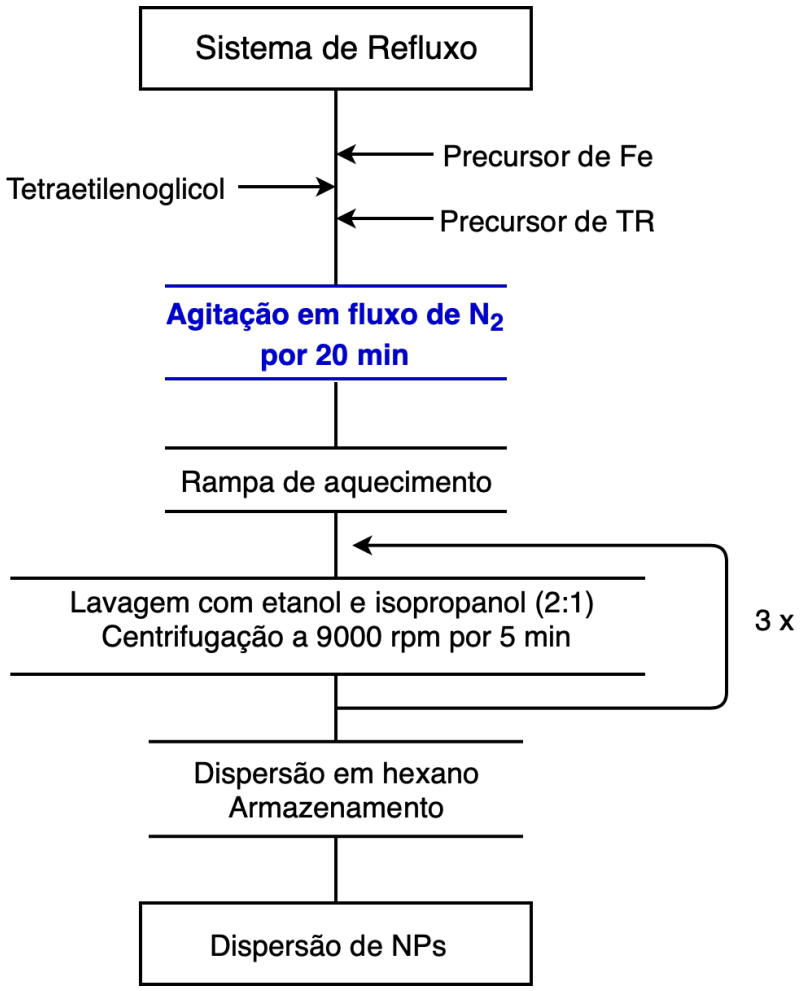

Fonte: Autoria própria. 


\subsection{Síntese das NPF dopadas com íons terras raras utili- zando acetilacetonato de TR(III)}

Para a síntese das ferritas dopadas, quantidades variadas de acetilacetonato de neodímio(III) hidratado ( $\mathrm{Nd}(\mathrm{acac})_{3}$ ) (Sigma-Aldrich) ou acetilacetonato de európio(III) $\left(\mathrm{Eu}(\mathrm{acac})_{3}\right)$ (sintetizado no laboratório) foram adicionados ao balão de três bocas, juntamente com $1 \mathrm{mmol}$ de $\mathrm{Fe}(\mathrm{acac})_{3}$ e $10 \mathrm{~mL}$ de TTEG, conforme mostra a Tabela 3.

Tabela 3 - Variações nos parâmetros de reação empregados durante a síntese de NPF dopadas com terras raras.

\begin{tabular}{|c|c|c|c|c|c|c|}
\hline \multirow{2}{*}{ Amostra } & \multicolumn{2}{|c|}{ Precursor de terra rara } & \multicolumn{2}{|c|}{ Precursor de Fe } & \multirow{2}{*}{ Proporção TR/Fe } & \multirow{2}{*}{ Tempo de refluxo (h) } \\
\hline & Tipo & Qtde (mmol) & Tipo & Qtde (mmol) & & \\
\hline Nd:NPF_0,5 & $\mathrm{Nd}(\mathrm{acac})_{3}$ & 0,01 & $\mathrm{Fe}(\text { acac })_{3}$ & 0,1 & $1 / 10$ & 0,5 \\
\hline Nd:NPF_1 & $\mathrm{Nd}(\mathrm{acac})_{3}$ & 0,01 & $\mathrm{Fe}(\mathrm{acac})_{3}$ & 0,1 & $1 / 10$ & 1,0 \\
\hline Nd:NPF_1,5 & $\mathrm{Nd}(\mathrm{acac})_{3}$ & 0,01 & $\mathrm{Fe}(\text { acac })_{3}$ & 0,1 & $1 / 10$ & 1,5 \\
\hline Nd:NPF_2 & $\mathrm{Nd}(\mathrm{acac})_{3}$ & 0,01 & $\mathrm{Fe}(\text { acac })_{3}$ & 0,1 & $1 / 10$ & 2,0 \\
\hline Nd:NPF_2,5 & $\mathrm{Nd}(\mathrm{acac})_{3}$ & 0,01 & $\mathrm{Fe}(\mathrm{acac})_{3}$ & 0,1 & $1 / 10$ & 2,5 \\
\hline Nd:NPF_3 & $\mathrm{Nd}(\mathrm{acac})_{3}$ & 0,01 & $\mathrm{Fe}(\mathrm{acac})_{3}$ & 0,1 & $1 / 10$ & 3,0 \\
\hline Nd:NPF_3,5 & $\mathrm{Nd}(\mathrm{acac})_{3}$ & 0,01 & $\mathrm{Fe}(\text { acac })_{3}$ & 0,1 & $1 / 10$ & 3,5 \\
\hline Nd:NPF_4 & $\mathrm{Nd}(\mathrm{acac})_{3}$ & 0,01 & $\mathrm{Fe}(\mathrm{acac})_{3}$ & 0,1 & $1 / 10$ & 4,0 \\
\hline Nd:NPF_10 & $\mathrm{Nd}(\mathrm{acac})_{3}$ & 0,01 & $\mathrm{Fe}(\text { acac })_{3}$ & 0,1 & $1 / 10$ & 3,0 \\
\hline Nd:NPF_20 & $\mathrm{Nd}(\mathrm{acac})_{3}$ & 0,02 & $\mathrm{Fe}(\mathrm{acac})_{3}$ & 0,1 & $2 / 10$ & 3,0 \\
\hline Nd:NPF_30 & $\mathrm{Nd}(\mathrm{acac})_{3}$ & 0,03 & $\mathrm{Fe}(\mathrm{acac})_{3}$ & 0,1 & $3 / 10$ & 3,0 \\
\hline Eu:NPF_10 & $\mathrm{Eu}(\mathrm{acac})_{3}$ & 0,01 & $\mathrm{Fe}(\mathrm{acac})_{3}$ & 0,1 & $1 / 10$ & 3,0 \\
\hline Eu:NPF_20 & $\mathrm{Eu}(\mathrm{acac})_{3}$ & 0,02 & $\mathrm{Fe}(\mathrm{acac})_{3}$ & 0,1 & $2 / 10$ & 3,0 \\
\hline Eu:NPF_30 & $\mathrm{Eu}(\mathrm{acac})_{3}$ & 0,03 & $\mathrm{Fe}(\mathrm{acac})_{3}$ & 0,1 & $3 / 10$ & 3,0 \\
\hline Eu:NPF_40 & $\mathrm{Eu}(\mathrm{acac})_{3}$ & 0,04 & $\mathrm{Fe}(\mathrm{acac})_{3}$ & 0,1 & $4 / 10$ & 3,0 \\
\hline
\end{tabular}

Fonte: Autoria própria.

As sínteses foram realizadas seguindo o procedimento descrito para a síntese de magnetita, sem atmosfera de $\mathrm{N}_{2}$. No entanto, o tempo de refluxo foi variado para determinadas sínteses, como também mostra a Tabela 3. Após o resfriamento até temperatura ambiente, as nanopartículas foram lavadas e centrifugadas conforme descrito no item 3.1 e estocadas em hexano. O procedimento é representado de forma geral na Figura 17. 
Figura 17 - Fluxograma do procedimento experimental empregado na síntese das NPF dopadas com íons de terras raras.

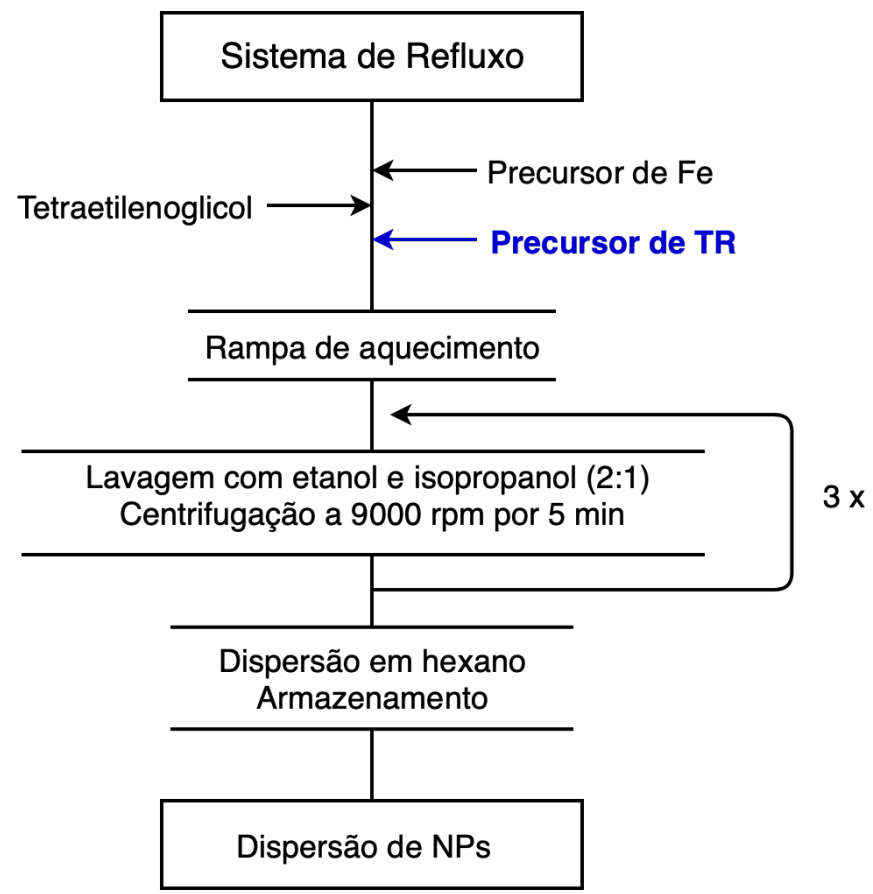

Fonte: Autoria própria.

\subsection{Caracterização}

\subsubsection{Difratometria de raios X (DRX)}

A difratometria de raios $\mathrm{X}$ foi utilizada para análise da estrutura cristalina e identificação das fases cristalográficas presentes nas amostras. Preparou-se as amostras gotejando a dispersão de nanopartículas em hexano sobre um substrato de silício ("zero background") e deixando o solvente evaporar a temperatura ambiente. As medidas foram realizadas utilizando o difratômetro D8 Advance da Bruker, operando com radiação $\mathrm{K} \alpha$ do cobre $(\lambda=1,5418 \AA ̊ \AA)$.

O diâmetro médio de cristalito $\left(\mathrm{D}_{h k l}\right)$ foi calculado a partir da medida da largura a meia altura dos picos de difração de maior intensidade das amostras, correspondentes ao plano (311), por meio da equação de Scherrer(79):

$$
D_{h k l}=\frac{0,9 \lambda}{\beta \cos \theta}
$$

Onde $\lambda=$ comprimento de onda da radiação incidente $(1,5418 \AA), \beta=$ largura a meia altura e $\theta=$ ângulo de Bragg. 


\subsubsection{Microscopia eletrônica de transmissão (MET)}

A morfologia, tamanho e dispersão das nanopartículas sintetizadas foram analisadas utilizando a técnica de microscopia eletrônica de transmissão. Para a análise, foi utilizado um microscópio eletrônico JEOL, modelo JEM-2100, operando a 200kV. As amostras foram preparadas com suspensões diluídas das NP em hexano, que foram dispersas em banho de ultrassom. Uma gota da dispersão foi depositada sobre uma grade de cobre recoberta com um filme duplo de polímero Formvar® e uma camada de carbono depositado por sputtering. O solvente foi evaporado a temperatura ambiente e as grades de cobre foram armazenadas em dessecador a vácuo. Para as amostras Nd:NPF_20, Nd:NPF_30, Eu:NPF_30 e Eu:NPF_40 foi adicionada uma gota de oleilamina (Sigma-Aldrich, $70 \%$ ) no preparo da suspensão a fim de suprimir a agregação característica de materiais magnéticos e facilitar a delimitação das nanopartículas. O mapeamento dos elementos metálicos foi realizado utilizando a técnica STEM (scanning-transmission electron microscopy). Foram realizadas estimativas de diâmetro médio (D) a partir da contagem de 400 partículas de cada amostra utilizandose do software livre de processamento de imagem ImageJ versão 1.52a. Com base nos valores de desvio padrão obtidos (SD), calculou-se o índice de polidispersividade (PDI) para os materiais conforme a equação 3.2. Um conjunto de NP pode ser classificado como monodisperso quando o PDI possui valores abaixo de $5 \%$ e quase monodisperso quando o valor do PDI se encontra entre 5 e $15 \% .(80)$

$$
P D I=\frac{\text { Desvio Padrão }}{\text { Diâmetro Médio }} \cdot 100 \%
$$

\subsubsection{Espectroscopia de energia dispersiva de raios X (EDX)}

A composição química de algumas amostras foi determinada semi quantitativamente por EDX. As análises foram realizadas no microscópio JEOL JEM-2100, obtidas com um detector OXFORD X-MaxN 80 T.

\subsubsection{Espectroscopia no infravermelho com transformada de Fourier (FTIR)}

A espectroscopia no infravermelho com transformada de Fourier foi realizada para análise dos grupos funcionais presentes nas amostras. Para a análise foi utilizado um espectrômetro Shimadzu, IRPrestige 21. As amostras foram preparadas na forma de pastilhas utilizando $100 \mathrm{mg}$ de $\mathrm{KBr}$ e $1 \mathrm{mg}$ das nanopartículas. Os espectros foram obtidos no intervalo de $400 \mathrm{~cm}^{-1}$ a $4000 \mathrm{~cm}^{-1}$, com resolução de $4 \mathrm{~cm}^{-1}$ e 32 varreduras. 


\subsubsection{Espectroscopia de fluorescência}

As análises das propriedades luminescentes, tais como bandas de excitação e emissão, foram realizadas utilizando um espectrofluorímetro Horiba, Fluorolog FL322i, em colaboração com o Prof. Dr. Fernando Aparecido Sigoli, do Instituto de Química da Universidade Estadual de Campinas. As amostras foram preparadas dispersando cerca de $2 \mathrm{mg}$ de cada amostra em solvente.

\subsubsection{Análise termogravimétrica (TG)}

A análise termogravimétrica dos compostos de terras raras $\left(\mathrm{Eu}(\mathrm{acac})_{3}, \mathrm{Eu}(\mathrm{TTA})_{3}\right.$, $\mathrm{Nd}(\mathrm{acac})_{3}$ e $\mathrm{Nd}(\mathrm{TTA})_{3}$ ) foi realizada utilizando um analisador térmico Shimadzu TA50WSI equipado com um módulo TGA-50, em fluxo de ar sintético com taxa de aquecimento de $10^{\circ} \mathrm{C} / \mathrm{min}$.

\subsubsection{Magnetometria de Amostra Vibrante (VSM)}

As curvas de magnetização por campo externo aplicado foram obtidas utilizando um magnetômetro de amostra vibrante convencional, em colaboração com o Prof. Dr. Daniel Reinaldo Cornejo, do Departamento de Física dos Materiais e Mecânica do Instituto de Física da Universidade de São Paulo. Para a realização das análises, as amostras foram secas, pesadas e adicionadas ao interior de uma cápsula de medicamento vazia, que foi então centralizada no compartimento de medida do equipamento. As medidas foram realizadas à temperatura de $300 \mathrm{~K}$ e o campo magnético aplicado foi variado entre 15 e -15 kOe. 


\section{Resultados e Discussão}

\subsection{Síntese da ferrita de ferro (magnetita)}

No processo poliol modificado, a temperatura elevada leva à desidratação do etilenoglicol, formando um aldeído que atua como reagente redutor, como mostra a Equação 4.1. Na presença dos íons metálicos (M(II)), o aldeído é oxidado, reduzindo o metal, tendo como subproduto $\mathrm{O}_{2}$, um forte agente redutor que, se permanecido dissolvido na solução, pode auxiliar na redução ou pode ser eliminado com a presença de um gás de arraste no sistema. $(67,68)$

$$
2 \mathrm{CH}_{2} \mathrm{OH}-\mathrm{CH}_{2} \mathrm{OH} \stackrel{-2 \mathrm{H}_{2} \mathrm{O}}{\longrightarrow} 2 \mathrm{CH}_{3} \mathrm{CHO} \stackrel{\mathrm{M}(\mathrm{II})}{\longrightarrow} \mathrm{CH}_{3} \mathrm{COCOCH}_{3}+\mathrm{H}_{2}+M^{0}
$$

O método poliol modificado pode resultar em NP de diferentes composições e tamanho de acordo com a variação do precursor de íon metálico utilizado e a proporção dos reagentes (68). Um dos objetivos deste trabalho é adequar a metodologia de síntese do processo poliol/poliol modificado para a obtenção da fase espinélio da ferrita de ferro não dopada. Análises detalhadas acerca da composição das partículas foram realizadas. $O$ resultado da análise de difratometria de raios $X$ (Figura 18) foi comparada com o padrão de difração (JCPDF 19-629) das fases cristalinas da magnetita. Os principais picos de difração da amostra foram indexados conforme a fase espinélio da ferrita de ferro, sendo eles em $30,1^{\circ}, 35,3^{\circ}, 42,9^{\circ}, 56,8^{\circ} \mathrm{e} 62,4^{\circ} \mathrm{em} 2 \theta$, correspondendo aos planos (220), (311), (400), (511) e (440), respectivamente.(81) É possível observar que o pico principal encontra-se deslocado para um menor valor de $2 \theta$ em relação ao padrão $\left(35,4^{\circ}\right)$ e esse deslocamento é um indício de defeitos na estrutura cristalina resultantes do processo de síntese empregado. $(82,83)$ De acordo com esse resultado é possível inferir que o produto sintetizado se trata de magnetita. 
Figura 18 - Difratograma de raios $X$ obtido para a amostra de ferrita sintetizada em comparação ao padrão JCPDF 19-629 da fase espinélio invertida de magnetita.

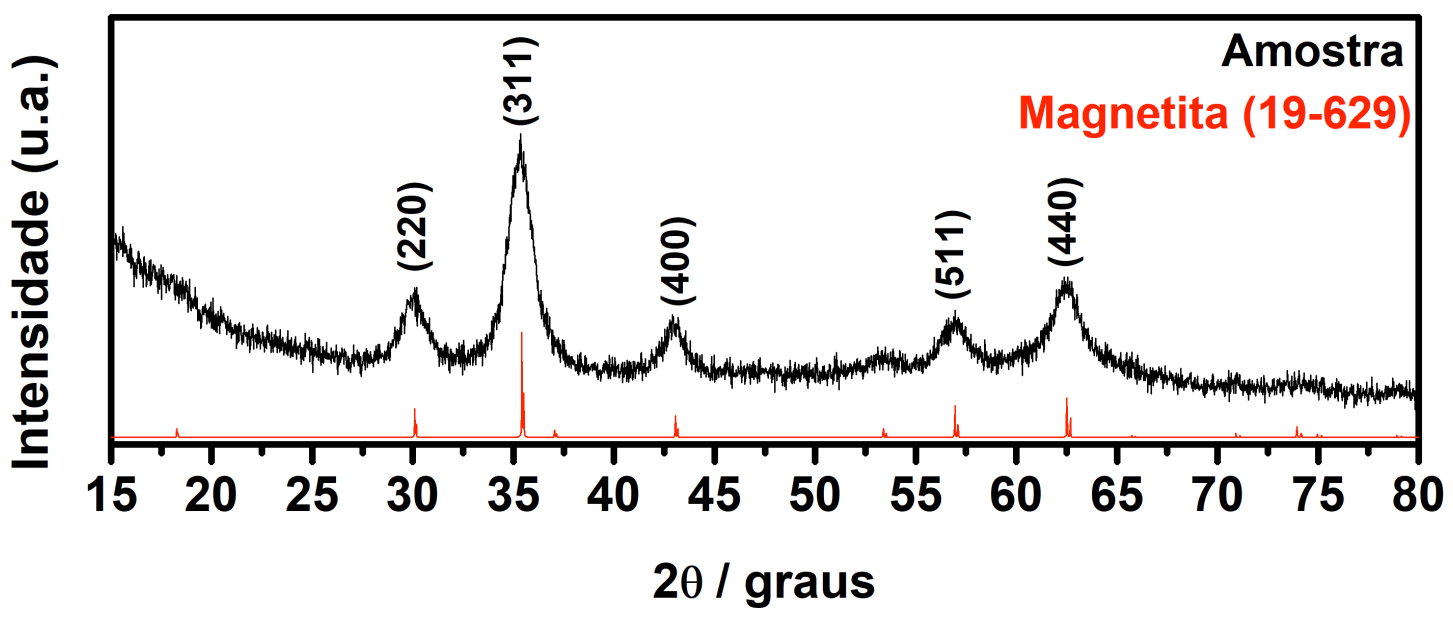

Fonte: Autoria própria.

Pela análise de espectroscopia no infravermelho com transformada de Fourier é possível caracterizar as ligações presentes nas nanopartículas, principalmente as que ocorrem com moléculas ligadas à superfície. O espectro na Figura 19 apresenta banda de vibração em $578 \mathrm{~cm}^{-1}$, característica de ligações Fe-O em sítios octaédricos e tetraédricos da estrutura cúbica de espinélio invertida da magnetita.(81) O processo de síntese via método poliol leva à oxidação do solvente, que também sofre degradação térmica e dentre os derivados formados estão espécies como $\mathrm{H}_{2} \mathrm{O}, \mathrm{CO}, \mathrm{CO}_{2}$ e radicais com uma ou mais unidades de $-\mathrm{CH}_{2}-\mathrm{O}$ - . $(84,85)$ É sabido que os produtos da oxidação e da degradação do solvente podem ser adsorvidos na superfície da partícula e as bandas presentes na região em destaque na Figura 19, de $3000 \mathrm{~cm}^{-1}$ a $800 \mathrm{~cm}^{-1}$ indicam a presença desses derivados sobre as superfície das nanopartículas formadas, uma vez que bandas nessa região são características de estiramentos de ligações do tipo $\mathrm{C}=\mathrm{O}, \mathrm{C}=\mathrm{C}, \mathrm{C}-\mathrm{O}$ e deformações $\mathrm{C}-\mathrm{H} .(68,84,85,86) \mathrm{A}$ banda presente em $3741 \mathrm{~cm}^{-1}$ pode ser atribuída ao estiramento de grupos $\mathrm{OH}$ ligados à superfície das partículas, que podem estar coordenados a um, dois ou três átomos de Fe. $(81,87)$ 
Figura 19 - Espectro FTIR para a amostra de magnetita. A área em destaque apresenta bandas referentes à derivados da síntese ligados à superfície das NPF.

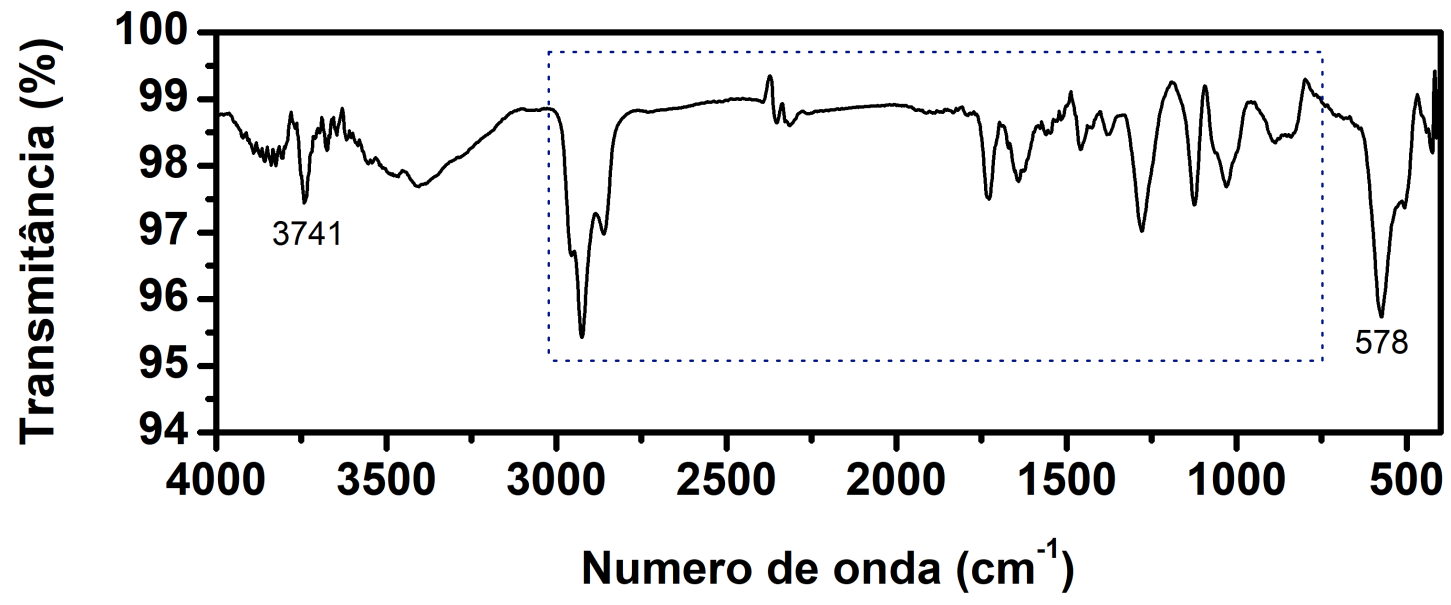

Fonte: Autoria própria.

A curva de magnetização obtida por magnetometria de amostra vibrante para a NPF (Figura 20) mostra um comportamento próximo ao superparamagnético, com magnetização de saturação (Ms) de 52,8 emu/g, valor inferior ao apresentado pela magnetita na forma bulk, em torno de 90 a 100 emu/g.(81) Essa diminuição na Ms ocorre devido às pequenas dimensões das nanopartículas e à grande quantidade de produtos de oxidação e degradação do meio de reação presentes na superfície dessas NP, contribuindo para a massa, mas não para a magnetização da amostra.

Figura 20 - Curva de magnetização da amostra de magnetita. Região em destaque na figura mostra o deslocamento da curva devido ao efeito de exchange bias negativo.

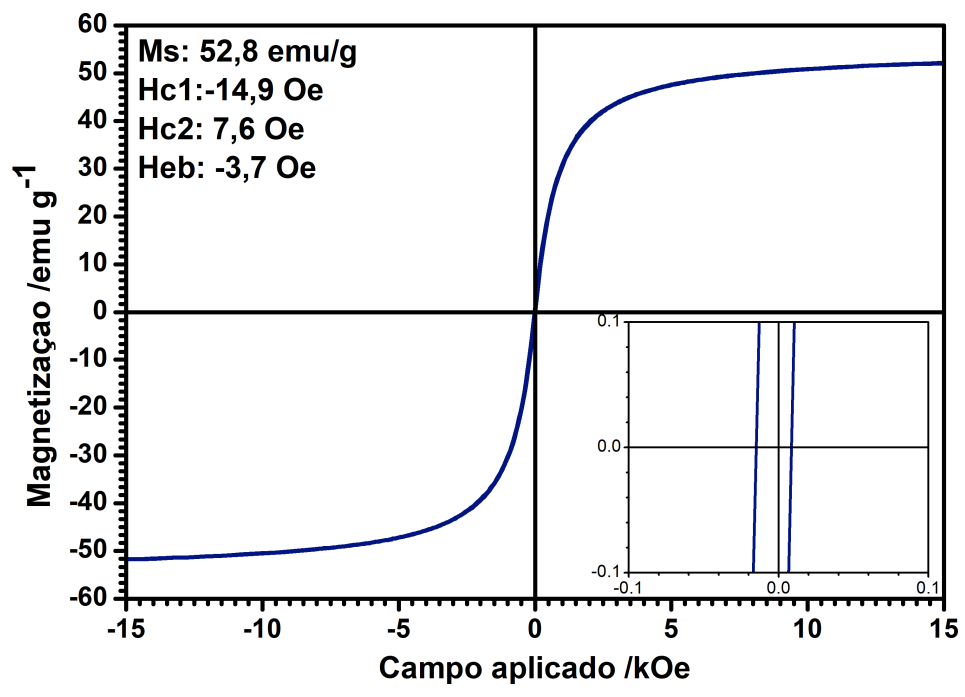

Fonte: Autoria própria. 
Como é possível observar pelos valores de coercividade (Hc1 e Hc2) apresentados, a curva de magnetização se encontra levemente deslocada para valores de campo magnético negativos, indicando a ocorrência de exchange bias, com Heb de 3,7 Oe. A presença de EB pode estar relacionada à existência de defeitos de superfície causados pelo método de síntese e também à mudança de coordenação dos átomos de superfície. A banda referente ao estiramento $\mathrm{OH}$ estrutural $\left(3741 \mathrm{~cm}^{-1}\right)$ presente na análise de FTIR mostra a formação de ligações do tipo Fe-OH na superfície, o que sugere a formação de uma camada de superfície de oxi-hidróxido de Fe, diferente do núcleo da partícula. Essa diferença de composição pode fazer com que haja diferença no ordenamento dos spins do núcleo e da superfície, fazendo com que essas camadas tenham comportamento magnético diferentes, agindo como um sistema de duas fases magnéticas distintas (spins do núcleo e spins de superfície), que podem acoplar magneticamente.(11,15) A determinação das fases que compõem o núcleo e a superfície das NP, assim como o comportamento magnético de cada uma, é possível por meio de espectroscopia Mossbauer. No entanto, devido à pandemia de Covid-19, essa análise não pôde ser realizada.

A análise de microscopia eletrônica de transmissão apresentada pela Figura 21 em conjunto com o histograma de distribuição do tamanho das NP, mostra que foram obtidas nanopartículas com controle de forma, diâmetro médio de 6,95 nm e índice de polidispersividade de $20 \%$. O diâmetro médio de cristalito $\left(D_{h k l}\right)$ calculado por meio da equação de Scherrer, utilizando a reflexão do plano (311) no difratograma, foi de 6,38 nm, corroborando o resultado obtido a partir da análise de microscopia. Embora não tenham sido obtidas NPF monodispersas, o valor do PDI alcançado foi considerado bom para essa etapa do projeto. A partir da obtenção da ferrita de ferro, pôde-se prosseguir com a obtenção das ferritas dopadas com íons de terras raras. 
Figura 21 - Microscopia eletrônica de transmissão da amostra de ferrita de ferro e histograma de distribuição dos tamanhos das nanopartículas medidas.
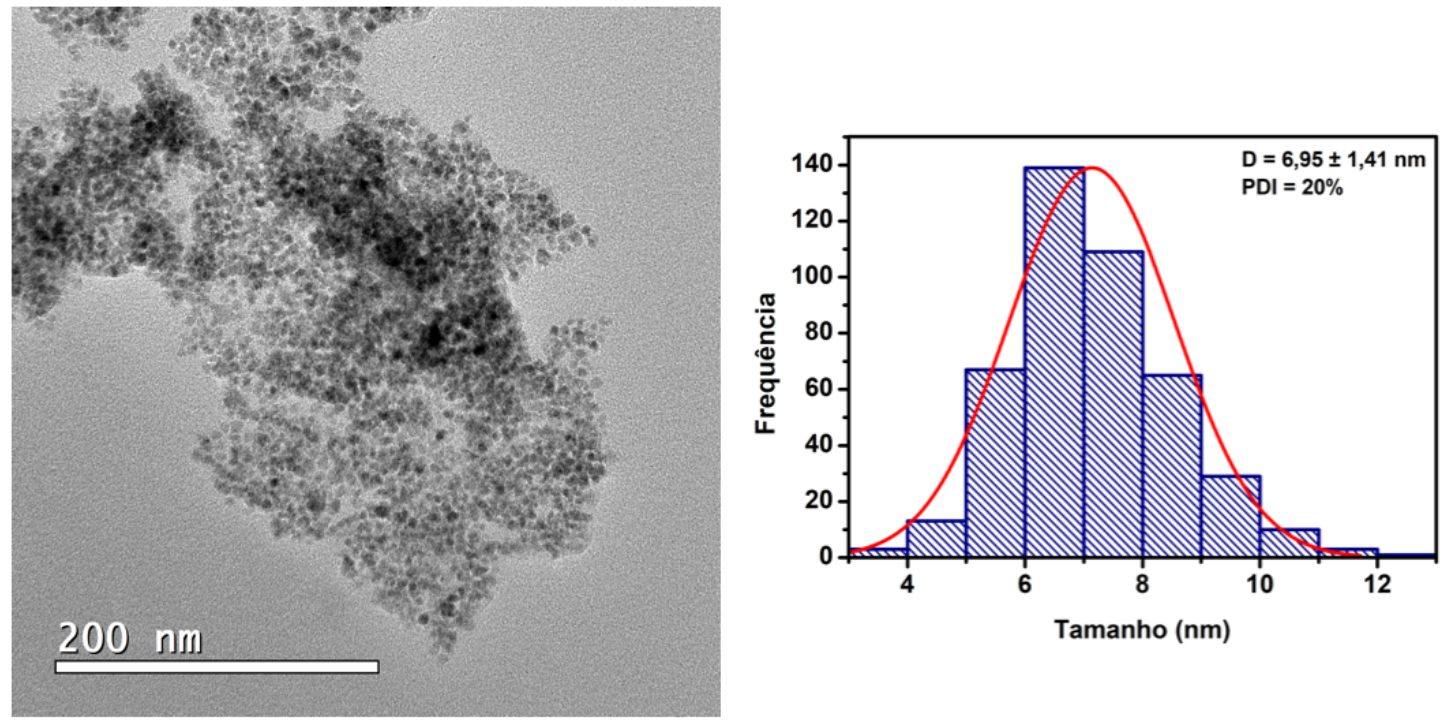

Fonte: Autoria própria.

\subsection{Síntese dos complexos $\mathrm{Eu}(\mathrm{TTA})_{3}$ e $\mathrm{Nd}(\mathrm{TTA})_{3}$}

Os complexos $\mathrm{Eu}(\mathrm{TTA})_{3}$ (Figura 22b) e $\mathrm{Nd}(\mathrm{TTA})_{3}$ utilizados nos experimentos que avaliam o efeito da atmosfera de $\mathrm{N}_{2}$ nas NPF dopadas foram sintetizados seguindo procedimento descrito por Charles e OhImann.(77) Os espectros FTIR referentes aos complexos apresentam bandas características dos compostos referentes às ligações $\mathrm{C}=\mathrm{O}$ na região de 1604 a $1710 \mathrm{~cm}^{-1}, \mathrm{C}=\mathrm{C}$ em 1542 e $1411 \mathrm{~cm}^{-1}$ e $\mathrm{C}_{-} \mathrm{CF}_{3}$ em 1141 e $1303 \mathrm{~cm}^{-1}$.(86) Em comparação ao espectro do ligante livre, observa-se uma mudança da banda referente à ligação $\mathrm{C}=\mathrm{O}$ para menor número de onda, que se encontra em $1651 \mathrm{~cm}^{-1}$ para o TTA e em $1604 \mathrm{~cm}^{-1}$ para os complexos, o desaparecimento da banda referente à ligação $\mathrm{H}-\mathrm{O} \cdot \cdots \mathrm{O}$ em $732 \mathrm{~cm}^{-1}$ e o surgimento de uma nova banda em $578 \mathrm{~cm}^{-1}$, referente à ligação Eu-O e $\mathrm{Nd}-\mathrm{O} .(88,89,90) \mathrm{De}$ acordo com esse resultado, é possível inferir que os produtos sintetizados se tratam dos complexos $\mathrm{Eu}(\mathrm{TTA})_{3} \mathrm{e}$ $\mathrm{Nd}(\mathrm{TTA})_{3}$. A coloração avermelhada apresentada pelo complexo de Eu sob irradiação de luz ultravioleta (365 nm) (Figura 22c) corrobora essa afirmação, pois é um indicativo da valência 3+ do európio na amostra. $(52,91)$ 
Figura 22 - Espectros FTIR do $\mathrm{Eu}(T T A)_{3}$ sintetizado e de seus precursores $\mathrm{Eu}_{2} \mathrm{O}_{3}$ e TTA (a), estrutura molecular do complexo $\mathrm{Eu}(\mathrm{TTA})_{3}$ hidratado (b) e fotos da amostra sob irradiação de luz ultravioleta $(365 \mathrm{~nm})(\mathrm{c})$.

a)

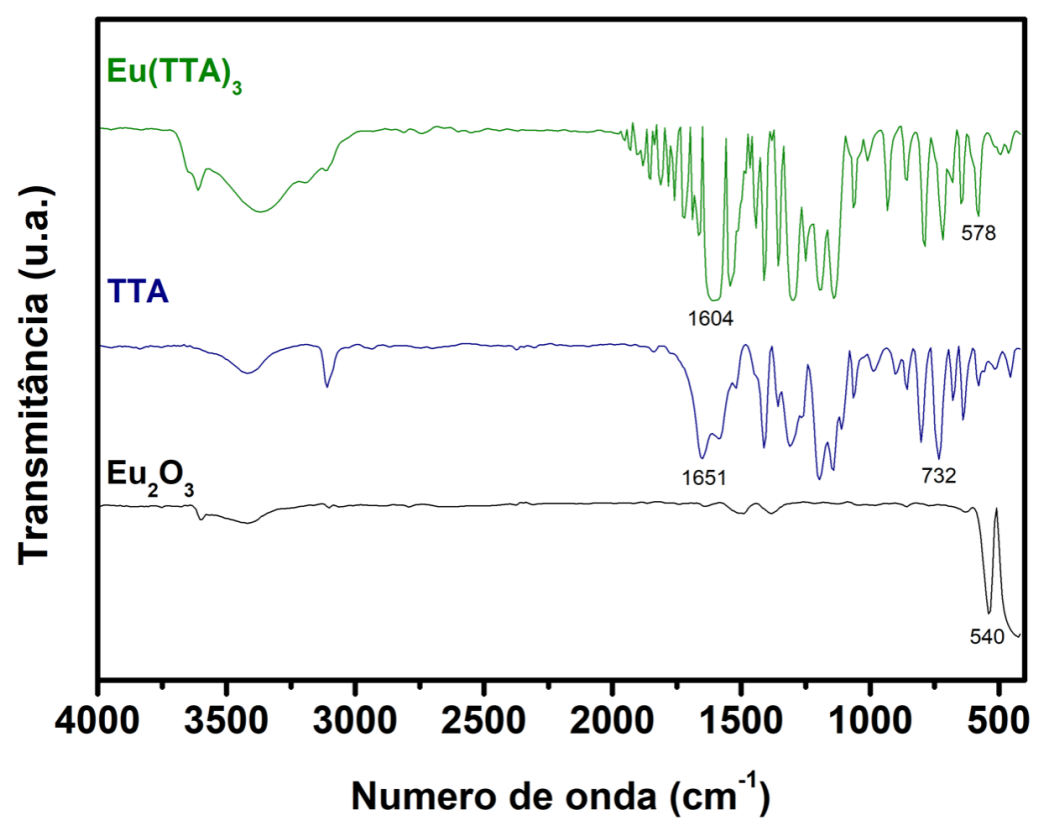

b)

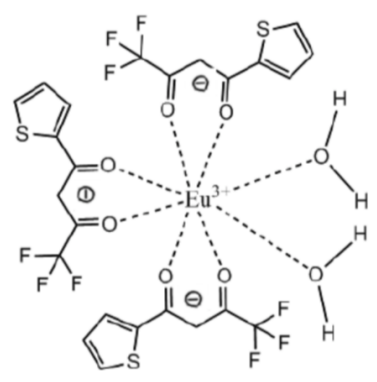

c)

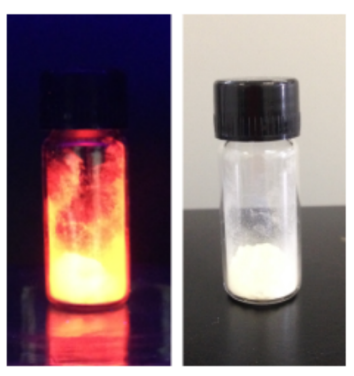

Fonte: Autoria própria.

Figura 23 - Espectros FTIR do $\mathrm{Nd}(\mathrm{TTA})_{3}$ sintetizado e de seus precursores $\mathrm{Nd}_{2} \mathrm{O}_{3}$ e TTA.

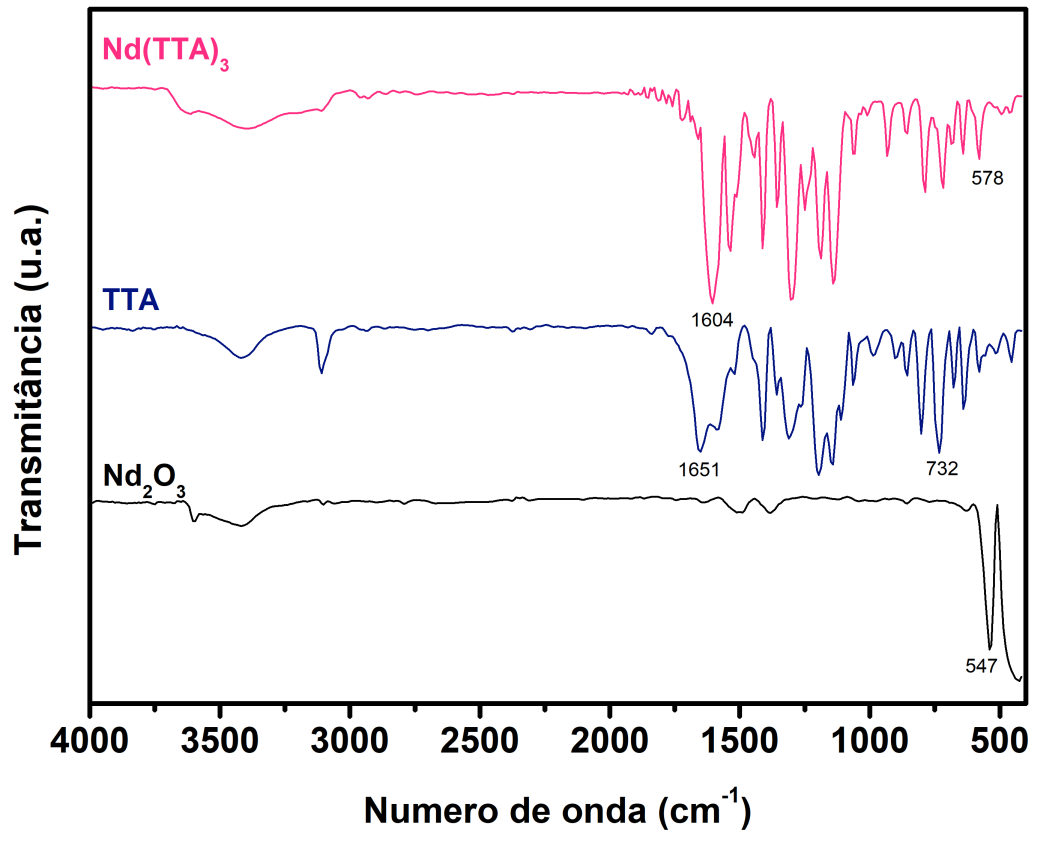

Fonte: Autoria própria. 


\subsection{Síntese de magnetitas dopadas com íons terras raras em atmosfera de $\mathrm{N}_{2}$}

Inspiradas pela síntese de magnetitas dopadas com íons de terras raras descrita por Silva et. al.(92), as sínteses desenvolvidas inicialmente neste trabalho foram realizadas em atmosfera de $\mathrm{N}_{2}$, utilizando $\mathrm{Eu}(\mathrm{TTA})_{3}$ e $\mathrm{Nd}(\mathrm{TTA})_{3}$ como precursores de európio e neodímio, respectivamente. Com o intuito de analisar a influência do tempo de refluxo na formação das nanopartículas e em suas propriedades, foram realizadas diversas sínteses com tempos de refluxo distintos, fixando os demais parâmetros de síntese como mostra a Tabela 4.

Tabela 4 - Variações no tempo de refluxo empregado durante a síntese de NPF dopadas com terras raras em atmosfera de $\mathrm{N}_{2}$.

\begin{tabular}{c|cc|c}
\hline \multicolumn{1}{c}{ Amostra } & \multicolumn{2}{c|}{ Precursor de TR } & Tempo de refluxo (h) \\
\hline Eu:NPF_TTA_22 & $\mathrm{Eu}(\mathrm{TTA})_{3}$ & Qtde $(\mathrm{mmol})$ & 0,02 \\
\hline Eu:NPF_TTA_20 & $\mathrm{Eu}(\mathrm{TTA})_{3}$ & 0,02 & $\mathbf{2 2}$ \\
\hline Eu:NPF_TTA_18 & $\mathrm{Eu}(\mathrm{TTA})_{3}$ & 0,02 & $\mathbf{2 0}$ \\
\hline Eu:NPF_TTA_16 & $\mathrm{Eu}(\mathrm{TTA})_{3}$ & 0,02 & $\mathbf{1 8}$ \\
\hline Eu:NPF_TTA_14 & $\mathrm{Eu}(\mathrm{TTA})_{3}$ & 0,02 & $\mathbf{1 6}$ \\
\hline Eu:NPF_TTA_12 & $\mathrm{Eu}(\mathrm{TTA})_{3}$ & 0,02 & $\mathbf{1 4}$ \\
\hline Eu:NPF_TTA_10 & $\mathrm{Eu}(\mathrm{TTA})_{3}$ & 0,02 & $\mathbf{1 2}$ \\
\hline Eu:NPF_TTA_8 & $\mathrm{Eu}(\mathrm{TTA})_{3}$ & 0,02 & $\mathbf{1 0}$ \\
\hline Eu:NPF_TTA_6 & $\mathrm{Eu}(\mathrm{TTA})_{3}$ & 0,02 & $\mathbf{6}$ \\
\hline Eu:NPF_TTA_3 & $\mathrm{Eu}(\mathrm{TTA})_{3}$ & 0,02 & $\mathbf{3}$ \\
\hline Nd:NPF_TTA_6 & $\mathrm{Nd}(\mathrm{TTA})_{3}$ & 0,02 & $\mathbf{6}$ \\
\hline Nd:NPF_TTA_3 & $\mathrm{Nd}(\mathrm{TTA})_{3}$ & 0,02 & $\mathbf{3}$ \\
\hline
\end{tabular}

Fonte: Autoria própria.

\subsubsection{Síntese de magnetita dopada com európio (Eu:NPF)}

A Figura 24 apresenta o difratograma de raios $X$ das amostras de Eu:NPF obtidas por meio de sínteses com tempos de refluxo de 3 a 22 horas em comparação ao padrão cristalográfico da magnetita (JCPDF 19-629). As amostras apresentam os principais picos de difração característicos da magnetita em $2 \theta$ igual a $30,1^{\circ}, 35,3^{\circ}$, $42,9^{\circ}, 56,8^{\circ}$ e $62,4^{\circ}$, correspondentes aos planos de difração (220), (311), (400), (511) e (440), respectivamente.(81) Conforme reportado na literatura, a dopagem de magnetita com terras raras leva à segregação de fase quando a concentração de íons TR no sistema ultrapassa a concentração de saturação na incorporação de íons de TR na estrutura, causando a formação de fases amorfas ou cristalinas como TRFeO ${ }_{3}, \alpha-\mathrm{Fe}_{2} \mathrm{O}_{3}$ e monóxidos metálicos. $(24,93,94)$ Devido à proporção de $\mathrm{Eu}^{3+} / \mathrm{Fe}^{3+}$ utilizada $(2: 10)$ 
para a realização das sínteses, além dos picos de magnetita, as amostras apresentam picos em $27,8^{\circ}, 29,4^{\circ} \mathrm{e} 46,2^{\circ}$, que sugerem a formação de uma segunda fase similar ao óxido de európio, possivelmente não estequiométrica. Análises acerca da estrutura da fase secundária não foram realizadas, não sendo possível afirmar a qual composto os picos apresentados correspondem. É possível observar nos difratogramas que a intensidade dos picos referentes à fase secundária diminui com a redução do tempo de síntese, o que indica que o maior tempo de refluxo favorece à formação da fase extra, possivelmente por acarretar em diversas etapas de nucleação, por meio do processo de envelhecimento de Ostwald.

Figura 24 - Difratograma de raios $\mathrm{X}$ obtido para as amostras de magnetita dopadas com európio sintetizadas com tempos de refluxo iguais a 3h (Eu:NPF_TTA_3), 6h (Eu:NPF_TTA_6), 8h (Eu:NPF_TTA_8), 10h (Eu:NPF_TTA_10), 12h (Eu:NPF_TTA_12), 14h (Eu:NPF_TTA_14), 16h (Eu:NPF_TTA_16), 18h (Eu:NPF_TTA_3), 20h (Eu:NPF_TTA_20) e 22h (Eu:NPF_TTA_22) em comparação ao padrão JCPDF 19-629 da fase espinélio invertida de magnetita. As linhas tracejadas indicam a presença de picos referentes a uma fase secundária.

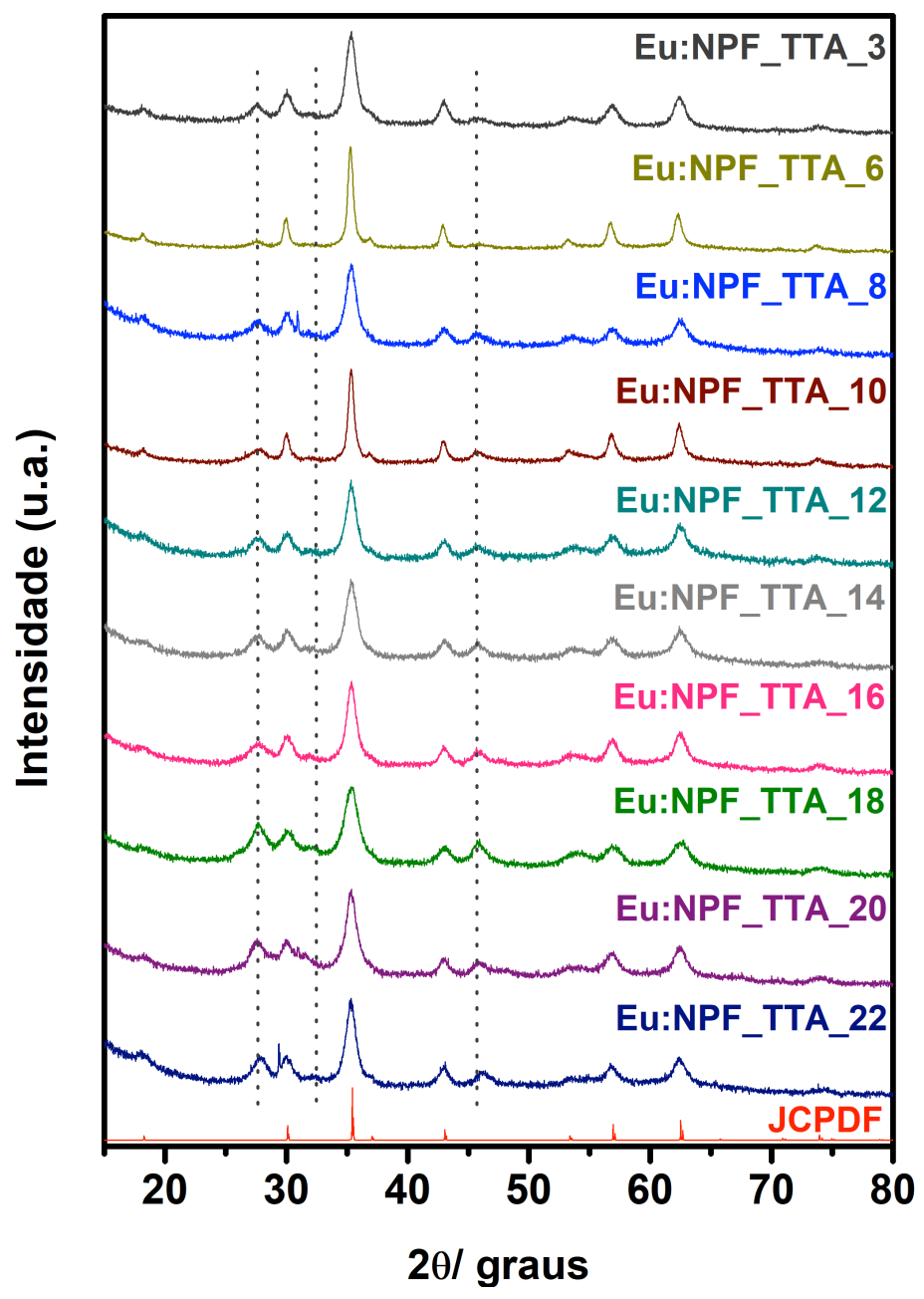

Fonte: Autoria própria. 
O espectro FTIR referente à amostra Eu:NPF_TTA_3 na Figura 25 apresenta banda de vibração em $578 \mathrm{~cm}^{-1}$, característica de ligações $\mathrm{Fe}-\mathrm{O}$ em sítios octaédricos e tetraédricos da estrutura cúbica de espinélio invertida da magnetita.(81) Assim como o espectro FTIR da ferrita pura, o espectro da amostra dopada com európio também apresenta bandas referentes à produtos de oxidação e degradação do solvente adsorvidos na superfície da partícula, que podem ser atribuídas a estiramentos de ligações do tipo $\mathrm{C}=\mathrm{O}, \mathrm{C}=\mathrm{C}, \mathrm{C}-\mathrm{O}$ e deformações $\mathrm{C}-\mathrm{H}$, presentes na região em destaque na $\mathrm{Fi}-$ gura 25. $(68,84,85,86)$ A banda alargada na região de $3400 \mathrm{~cm}^{-1}$ pode ser atribuída ao estiramento de grupos $\mathrm{OH}$ devido à presença de água na amostra. (86)

Figura 25 - Espectro FTIR da amostra Eu:NPF_TTA_3. A área em destaque apresenta bandas referentes à derivados da síntese ligados à superfície das NPF.

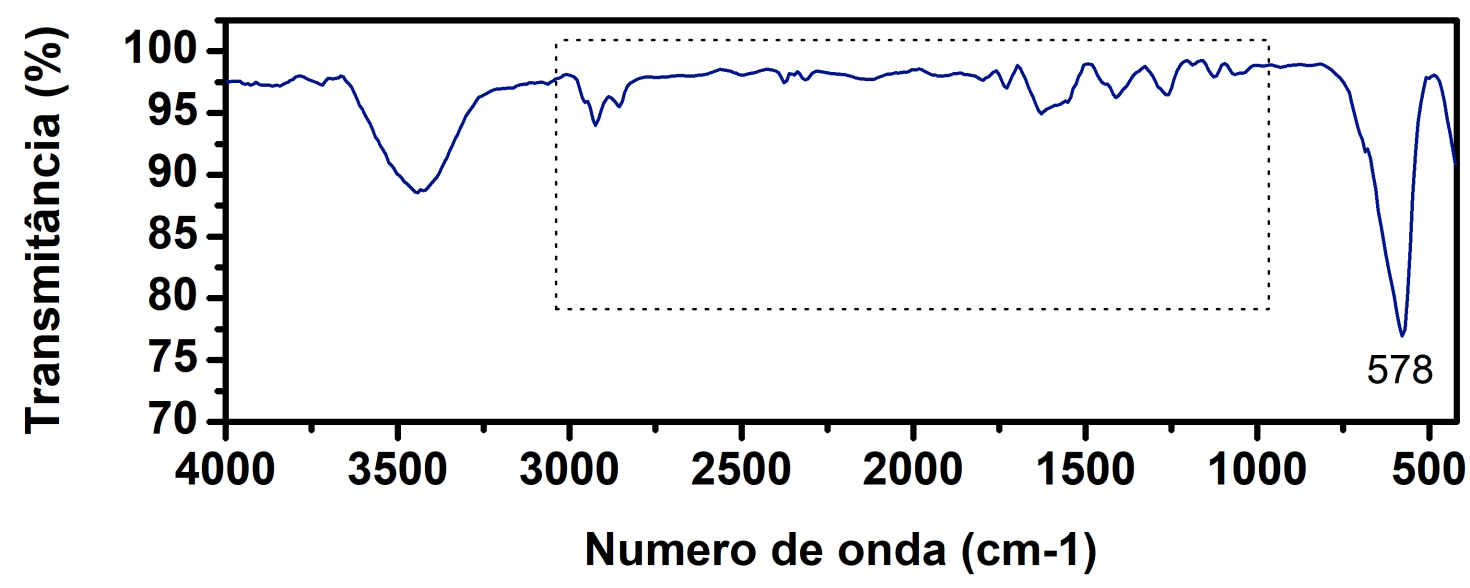

Fonte: Autoria própria.

A Figura 26 apresenta micrografias obtidas por análise de microscopia de transmissão e a Figura 27 apresenta os histogramas de distribuição de tamanho das NP. O diâmetro médio das NP calculado a partir do difratograma por meio da equação de Scherrer e o diâmetro médio obtido por meio da medição das partículas a partir das micrografias são mostrados pela Tabela 5 . 
Figura 26 - Microscopia eletrônica de transmissão das amostras de magnetita dopadas com európio Eu:NPF_TTA_22 (a), Eu:NPF_TTA_20 (b), Eu:NPF_TTA_18 (c), Eu:NPF_TTA_16 (d), Eu:NPF_TTA_14 (e), Eu:NPF_TTA_12 (f), Eu:NPF_TTA_10 (g), Eu:NPF_TTA_8 (h), Eu:NPF_TTA_6 (i) e Eu:NPF_TTA_3 (j).
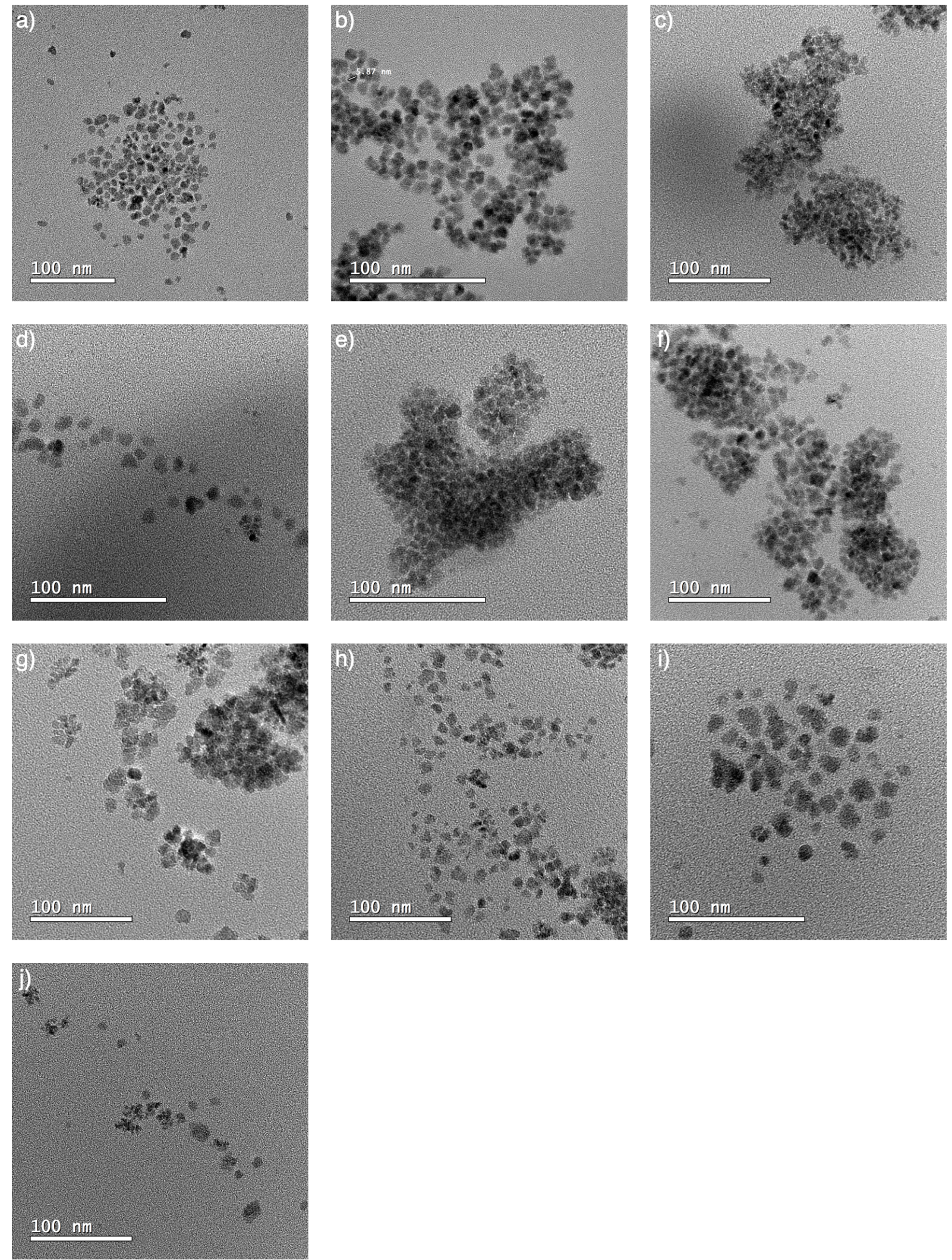

Fonte: Autoria própria. 
Figura 27 - Histogramas de distribuição de tamanho das NP de magnetita dopadas com európio (Eu:NPF).
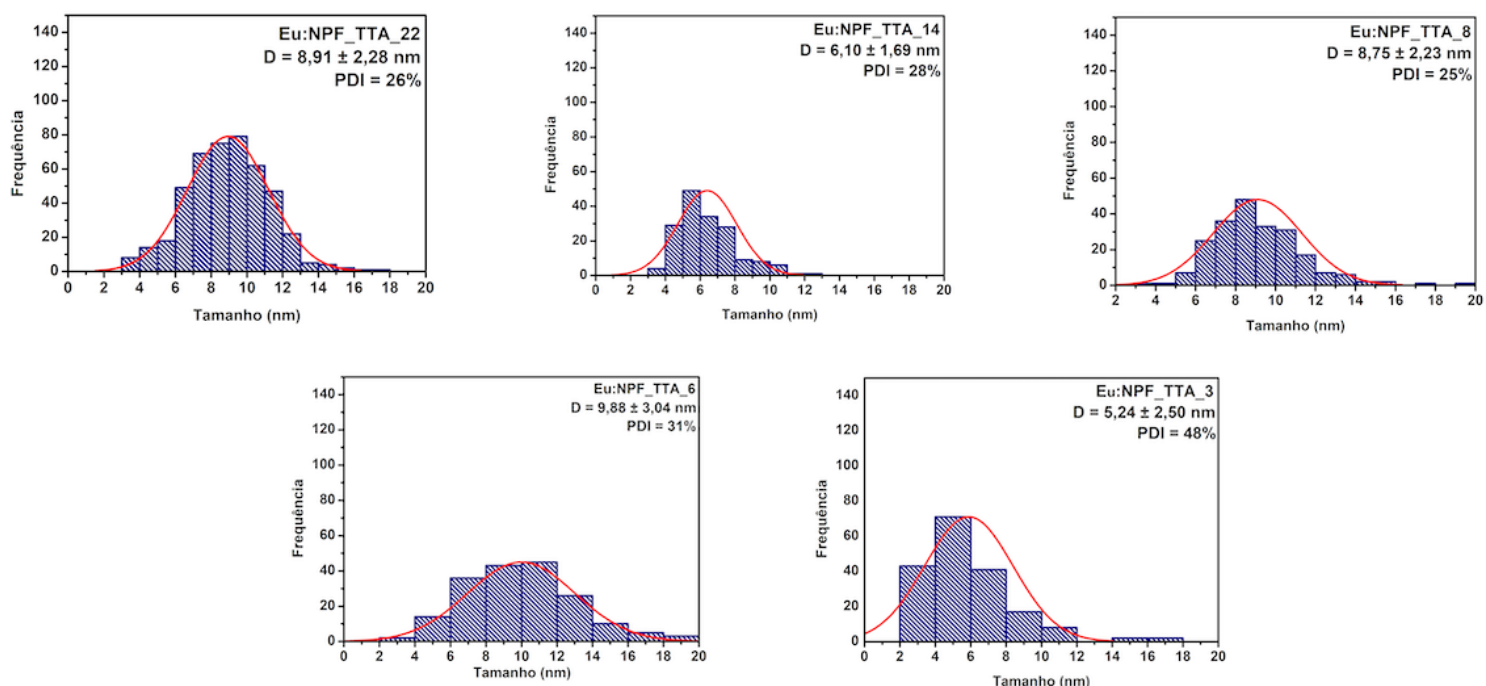

Fonte: Autoria própria.

Tabela 5 - Comparação entre os valores de diâmetro médio (D) e tamanho de cristalito $\left(D_{h k l}\right)$ para as amostras de magnetita dopadas com európio (Eu:NPF) em atmosfera de $\mathrm{N}_{2}$.

\begin{tabular}{lcc}
\hline \multicolumn{1}{c}{ Amostra } & $\mathrm{D}_{h k l}(\mathrm{~nm})$ & $\mathrm{D}(\mathrm{nm})$ \\
\hline Eu:NPF_TTA_22 & 9,98 & 8,91 \\
\hline Eu:NPF_TTA_14 & 8,80 & 6,10 \\
\hline Eu:NPF_TTA_8 & 9,40 & 8,75 \\
\hline Eu:NPF_TTA_6 & 22,47 & 9,88 \\
\hline Eu:NPF_TTA_3 & 9,91 & 5,24 \\
\hline
\end{tabular}

Fonte: Autoria própria.

A pequena divergência entre os valores se deve ao baixo contraste das nanopartículas nas micrografias, gerado pela queima de compostos orgânicos presentes na amostra durante a análise de microscopia, o que dificulta a delimitação da superfície, podendo acarretar em erros de medição. Para as amostras obtidas com tempo de refluxo de 6 h e $3 \mathrm{~h}$, os valores de tamanho médio de cristalito $\left(D_{h k l}\right)$ e de partículas (D) são bastante discrepantes. Embora se note um menor alargamento do pico (311) para o tempo de 6 horas, nas micrografias TEM não foi observada a presença de nanopartículas de tamanhos maiores. Infelizmente, a região observada no porta-amostra durante a análise TEM é bastante limitada e devem existir NP maiores, mesmo em pequeno número, que não foram observadas durante a varredura realizada no porta-amostra. Como a técnica de DRX observa uma média de difração global da amostra, um número pequeno de nanopartículas com tamanhos maiores pode gerar um padrão de difração mais bem definido, levando às discrepâncias observadas entre os tamanhos 
médios de cristalito e partícula para essas duas amostras, ainda que para a amostra sintetizada em 3h, o efeito seja menos pronunciado. A partir destas análises, é possível observar que o tempo de refluxo não tem um impacto linear no diâmetro médio das NP, gerando partículas com tamanhos e distribuições variadas.

Análises de energia dispersiva de raios $X$ mostram um discreto aumento na concentração de európio nas amostras conforme a redução do tempo de refluxo. $A$ porcentagem de Eu calculada para as amostras Eu:NPF_TTA_22, Eu:NPF_TTA_6 e Eu:NPF_TTA_3, em relação ao Fe, foi de 5,1\%, 6,7\% e 7,7\%, respectivamente. A análise de EDX indica a presença do TR nas amostras, no entanto, não é possível afirmar a quantidade de Eu incorporada na estrutura da magnetita. A pequena diferença entre a quantidade de Eu nas amostras sugere que o tempo de refluxo não exerce grande influência na concentração final de TR no material sintetizado. A Figura 28 apresenta o mapeamento dos elementos Fe e Eu na amostra Eu:NPF_TTA_3.

Figura 28 - Mapeamento dos elementos Fe e Eu por STEM na amostra Eu:NPF_TTA_3.
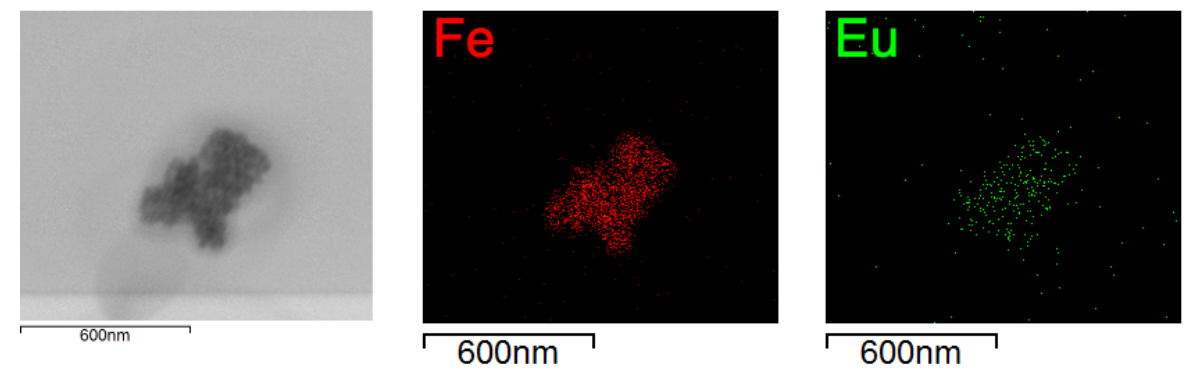

Fonte: Autoria própria.

As curvas de magnetização das amostras dopadas com európio são apresentadas pela Figura 29 e os valores de coercividade $(\mathrm{Hc})$ e magnetização de saturação (Ms) são dados pela Tabela 6. As amostras analisadas apresentam menores valores de Ms em comparação à magnetita não dopada (52,8 emu/g). Essa diminuição na Ms pode ser explicada por uma combinação entre defeitos na rede cristalina e interações de supertroca magnéticas mais fracas entre os sítios A e B nas ferritas. 
Figura 29 - Curva de magnetização das amostras Eu:NPF_TTA_3, Eu:NPF_TTA_6, Eu:NPF_TTA_8, Eu:NPF_TTA_14 e Eu:NPF_TTA_22. Região em destaque na figura mostra o deslocamento das curvas de histerese devido ao efeito de exchange bias negativo.

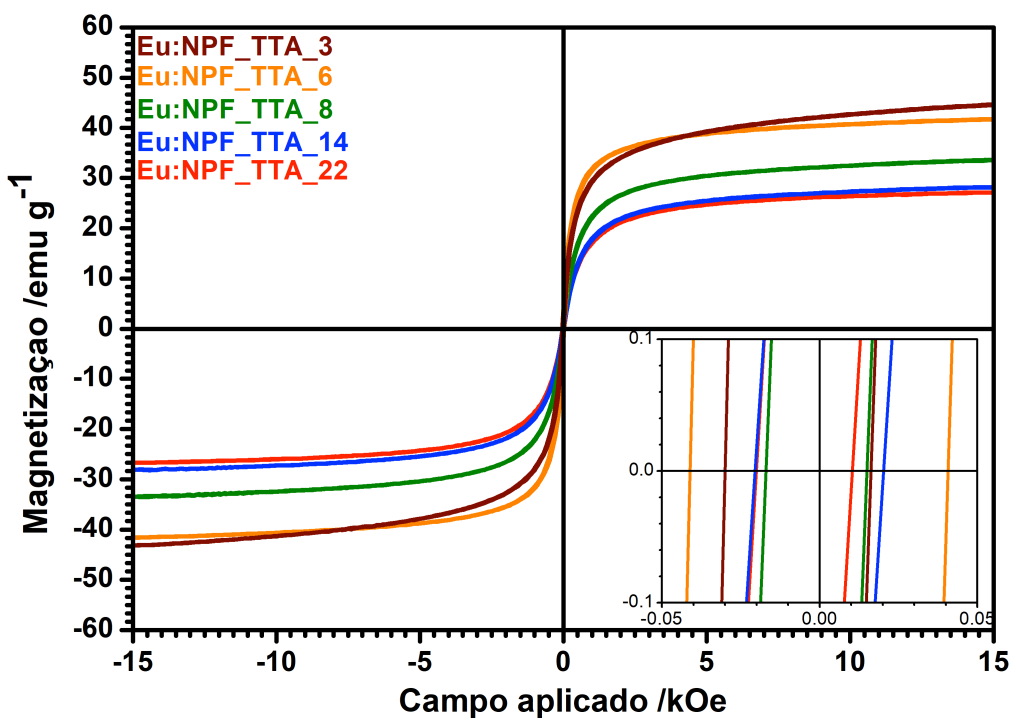

Fonte: Autoria própria.

Tabela 6 - Valores de magnetização de saturação (Ms), coercividade (Hc) e campo de exchange bias (Heb) das amostras de magnetita dopadas com európio (Eu:NPF) em atmosfera de $\mathrm{N}_{2}$.

\begin{tabular}{lcc|c|c|c}
\hline \multicolumn{1}{c}{ Amostra } & Ms (kOe) & Hc1 (Oe) & Hc2 (Oe) & Heb (Oe) \\
\hline Eu:NPF_TTA_22 & 27,2 & $-20,7$ & 10,5 & $-5,1$ \\
\hline Eu:NPF_TTA_14 & 28,2 & $-20,5$ & 20,4 & $-0,05$ \\
\hline Eu:NPF_TTA_8 & 33,5 & $-17,2$ & 15,2 & -1 \\
\hline Eu:NPF_TTA_6 & 41,7 & $-36,9$ & 36,5 & $-0,2$ \\
\hline Eu:NPF_TTA_3 & 41,6 & -30 & 15,4 & $-7,3$ \\
\hline
\end{tabular}

Fonte: Autoria própria.

A magnetita com estrutura do tipo espinélio invertido possui 8 íons $\mathrm{Fe}^{3+}$ ocupando o sítio tetraédrico $(A)$, enquanto 8 íons $\mathrm{Fe}^{3+}$ e 8 íons $\mathrm{Fe}^{2+}$ ocupam o sítio octaédrico (B). Devido à oposição dos spins, os momentos magnéticos dos íons $\mathrm{Fe}^{3+}$ são cancelados. Dessa forma, o momento magnético da magnetita é determinado pelos íons $\mathrm{Fe}^{2+} .(29,93)$ No processo de dopagem da magnetita, é esperado que os íons $\mathrm{Eu}^{3+}$ sejam incorporados no sítio octaédrico, substituindo os íons $\mathrm{Fe}^{3+}$. Como o raio iônico do $\mathrm{Eu}^{3+}(1,1066 \AA ̊)(95)$ é maior do que o do $\mathrm{Fe}^{3+}(0,785 \AA ̊)(96)$, a dopagem leva à redução da simetria cristalina geral, aumentando a anisotropia magnética.(93) Com a dopagem, as interações de supertroca (interações de longo alcance, ex.: entre os sítios $A$ e B) são enfraquecidas, devido ao acoplamento 4f-3d, resultando em uma diminuição na magnetização total da amostra. $(97,73)$ 
Além das fracas interações de troca magnética entre os íons $\mathrm{Eu}^{3+} \mathrm{e} \mathrm{Fe}^{3+}$, a diminuição da Ms também pode ser explicada por meio do momento magnético do dopante. Embora o íon $\mathrm{Eu}^{3+}$ apresente momento magnético superior ao $\mathrm{Fe}^{3+}\left(\mathrm{Eu}^{3+}: 7 \mu \mathrm{B}\right.$, $\left.\mathrm{Fe}^{3+}: 5 \mu \mathrm{B}\right)(98)$, o ordenamento magnético dos íons terras raras se dá em temperaturas inferiores a $40 \mathrm{~K}$. Portanto, em temperatura ambiente, os momentos magnéticos permanecem desordenados e os TR se comportam como átomos paramagnéticos.(94, 98, 99) Dessa forma, os íons $\mathrm{Eu}^{3+}$, paramagnéticos por natureza, contribuem para a diminuição da magnetização de saturação da ferrita quando inseridos na rede cristalina.

É possível observar que a curva de magnetização da amostra Eu:NPF_TTA_3 não está saturada. Em nanopartículas, a magnetização de saturação pode ser difícil de ser obtida devido ao inclinamento dos spins de superfície, fenômeno conhecido como spin canting, no qual os spins são inclinados ligeiramente em relação ao plano magnético, permanecendo em posições que não são paralelas nem antiparalelas uns aos outros.(98, 99, 100) Este fenômeno leva a uma forte anisotropia magnética e se deve à presença de defeitos na rede cristalina, ocorrendo em ferritas do tipo espinélio quando a interação de troca magnética entre os íons no sítio octaédrico é forte o suficiente para competir com a interação de supertroca entre os sítios A e B.(101)

A diminuição na Ms das amostras conforme o aumento no tempo de refluxo mostra que ocorre uma desestruturação no sistema em sínteses prolongadas. Pressupõese que o aumento do tempo de síntese leve a um aumento na substituição dos íons $\mathrm{Fe}^{3+}$ por íons $\mathrm{Eu}^{3+}$ até que o sistema atinja a concentração crítica de dopagem. Como descrito anteriormente, o processo de dopagem leva a um aumento na anisotropia do sistema, portanto, em maiores quantidades de dopante, espera-se uma menor magnetização de saturação. Com o aumento no tempo de refluxo também ocorre uma maior formação da fase secundária, que supõe-se possuir comportamento antiferromagnético, fazendo com que ela contribua apenas para a massa, mas não para a magnetização da amostra.

Na região em destaque na Figura 29 é possível observar que a amostra Eu:NPF_TTA_6 possui maior coercividade magnética em relação às demais. De acordo com o relatado na literatura, espera-se que o aumento na concentração do dopante ocasione um aumento na coercividade magnética até que se atinja a concentração crítica de dopagem. $(93,99)$ A abertura da curva de histerese para a amostra Eu:NPF_TTA_6 indica a ocorrência de uma melhor estruturação na rede cristalina em comparação às demais amostras e que tempos de refluxo superiores a $6 \mathrm{~h}$ não contribuem para a dopagem da ferrita.

Como é possível observar pelos valores apresentados na Tabela 6, as curvas de magnetização se encontram levemente deslocadas para valores de campo magné- 
tico negativos, indicando a ocorrência de exchange bias. A presença de EB pode estar relacionada à existência de defeitos de superfície causados pelo método de síntese, mudança de coordenação dos átomos de superfície e interações magnéticas entre as fases de magnetita dopada e a fase secundária de $\mathrm{TRFeO}_{3}$, que podem apresentar comportamentos magnéticos distintos. Análises acerca da composição da fase secundária e da interação entre as fases não foram realizadas em decorrência da pandemia de Covid-19.

\subsubsection{Síntese de magnetita dopada com neodímio (Nd:NPF)}

Em decorrência dos resultados obtidos para as amostras de magnetita dopadas com európio, as sínteses de NP de magnetita dopadas com neodímio foram realizadas apenas com tempos de refluxo iguais a 6 e 3 horas. A Figura 30 apresenta $o$ difratograma de raios $X$ das amostras de Nd:NPF_TTA_6 e Nd:NPF_TTA_3 em comparação ao padrão cristalográfico da magnetita (JCPDF 19-629). As amostras apresentam os principais picos de difração característicos da magnetita em $2 \theta$ igual a $30,1^{\circ}, 35,3^{\circ}$, $42,9^{\circ}, 56,8^{\circ} \mathrm{e} 62,4^{\circ}$, correspondentes aos planos de difração (220), (311), (400), (511) e (440), respectivamente.(81) Assim como no caso da dopagem com európio relatado anteriormente, a dopagem com neodímio levou à formação de uma fase secundária, com picos correspondentes em $2 \theta$ igual a $27,8^{\circ}, 29,4^{\circ} \mathrm{e} 46,2^{\circ}$. Análises acerca da estrutura da fase secundária não foram realizadas, não sendo possível afirmar a qual composto os picos apresentados correspondem. 
Figura 30 - Difratograma de raios $\mathrm{X}$ obtido para as amostras de magnetita dopadas com neodímio sintetizadas com tempos de refluxo iguais a $3 \mathrm{~h}$ (Nd:NPF_TTA_3) e 6h (Nd:NPF_TTA_6), em comparação ao padrão JCPDF 19-629 da fase espinélio invertida de magnetita. As linhas tracejadas indicam a presença de picos referentes a uma fase secundária.

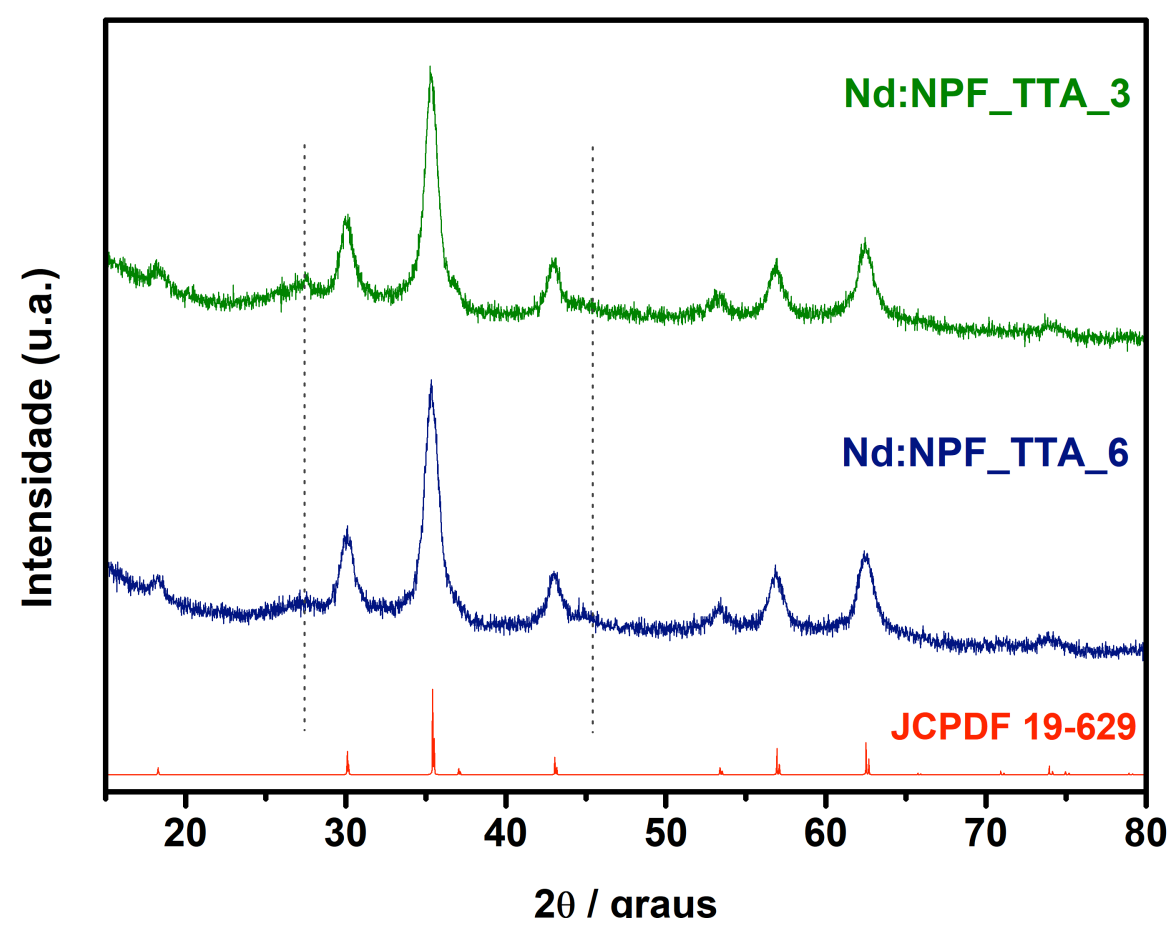

Fonte: Autoria própria.

A Figura 31 apresenta micrografias obtidas por análise de microscopia eletrônica de transmissão em conjunto com os histogramas de distribuição do tamanho das NP. O diâmetro médio de cristalito $\left(D_{h k l}\right)$ calculado por meio da equação de Scherrer, utilizando a reflexão do plano (311) nos difratogramas, foi de 9,53 nm para a amostra Nd:NPF_TTA_6 e 10,63 nm para a amostra Nd:NPF_TTA_3. A pequena divergência entre os valores se deve ao baixo contraste das nanopartículas nas micrografias, gerado pela queima de compostos orgânicos presentes na amostra durante a análise de microscopia, o que dificulta a delimitação da superfície, podendo acarretar em erros de medição. A partir destas análises, é possível observar que o tempo de refluxo não tem um impacto expressivo no diâmetro médio e forma das NP. 
Figura 31 - Microscopia eletrônica de transmissão das amostras de magnetita dopadas com neodímio Nd:NPF_TTA_6 (a) e Nd:NPF_TTA_3 (b) e os respectivos histogramas de distribuição de tamanho das NP.
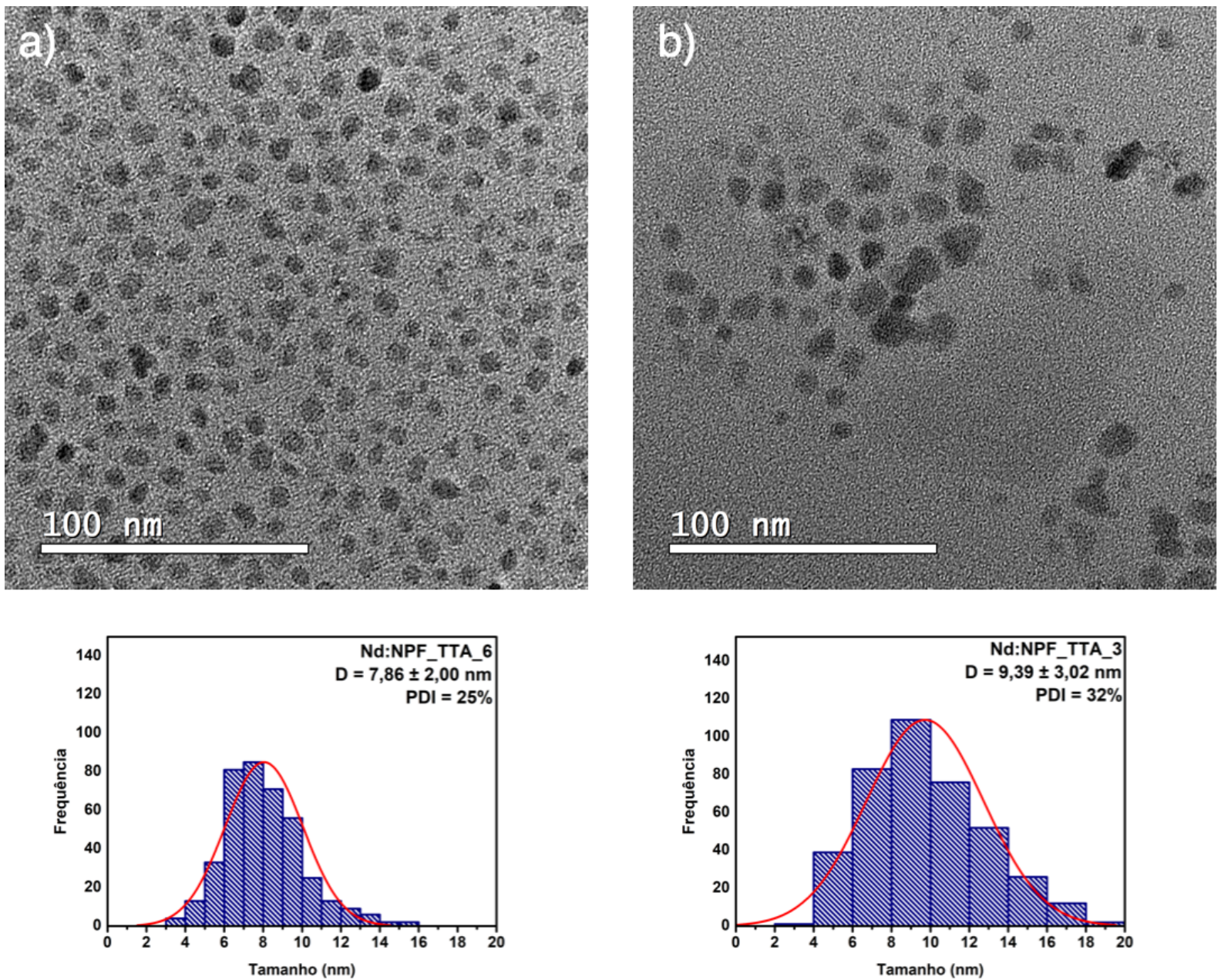

Fonte: Autoria própria.

Análises de energia dispersiva de raios $X$ mostram uma diminuição na concentração de neodímio nas amostras conforme a redução do tempo de refluxo. A porcentagem de Nd calculada para as amostras Nd:NPF_TTA_6 e Nd:NPF_TTA_3, em relação ao $\mathrm{Fe}$, foi de $11,4 \%$ e $7,8 \%$, respectivamente. A análise de EDX indica a presença do TR nas amostras, no entanto não é possível afirmar a quantidade de $\mathrm{Nd}$ de fato incorporada na estrutura da magnetita. A diminuição na quantidade de $\mathrm{Nd}$ indicada pela análise pode estar atrelada não só à diminuição da incorporação do TR na estrutura, mas também à diminuição da fase secundária, como mostram os difratogramas. A Figura 32 apresenta o mapeamento dos elementos Fe e Nd na amostra Nd:NPF_TTA_6. 
Figura 32 - Mapeamento dos elementos Fe e Nd por STEM na amostra Nd:NPF_TTA_6.

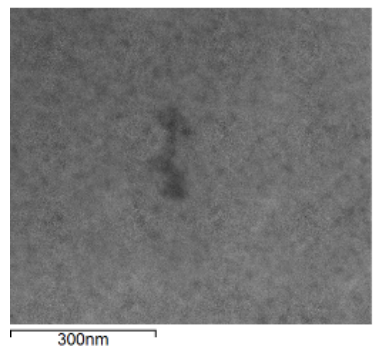

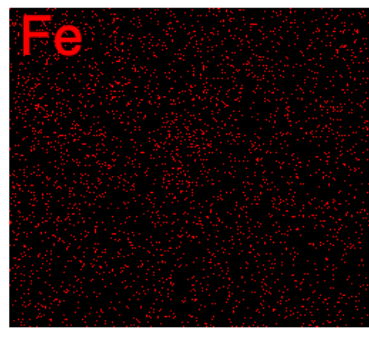

$\longdiv { 3 0 0 \mathrm { nm } }$

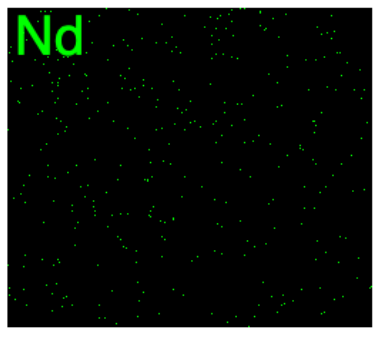

$300 \mathrm{~nm}$

Fonte: Autoria própria.

As curvas de magnetização das amostras dopadas com neodímio são apresentadas pela Figura 33 e os valores de coercividade $(\mathrm{Hc})$ e magnetização de saturação (Ms) são dados pela Tabela 7. As amostras analisadas apresentam comportamento próximo ao superparamagnético e menores valores de Ms em comparação à magnetita não dopada (52,8 emu/g).

Figura 33 - Curva de magnetização das amostras Nd:NPF_TTA_6 e Nd:NPF_TTA_3. Região em destaque na figura mostra o deslocamento das curvas de histerese devido ao efeito de exchange bias negativo.

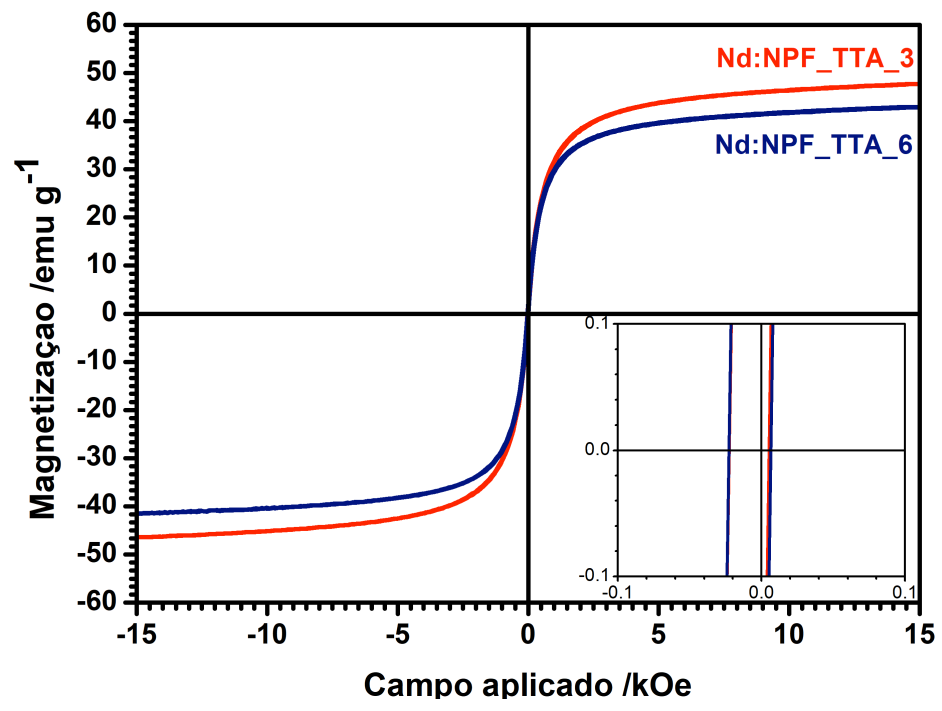

Fonte: Autoria própria. 
Tabela 7 - Valores de magnetização de saturação (Ms), coercividade (Hc) e campo de exchange bias (Heb) das amostras de magnetita dopadas com neodímio (Nd:NPF) em atmosfera de $\mathrm{N}_{2}$.

\begin{tabular}{cccccc}
\hline Amostra & Ms (kOe) & Hc1 (Oe) & Hc2 (Oe) & Heb (Oe) \\
\hline Nd:NPF_TTA_3 & 47,8 & $-22,6$ & 5,6 & $-8,5$ \\
\hline Nd:NPF_TTA_6 & 42,9 & $-23,1$ & 6,4 & $-8,35$ \\
\hline
\end{tabular}

Fonte: Autoria própria.

Conforme descrito anteriormente, a diminuição da Ms com a dopagem é decorrente de uma série de fatores. A substituição de íons $\mathrm{Fe}^{3+}$ por $\mathrm{Nd}^{3+}$ na estrutura cristalina da magnetita, além de diminuir a simetria da estrutura, enfraquece as interações de supertroca magnéticas entre os sítios tetraédricos $(A)$ e octaédricos $(B)$, levando a uma maior anisotropia e consequente diminuição na magnetização.(93, 97, 73) Assim como no $\mathrm{Eu}^{3+}$, o ordenamento magnético do $\mathrm{Nd}^{3+}$ ocorre em temperaturas em torno de $40 \mathrm{~K}$, fazendo com que ele apresente comportamento não magnético em temperatura ambiente e não contribua para a magnetização da amostra quando inserido na estrutura.(94)

É possível observar que a amostra sintetizada com maior tempo de refluxo (Nd:NPF_TTA_6) apresenta menor valor de magnetização de saturação. Isto sugere que em maior tempo de refluxo, maior quantidade de $\mathrm{Nd}^{3+}$ é incorporada à estrutura, levando a um aumento mais expressivo na anisotropia magnética, que acarreta em um menor valor de Ms.(93) A similaridade entre os valores de coercividade apresentados pelas amostras é um indicativo de que a diferença entre os tempos de refluxo não teve um grande impacto na organização da estrutura cristalina.

Como é possível observar pelos valores de coercividade, as curvas de magnetização se encontram deslocadas para valores de campo magnético negativos, indicando a ocorrência de exchange bias. A presença de EB pode estar relacionada à existência de defeitos e mudança de coordenação dos átomos de superfície, que fazem com que a partícula seja formada por camadas com comportamentos magnéticos distintos, que podem acoplar magneticamente. $(11,15)$ Também pode estar relacionada à interações magnéticas entre as fases de magnetita dopada e a fase secundária. No entanto, análises aprofundadas acerca da estrutura cristalina das amostras e da composição da fase secundária não foram realizadas em decorrência da pandemia de Covid-19. Desta forma, não é possível afirmar a origem do efeito de exchange bias nas amostras. 


\subsection{Síntese de magnetita dopada com neodímio utilizando $\mathrm{Nd}(\mathrm{acac})_{3}$ como precursor de TR}

Com o intuito de evitar a formação de fases secundárias, a substituição do complexo precursor $\mathrm{Nd}(\mathrm{TTA})_{3}$ pelo complexo $\mathrm{Nd}(\mathrm{acac})_{3}$ foi analisada. A Figura 34 apresenta as curvas de decomposição térmica dos compostos $\mathrm{Nd}(\mathrm{TTA})_{3}$ e $\mathrm{Nd}(\mathrm{acac})_{3}$ e as respectivas curvas de primeira derivada (DTG).

Figura 34 - Curvas termogravimétricas (TG) e curvas de primeira derivada (DTG) dos complexos $\mathrm{Nd}(\mathrm{acac})_{3}$ e $\mathrm{Nd}(\mathrm{TTA})_{3}$ obtidas em atmosfera de ar sintético.

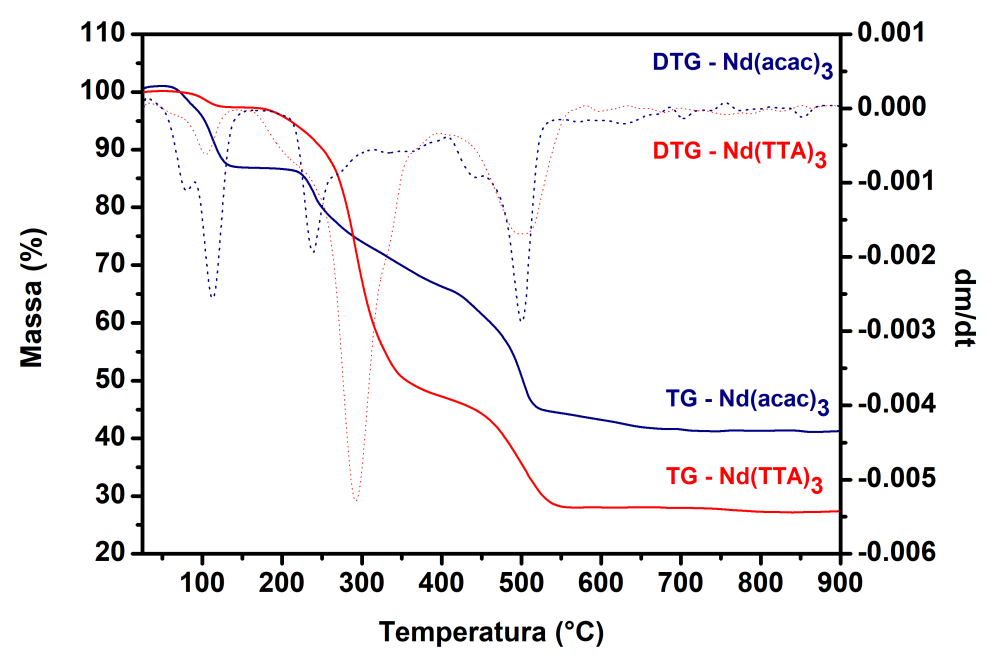

Fonte: Autoria própria.

É possível observar que o $\mathrm{Nd}(\mathrm{acac})_{3}$ possui uma decomposição mais lenta que o $\mathrm{Nd}(\mathrm{TTA})_{3}$, composta por várias etapas. Após a pequena perda de massa, referente à perda de água, o complexo $\mathrm{Nd}(\mathrm{TTA})_{3}$ apresenta uma etapa de decomposição expressiva em $290{ }^{\circ} \mathrm{C}$, levando a uma perda de massa de 48,5\%. Essa rápida etapa de decomposição na faixa da temperatura empregada para refluxo na síntese (288 $\left.{ }^{\circ} \mathrm{C}\right)$ leva a uma maior concentração de íons $\mathrm{Nd}^{3+}$ disponíveis no sistema de reação, favorecendo a formação de muitos núcleos, que podem levar à formação de fases secundárias. A lenta decomposição do $\mathrm{Nd}(\mathrm{acac})_{3}$ nesta faixa de temperatura indica que a utilização deste complexo como precursor deve reduzir ou até mesmo extinguir a formação de fases secundárias. A partir destes resultados, a substituição do $\mathrm{Nd}(\mathrm{TTA})_{3}$ foi realizada e os dados referentes às sínteses com $\mathrm{Nd}(\mathrm{acac})_{3}$ são apresentados a seguir. 


\subsubsection{Estudo do impacto do tempo de refluxo na síntese de magnetita dopada com neodímio}

Com o objetivo de analisar a influência do tempo de refluxo na formação das nanopartículas ao utilizar $\mathrm{Nd}(\mathrm{acac})_{3}$ como precursor de íons $\mathrm{Nd}^{3+}$, foram realizadas diversas sínteses com tempos de refluxo distintos, fixando os demais parâmetros de síntese como mostra a Tabela 8.

Tabela 8 - Variações no tempo de refluxo empregado durante a síntese de NPF dopadas com neodímio (Nd:NPF).

\begin{tabular}{l|cc|c}
\hline \multicolumn{1}{c|}{ Amostra } & \multicolumn{2}{|c|}{ Precursor de TR } & \multirow{2}{*}{ Tempo de refluxo (h) } \\
& Tipo & Qtde (mmol) & \\
\hline Nd:NPF_0,5 & $\mathrm{Nd}(\text { acac })_{3}$ & 0,01 & $\mathbf{0 , 5}$ \\
\hline Nd:NPF_1 & $\mathrm{Nd}(\text { acac })_{3}$ & 0,01 & $\mathbf{1}$ \\
\hline Nd:NPF_1,5 & $\mathrm{Nd}(\text { acac })_{3}$ & 0,01 & $\mathbf{1 , 5}$ \\
\hline Nd:NPF_2 & $\mathrm{Nd}(\text { acac })_{3}$ & 0,01 & $\mathbf{2}$ \\
\hline Nd:NPF_2,5 & $\mathrm{Nd}(\text { acac })_{3}$ & 0,01 & $\mathbf{2 , 5}$ \\
\hline Nd:NPF_3 & $\mathrm{Nd}(\text { acac })_{3}$ & 0,01 & $\mathbf{3}$ \\
\hline Nd:NPF_3,5 & $\mathrm{Nd}(\text { acac })_{3}$ & 0,01 & $\mathbf{3 , 5}$ \\
\hline Nd:NPF_4 & $\mathrm{Nd}(\text { acac })_{3}$ & 0,01 & $\mathbf{4}$ \\
\hline
\end{tabular}

Fonte: Autoria própria.

A Figura 35 apresenta os difratogramas obtidos para as amostras com tempo de refluxo de 0,5 a 4h, o difratograma da magnetita não dopada (NPF) e o padrão de difração JCPDF 19-629. Para sínteses com tempo de refluxo inferior a 1,5h é possível observar a formação de um material não cristalino. Sínteses com tempo de reação a partir de 1,5h apresentam difratogramas compatíveis com a fase espinélio invertida da magnetita. Como observado, as nanopartículas sintetizadas apresentam os principais picos de difração característicos da magnetita em $2 \theta$ igual a $30,1^{\circ}, 35,3^{\circ}, 43,0^{\circ}$, $56,8^{\circ} \mathrm{e} 62,5^{\circ}$, correspondentes aos planos de difração (220), (311), (400), (511) e (440), respectivamente.(81) 
Figura 35 - Difratograma de raios $\mathrm{X}$ obtido para as amostras de magnetita dopadas com $\mathrm{Nd}$ sintetizadas com tempos de refluxo iguais a 0,5h (Nd:NPF_0,5), 1,0h (Nd:NPF_1), 1,5h (Nd:NPF_1,5), 2,0h (Nd:NPF_2), 2,5h (Nd:NPF_2,5), 3,0h (Nd:NPF_3), 3,5h (Nd:NPF_3,5) e 3,5 (Nd:NPF_4) em comparação à ferrita não dopada (NPF) e ao padrão JCPDF 19-629 da fase espinélio invertida de magnetita.

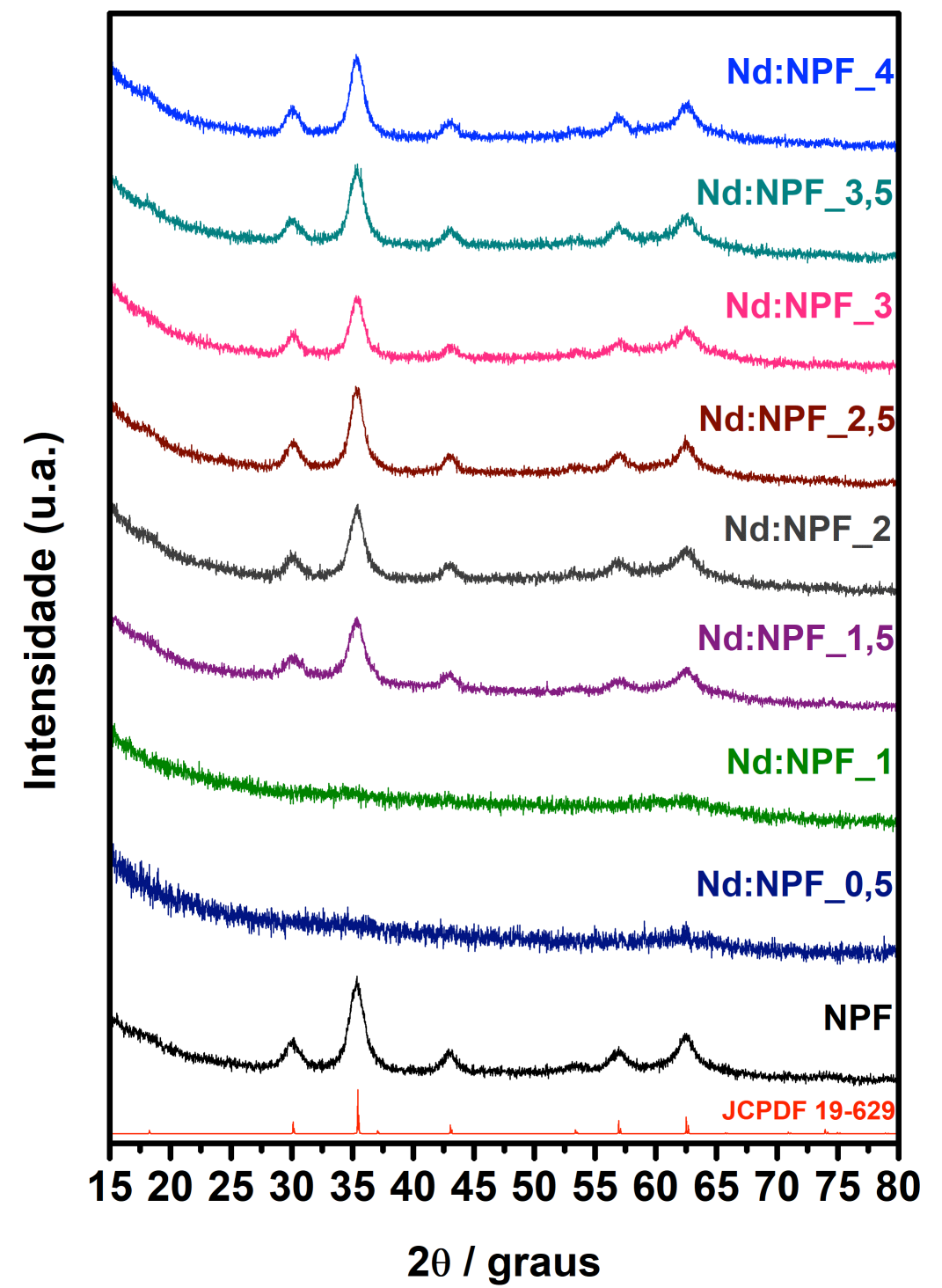

Fonte: Autoria própria.

Análises de espectroscopia de energia dispersiva de raios $X(E D X)$ realizadas mostram a presença do neodímio apenas nas amostras Nd:NPF_3, Nd:NPF_3,5 e Nd:NPF_4, ou seja, apenas nas amostras com tempo de síntese igual ou superior a 3,0h. As microscopias eletrônicas de transmissão apresentadas na Figura 36 corroboram o resultado dos difratogramas, mostrando que os materiais produzidos em sínteses com tempo de refluxo iguais a 0,5 e 1,0h não são cristalinos e mostram que as partículas sintetizadas obtidas nas demais sínteses possuem controle morfológico. Devido à ausência do elemento terra rara nas demais amostras, as distribuições de 
tamanho foram realizadas apenas para as amostras com tempo de reação de 3,0h, 3,5h e 4,0h, que apresentaram diâmetro médio de 6,76 nm, 6,32 nm e 6,75 nm, respectivamente, conforme mostra a Figura 37. Os diâmetros médios de cristalito $\left(D_{h k l}\right)$, calculados por meio da equação de Scherrer, foram de 7,03 nm, 6,46 nm e 7,56 nm.

Figura 36 - Microscopias eletrônicas de transmissão das amostras sintetizadas com tempos de refluxo iguais a a) 0,5h (Nd:NPF_0,5), b) 1,0h (Nd:NPF_1), c) 1,5h (Nd:NPF_1,5), d) 2,0h (Nd:NPF_2), e) 2,5h (Nd:NPF_2,5), f) 3,0h (Nd:NPF_3), g) 3,5h (Nd:NPF_3,5) e h) 3,5 (Nd:NPF_4).
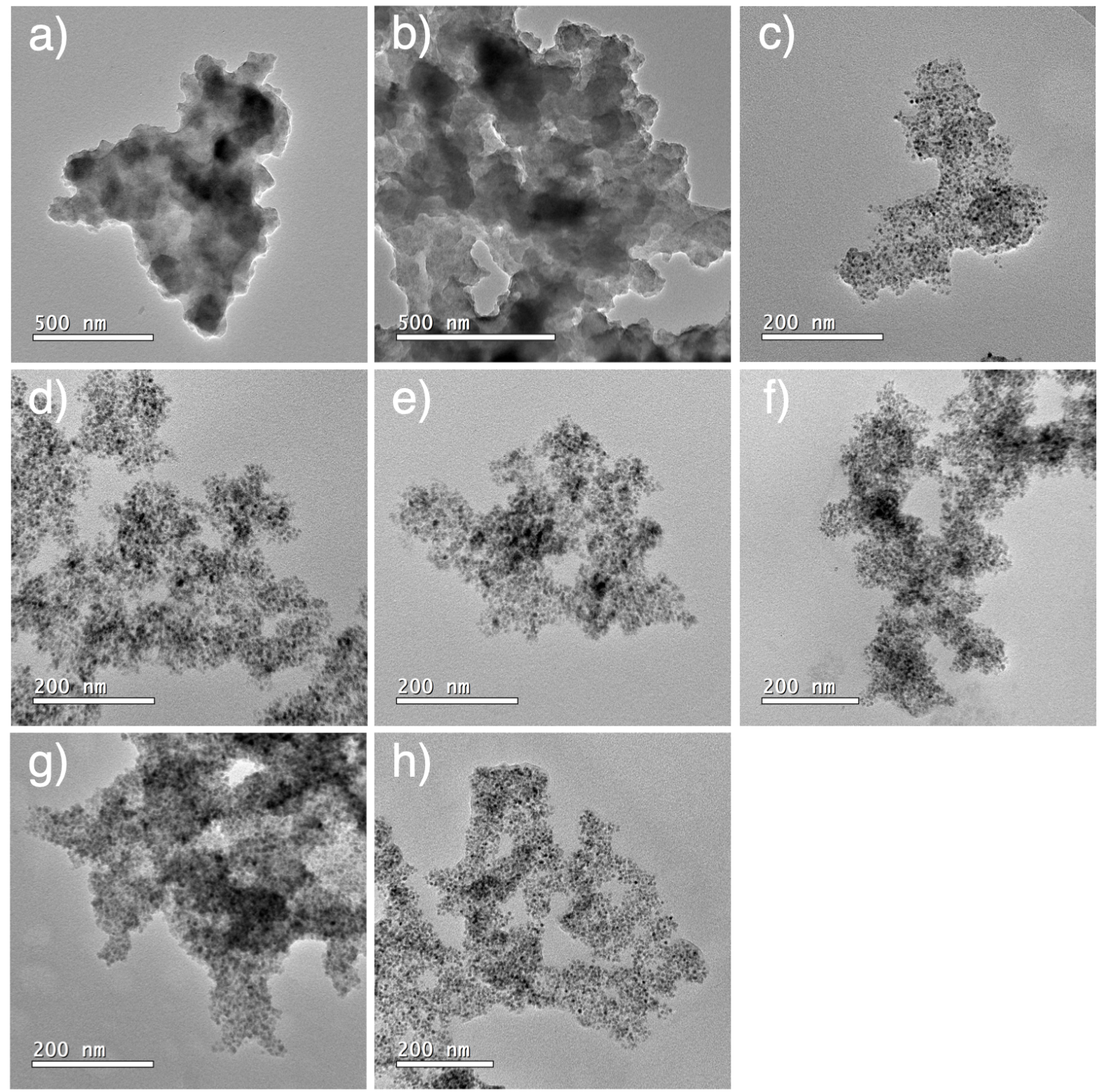

Fonte: Autoria própria. 
Figura 37 - Histogramas de distribuição dos tamanhos das nanopartículas medidas para as amostras (Nd:NPF_3), (Nd:NPF_3,5) e (Nd:NPF_4).
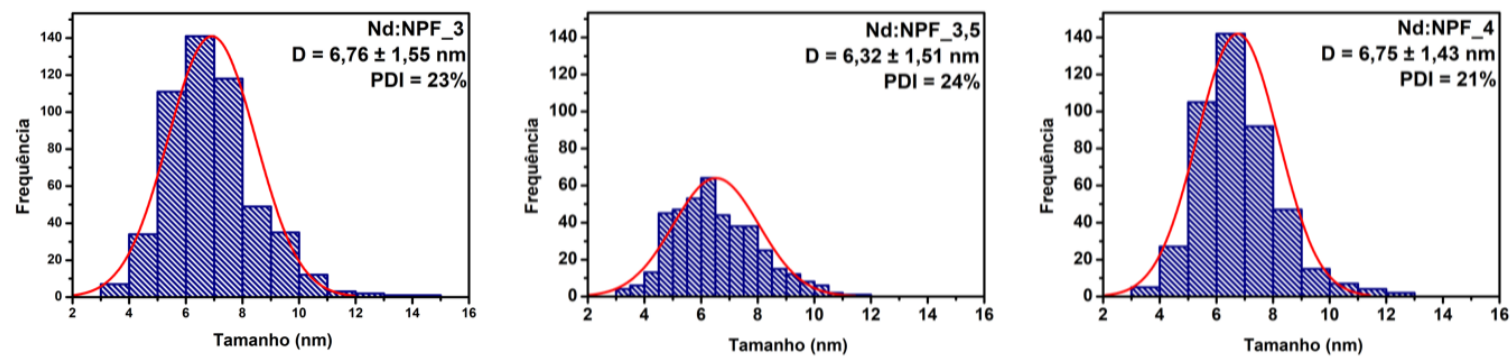

Fonte: Autoria própria.

Tendo em vista que as amostras Nd:NPF_3, Nd:NPF_3,5 e Nd:NPF_4 não apresentaram grandes diferenças em relação ao diâmetro médio, desvio padrão e cristalinidade, optou-se por conduzir os demais experimentos fixando o tempo de refluxo em 3,0h e variando a concentração do dopante.

\subsubsection{Síntese de magnetita dopada com neodímio em dife- rentes proporções}

Com o intuito de analisar o efeito da concentração do íon terra rara na dopagem das NPF, sínteses foram realizadas mantendo fixos o tempo de refluxo em 3 horas e a concentração do acetilacetonato de ferro(III) $(0,1 \mathrm{mmol})$, conforme mostra a Tabela 9.

Tabela 9 - Variações na proporção dos precursores utilizados na síntese de NPF dopadas com neodímio (Nd:NPF).

\begin{tabular}{c|cc|ccc}
\hline \multirow{2}{*}{ Amostra } & \multicolumn{2}{|c|}{ Precursor de TR } & \multicolumn{2}{c}{ Precursor de Fe } \\
& Tipo & Qtde (mmol) & Tipo & Qtde (mmol) \\
\hline Nd:NPF_10 & $\mathrm{Nd}(\mathrm{acac})_{3}$ & $\mathbf{0 , 0 1}$ & $\mathrm{Fe}(\mathrm{acac})_{3}$ & 0,1 \\
\hline $\mathrm{Nd}: N P F \_20$ & $\mathrm{Nd}(\mathrm{acac})_{3}$ & $\mathbf{0 , 0 2}$ & $\mathrm{Fe}(\mathrm{acac})_{3}$ & 0,1 \\
\hline Nd:NPF_30 & $\mathrm{Nd}(\mathrm{acac})_{3}$ & $\mathbf{0 , 0 3}$ & $\mathrm{Fe}(\mathrm{acac})_{3}$ & 0,1 \\
\hline
\end{tabular}

Fonte: Autoria própria.

Assim como nas etapas anteriores, análises de difratometria de raios $\mathrm{X}$ foram realizadas para as amostras e os resultados para as NPF dopadas com neodímio são mostrados na Figura 38. Os difratogramas foram comparados com o padrão da magnetita (JCPDF 19-629) e com a ferrita não dopada (NPF) a fim de verificar as fases cristalinas e analisar se o aumento na concentração do dopante causa distorções nos parâmetros da cela unitária, levando à um ligeiro deslocamento dos picos. $(83,102,103)$ Os resultados obtidos foram indexados de acordo com a fase espinélio da magnetita, 
sendo eles em $30,1^{\circ}, 35,3^{\circ}, 42,9^{\circ}, 56,8^{\circ}$ e $62,4^{\circ} \mathrm{em} 2 \theta$, correspondentes aos planos (220), (311), (400), (511) e (440), respectivamente.(81)

Figura 38 - Difratograma de raios $\mathrm{X}$ obtido para as amostras sintetizadas utilizando proporções de Nd/Fe iguais a 1/10 (Nd:NPF_10), 2/10 (Nd:NPF_20) e 3/10 (Nd:NPF_30) em comparação à ferrita não dopada (NPF) e ao padrão JCPDF 19-629 da fase espinélio invertida de magnetita.
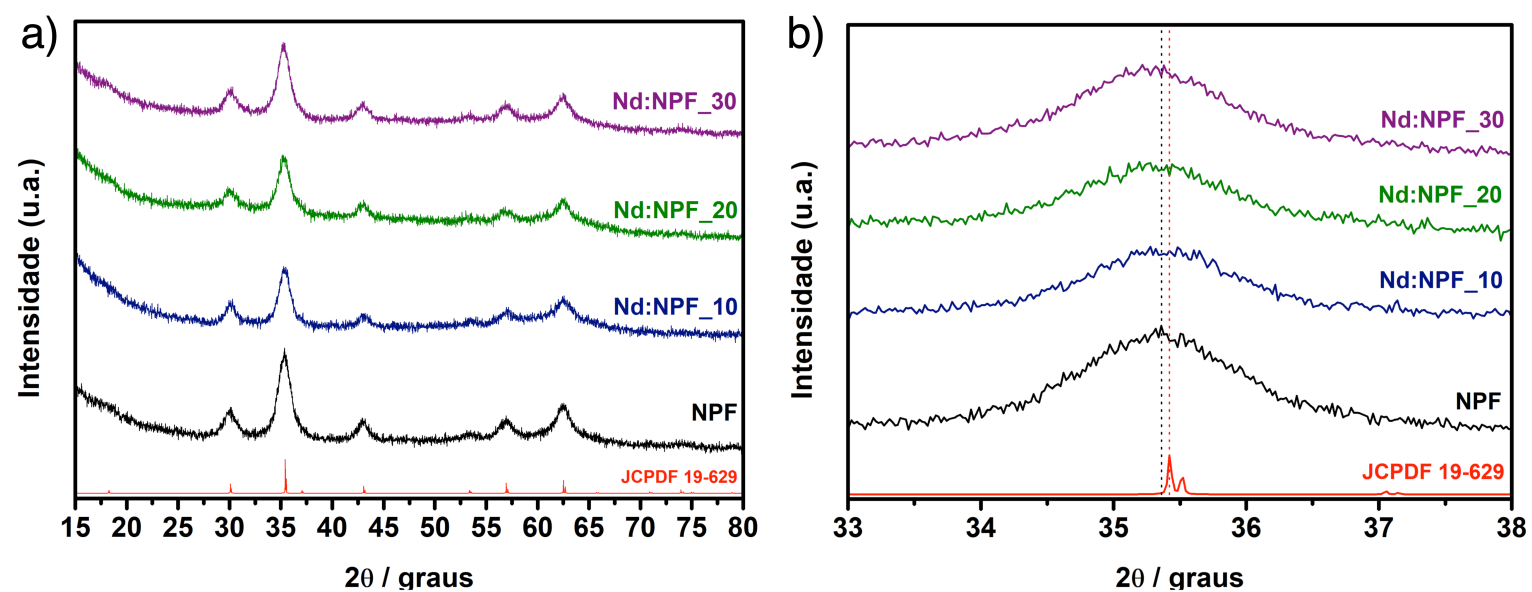

Fonte: Autoria própria.

Como descrito anteriormente, no processo de dopagem a substituição dos íons $\mathrm{Fe}^{3+}$ pelos íons $\mathrm{Nd}^{3+}$ acarreta em uma distorção na estrutura cristalina devido à diferença de tamanho entre os íons $\left(\mathrm{Fe}^{3+}: 0,785 \AA\right.$ e $\left.\mathrm{Nd}^{3+}: 1,109 \AA\right)(95,96)$ e essa distorção pode refletir em um deslocamento nos picos de difração das amostras para menores valores de $2 \theta$ no difratograma em relação ao padrão e à ferrita não dopada. $(83,102) 0$ pequeno deslocamento observado com o aumento na proporção de TR pode ser um indicativo de que houve a incorporação de íons $\mathrm{Nd}^{3+}$ na estrutura. No entanto, apenas com base nos difratogramas, não é possível afirmar se houve a dopagem ou se os deslocamentos se devem a defeitos estruturais.

O diâmetro médio de cristalito calculado a partir da reflexão do plano (311) nos difratogramas, foi de $7,03 \mathrm{~nm}$ para a amostra Nd:NPF_10, 6,6 nm para a amostra Nd:NPF_20 e 6,34 nm para a amostra Nd:NPF_30. A análise de microscopia de transmissão apresentada pela Figura 4.4.2 em conjunto com o histograma de distribuição de tamanho das NP, mostra que foram obtidas nanopartículas com diâmetro médio de 6,76 nm para a amostra Nd:NPF_10, 6,18 nm para a amostra Nd:NPF_20 e 6,67 para a amostra Nd:NPF_30. Embora o diâmetro médio diminua com o aumento da concentração utilizada de neodímio, o PDI aumenta, sendo 23\% para a amostra Nd:NPF_10 e 30\% para as amostras Nd:NPF_20 e Nd:NPF_30, o que mostra a diminuição da homogeneidade do sistema com o aumento da concentração do dopante. A substituição do íon $\mathrm{Fe}^{3+}$ pelo íon $\mathrm{Nd}^{3+}$ no processo de dopagem requer muita energia do sistema devido à diferença de tamanho entre os íons. Como consequência, a dopagem ocorre 
em detrimento da cristalinidade do sistema e do crescimento das partículas.(24) Dessa forma, a diminuição no diâmetro médio das NP sintetizadas indica um aumento na incorporação de íons $\mathrm{Nd}^{3+}$ na estrutura cristalina da magnetita.

Figura 39 - Imagens de MET obtidas para as amostras sintetizadas utilizando proporções de Nd/Fe iguais a 1/10 (Nd:NPF_10) (a), 2/10 (Nd:NPF_20) (b), 3/10 (Nd:NPF_30) (c) e histogramas de distribuição dos tamanhos das nanopartículas medidas (d).
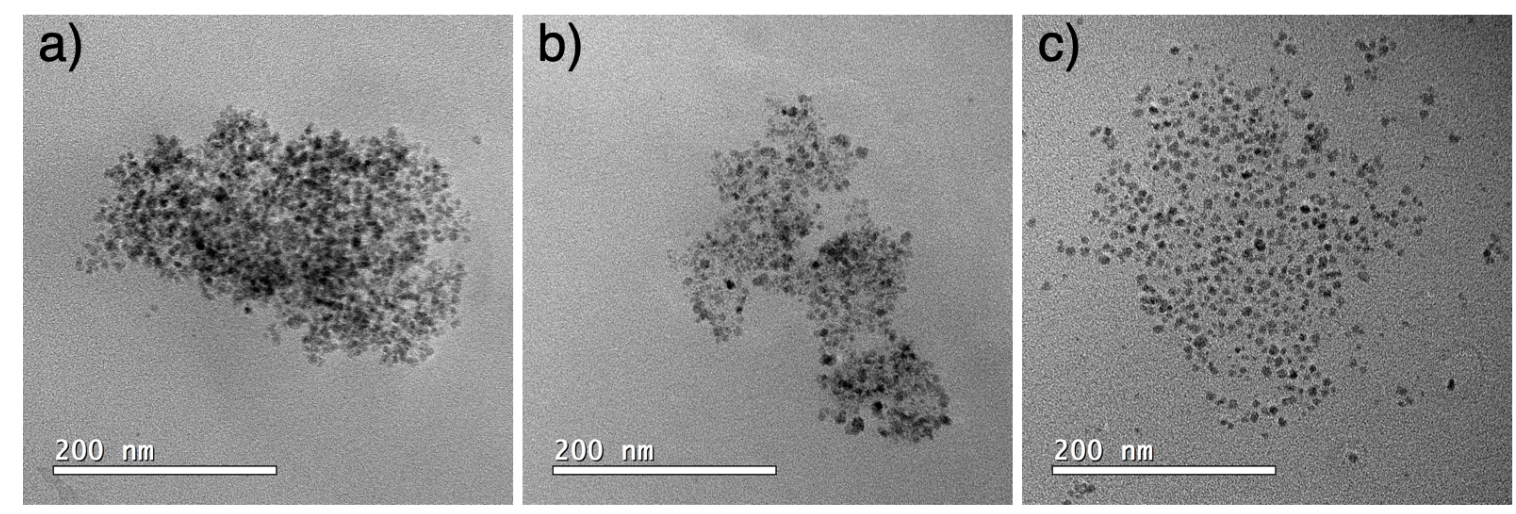

d)
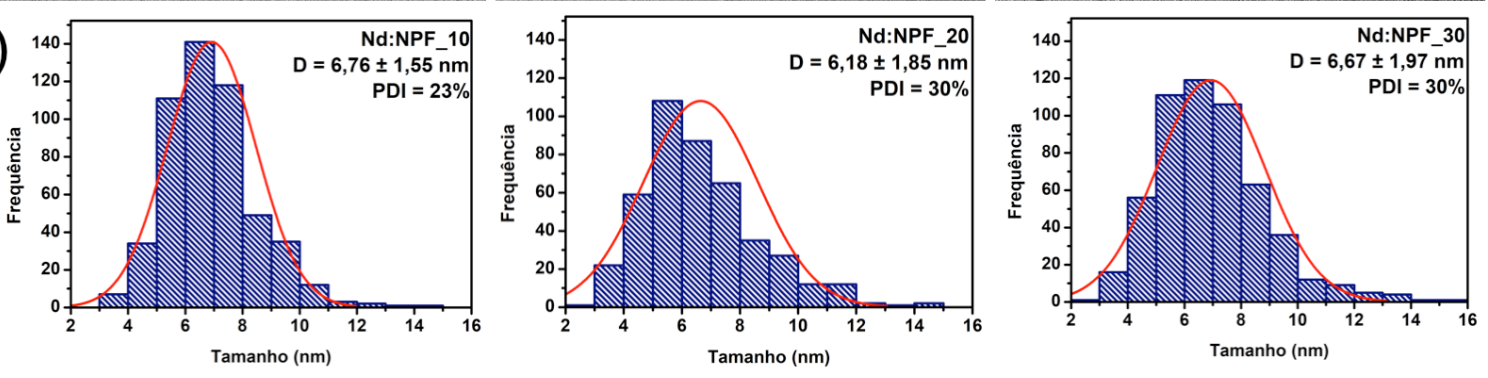

Fonte: Autoria própria.

As análises de energia dispersiva de raios $X$ apresentadas pela Figura 40a mostram um aumento na concentração de neodímio nas amostras conforme o aumento na proporção de $\mathrm{Nd}(\mathrm{acac})_{3}$ utilizada nas sínteses. A porcentagem de $\mathrm{Nd}$ calculada para as amostras Nd:NPF_20 e Nd:NPF_30, em relação ao Fe, foi de 10,8\% e 24,1\%, respectivamente. A análise de EDX indica a presença do TR nas amostras, no entanto, não é possível afirmar a quantidade incorporada na estrutura da magnetita. A Figura 40b apresenta o mapeamento dos elementos Fe e Nd na amostra Nd:NPF_10. 
Figura 40 - Espectros EDX das amostras Nd:NPF_20 e Nd:NPF_30 (a) e mapeamento por STEM dos elementos Fe e Nd na amostra Nd:NPF_10 (b).

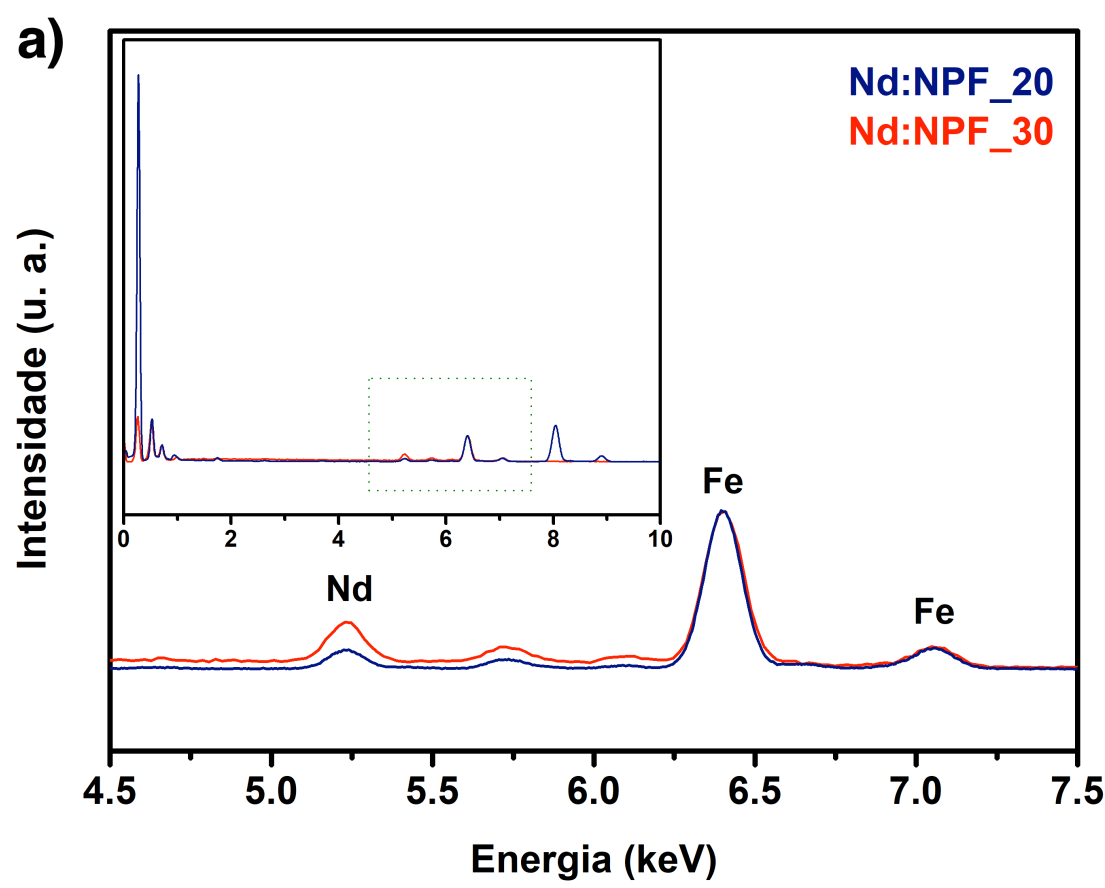

b)
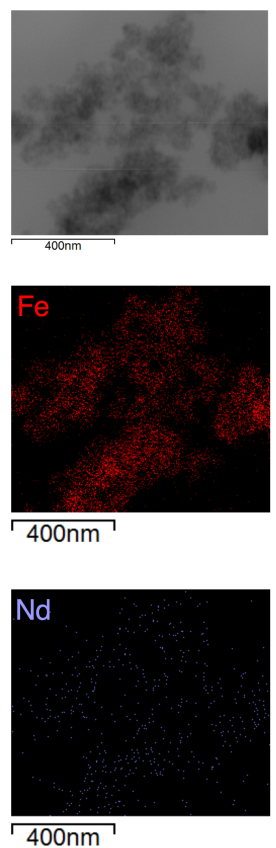

Fonte: Autoria própria.

As curvas de magnetização das amostras Nd:NPF_10, Nd:NPF_20 e Nd:NPF_30 são apresentadas pela Figura 41 e os valores de coercividade $(\mathrm{Hc})$ e magnetização de saturação (Ms) são dados pela Tabela 10. As amostras apresentam comportamento próximo ao superparamagnético e valores de Ms inferiores ao da magnetita não dopada $(52,8 \mathrm{emu} / \mathrm{g})$. 
Figura 41 - Curva de magnetização das amostras de magnetita dopadas com neodímio (Nd:NPF) em diferentes proporções. Região em destaque na figura mostra o deslocamento das curvas de histerese devido ao efeito de exchange bias negativo.

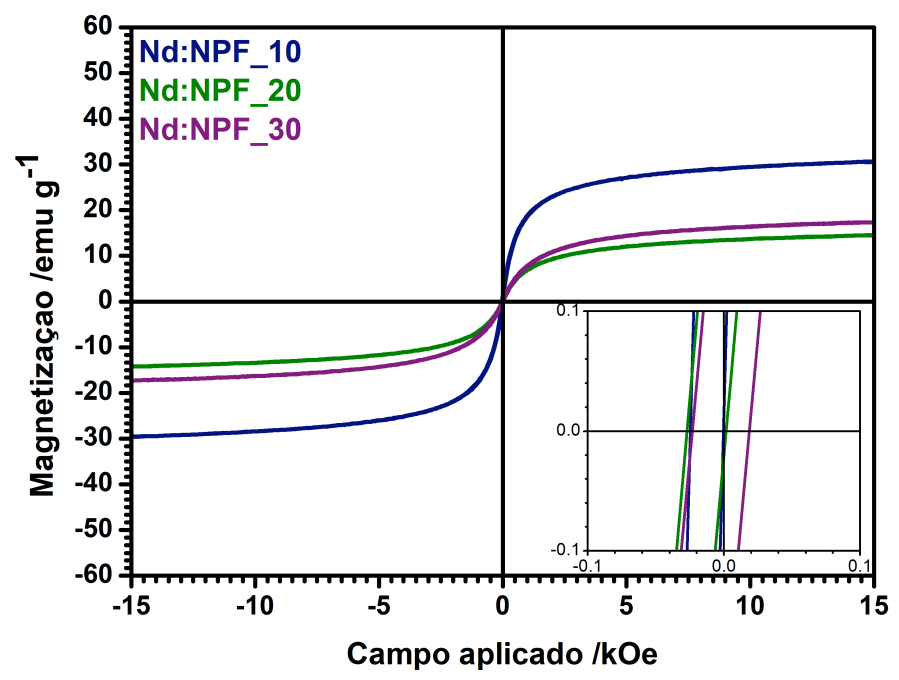

Fonte: Autoria própria.

Tabela 10 - Valores de magnetização de saturação (Ms), coercividade (Hc) e campo de exchange bias (Heb) das amostras de magnetita dopadas com neodímio (Nd:NPF).

\begin{tabular}{cccccc}
\hline Amostra & Ms (kOe) & Hc1 (Oe) & Hc2 (Oe) & Heb (Oe) \\
\hline Nd:NPF_10 & 30,7 & $-24,8$ & $-0,25$ & $-12,5$ \\
\hline Nd:NPF_20 & 14,5 & $-27,4$ & 1,4 & -13 \\
\hline Nd:NPF_30 & 17,3 & $-27,5$ & 18,3 & $-4,6$ \\
\hline
\end{tabular}

Fonte: Autoria própria.

A diminuição da Ms das amostras é um indicativo da substituição dos íons Fe3+ por $\mathrm{Nd}^{3+}$ na estrutura da magnetita. Em decorrência da diferença de tamanho entre os íons, a substituição acarreta em distorções na rede cristalina e no enfraquecimento de interações magnéticas entre os sítios que, por sua vez, levam a um aumento na anisotropia magnética e consequente diminuição na Ms. $(93,97,73)$

A diminuição na Ms das amostras com o aumento na proporção de TR indica um aumento na dopagem, causando uma maior desestruturação no sistema e consequente aumento na anisotropia magnética. A pequena diferença observada entre as amostras Nd:NPF_20 e Nd:NPF_30 é um indicativo de que a concentração crítica de dopagem foi atingida com as proporções utilizadas de TR. Na região em destaque na Figura 41 é possível observar que a amostra Nd:NPF_30 possui maior coercividade magnética em relação às demais. A abertura da curva de histerese para a amostra Nd:NPF_30 indica a ocorrência de uma melhor estruturação na rede cristalina em com- 
paração às demais amostras. $(93,99)$ Também é importante ressaltar que a redução de tamanho observada com o aumento da concentração de $\mathrm{Nd}^{3+}$ favorece a diminuição da Ms, uma vez que o efeito de superfície spin canting se torna mais expressivo, aumentando a anisotropia magnética. $(98,101,104)$

Como é possível observar pelos valores de coercividade, as curvas de magnetização se encontram deslocadas para valores de campo magnético negativos, indicando a ocorrência de exchange bias. A presença de EB pode estar relacionada à existência de defeitos e mudança de coordenação dos átomos de superfície, assim como ao efeito de spin canting, que fazem com que a partícula seja formada por camadas com comportamentos magnéticos distintos, que podem acoplar magneticamente.(11, 15) No entanto, análises aprofundadas acerca da estrutura cristalina das amostras não foram realizadas em decorrência da pandemia de Covid-19. Desta forma, não é possível afirmar a origem do efeito de exchange bias nas amostras.

De modo geral, a troca do precursor $\mathrm{Nd}(\mathrm{TTA})_{3}$ pelo $\mathrm{Nd}(\mathrm{acac})_{3}$ levou à mudanças positivas nos resultados, obtendo-se NP mais homogêneas, com fortes indícios de dopagem e extinção da formação de fases secundárias, conforme o esperado.

\subsection{Síntese do complexo $\mathrm{Eu}(\mathrm{acac})_{3}$}

O acetilacetonato de európio(III) (Figura 42b) a ser utilizado nos experimentos que avaliam a concentração do dopante foi sintetizado seguindo procedimento descrito na literatura.(78) $\mathrm{O}$ espectro FTIR referente ao $\mathrm{Eu}(\mathrm{acac})_{3}$ (Figura 42a) apresenta bandas características do composto referentes às ligações Eu-O em $532 \mathrm{~cm}^{-1}, \mathrm{C}-\mathrm{C}$, $\mathrm{C}-\mathrm{H}$ e C- $\mathrm{CH}_{3}$ em $653 \mathrm{~cm}^{-1}, 763 \mathrm{~cm}^{-1}, 920 \mathrm{~cm}^{-1}, 1018 \mathrm{~cm}^{-1}, 1259 \mathrm{~cm}^{-1}$ e $1392 \mathrm{~cm}^{-1}$ e $\mathrm{C}=\mathrm{C}, \mathrm{C}=\mathrm{O}$ e $\mathrm{C}-\mathrm{O}$ em $1519 \mathrm{~cm}^{-1}$ e $1608 \mathrm{~cm}^{-1}$, assim como os "ombros" presentes na banda em $1392 \mathrm{~cm}^{-1}\left(1355 \mathrm{~cm}^{-1}\right.$ e $\left.1454 \mathrm{~cm}^{-1}\right)$ são referentes aos estiramentos C-O e deformações simétricas de $\mathrm{CH}_{3} \cdot(105,106,107)$ De acordo com esse resultado é possível inferir que o produto sintetizado se trata de acetilacetonato de európio(III) e a coloração avermelhada apresentada pelo composto sob irradiação de luz ultravioleta (365 nm) (Figura 42c) corrobora essa afirmação, pois é um indicativo da valência 3+ do európio na amostra.(91) 
Figura 42 - Espectro FTIR do Eu(acac) $)_{3}$ sintetizado (a), estrutura molecular do acetilacetonato de európio (III) hidratado (b) e fotos da amostra sob irradiação de luz ultravioleta (365 nm) (c).

a)

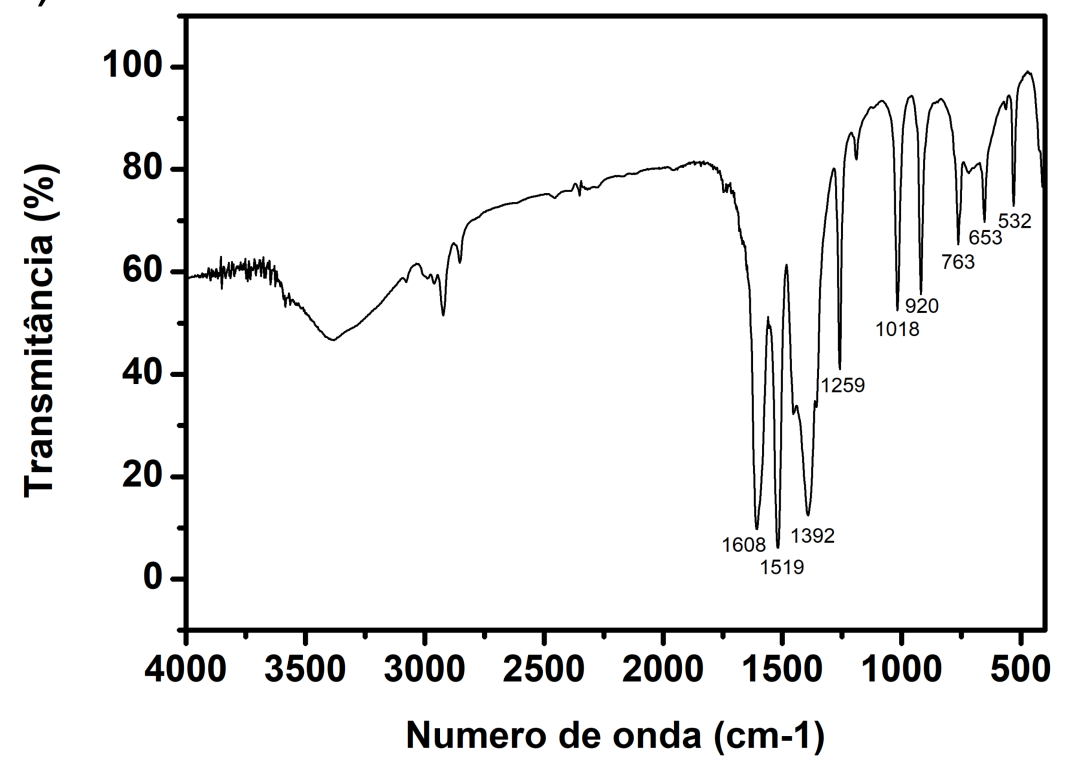

b)

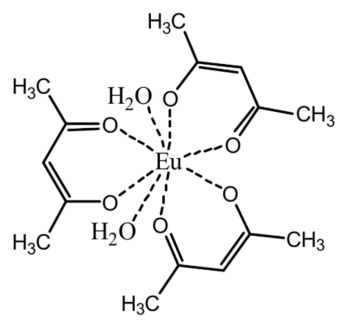

c)

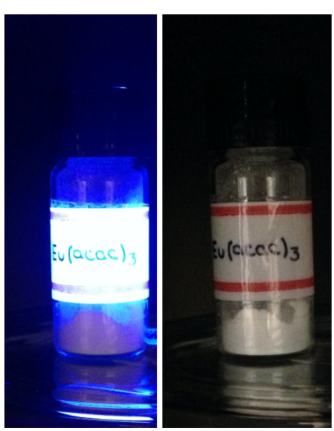

Fonte: Autoria própria.

\subsection{Síntese de magnetita dopada com európio utilizando $\mathrm{Eu}(\mathrm{acac})_{3}$ como precursor de TR}

A substituição do complexo $\mathrm{Eu}(\mathrm{TTA})_{3}$ por $\mathrm{Eu}(\mathrm{acac})_{3}$ como precursor na síntese de magnetita dopada com európio foi analisada por meio da degradação térmica dos compostos. A Figura 43 apresenta as curvas de decomposição térmica (TG) e as respectivas curvas de primeira derivada (DTG) dos complexos. A decomposição térmica dos compostos de európio possui o mesmo comportamento apresentado pelos complexos de neodímio, no qual o $\mathrm{Eu}(\mathrm{TTA})_{3}$ apresenta uma decomposição mais rápida e expressiva na faixa de temperatura de refluxo da síntese $\left(288^{\circ} \mathrm{C}\right)$, favorecendo a formação de fases secundárias. Portanto, a fim de evitar a formação de outras fases, o complexo $\mathrm{Eu}(\mathrm{acac})_{3}$ passou a ser utilizado como precursor de $\mathrm{Eu}^{3+}$. 
Figura 43 - Curvas termogravimétricas (TG) e suas respectivas derivadas (DTG) dos complexos $\mathrm{Eu}(\mathrm{acac})_{3}$ e $\mathrm{Eu}(\mathrm{TTA})_{3}$ obtidas em atmosfera de ar sintético.

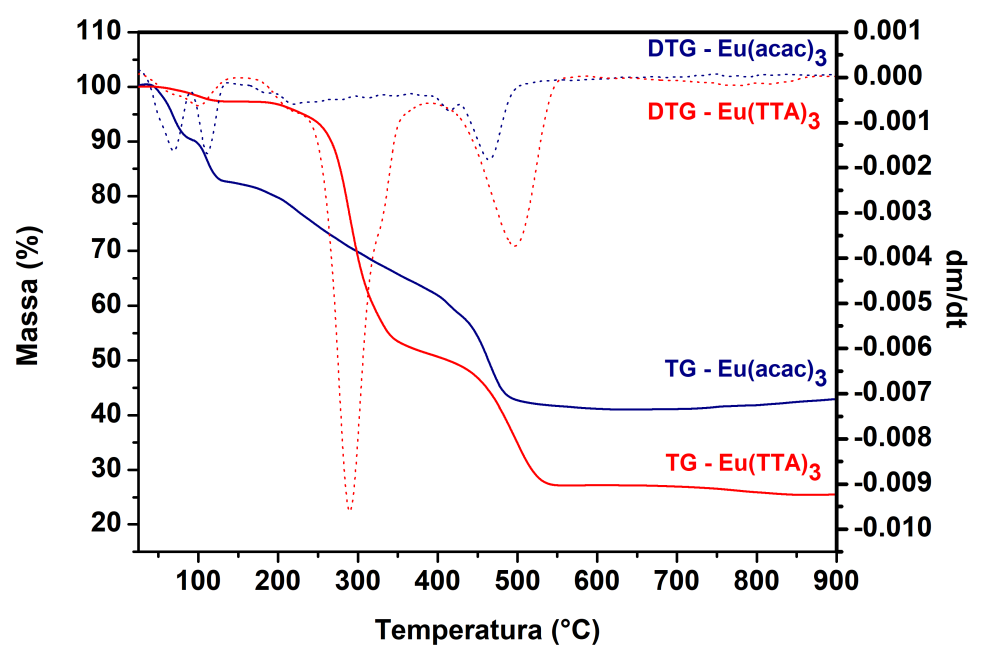

Fonte: Autoria própria.

Dando continuidade ao estudo do efeito da concentração do íon terra rara na dopagem das NPF, sínteses foram realizadas mantendo fixos o tempo de refluxo em 3 horas e a concentração do acetilacetonato de ferro(III) $(0,1 \mathrm{mmol})$, conforme mostra a Tabela 11, variando a concentração do $\mathrm{Eu}(\mathrm{acac})_{3}$.

Tabela 11 - Variações na proporção dos precursores utilizados na síntese de NPF dopadas com európio (Eu:NPF).

\begin{tabular}{c|cc|cc}
\hline \multirow{2}{*}{ Amostra } & \multicolumn{2}{|c|}{ Precursor de TR } & \multicolumn{2}{c}{ Precursor de Fe } \\
& Tipo & Qtde $(\mathrm{mmol})$ & Tipo & Qtde $(\mathrm{mmol})$ \\
\hline Eu:NPF_10 & $\mathrm{Eu}(\mathrm{acac})_{3}$ & $\mathbf{0 , 0 1}$ & $\mathrm{Fe}(\mathrm{acac})_{3}$ & 0,1 \\
\hline Eu:NPF_20 & $\mathrm{Eu}(\mathrm{acac})_{3}$ & $\mathbf{0 , 0 2}$ & $\mathrm{Fe}(\mathrm{acac})_{3}$ & 0,1 \\
\hline Eu:NPF_30 & $\mathrm{Eu}(\mathrm{acac})_{3}$ & $\mathbf{0 , 0 3}$ & $\mathrm{Fe}(\mathrm{acac})_{3}$ & 0,1 \\
\hline Eu:NPF_40 & $\mathrm{Eu}(\mathrm{acac})_{3}$ & $\mathbf{0 , 0 4}$ & $\mathrm{Fe}(\mathrm{acac})_{3}$ & 0,1 \\
\hline
\end{tabular}

Fonte: Autoria própria.

A Figura 44 apresenta os difratogramas de raios $X$ das amostras de Eu:NPF em comparação ao padrão cristalográfico da magnetita (JCPDF 19-629) e à ferrita não dopada. Os difratogramas foram comparados a fim de analisar se o aumento na concentração do dopante causa distorções nos parâmetros da cela unitária, levando a um ligeiro deslocamento dos picos. $(83,102,103)$ Os resultados obtidos foram indexados de acordo com a fase espinélio da magnetita, sendo eles em $30,1^{\circ}, 35,3^{\circ}$, $42,9^{\circ}, 56,8^{\circ} \mathrm{e} 62,4^{\circ} \mathrm{em} 2 \theta$, correspondentes aos planos (220), (311), (400), (511) e (440), respectivamente.(81) Um pequeno deslocamento do pico principal pode ser observado com o aumento na proporção de TR (Figura 44b). Este deslocamento pode ser um in- 
dicativo de que houve a incorporação de íons $\mathrm{Eu}^{3+}$ na estrutura. No entanto, apenas com base nos difratogramas, não é possível afirmar se houve a dopagem ou se os deslocamentos se devem a defeitos estruturais.

Figura 44 - Difratograma de raios $X$ obtido para as amostras sintetizadas utilizando proporções de Eu/Fe iguais a 1/10 (Eu:NPF_10), 2/10 (Eu:NPF_20), 3/10 (Eu:NPF_30) e 4/10 (Eu:NPF_40) em comparação à ferrita não dopada (NPF) e ao padrão JCPDF 19-629 da fase espinélio invertida de magnetita.

a)

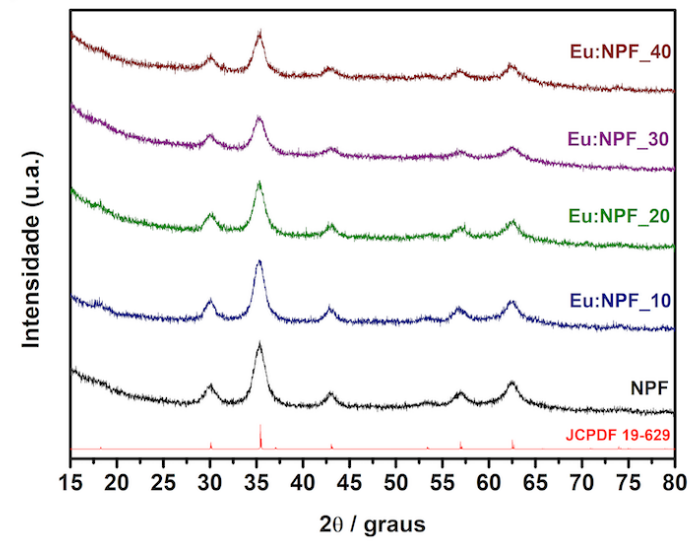

b)

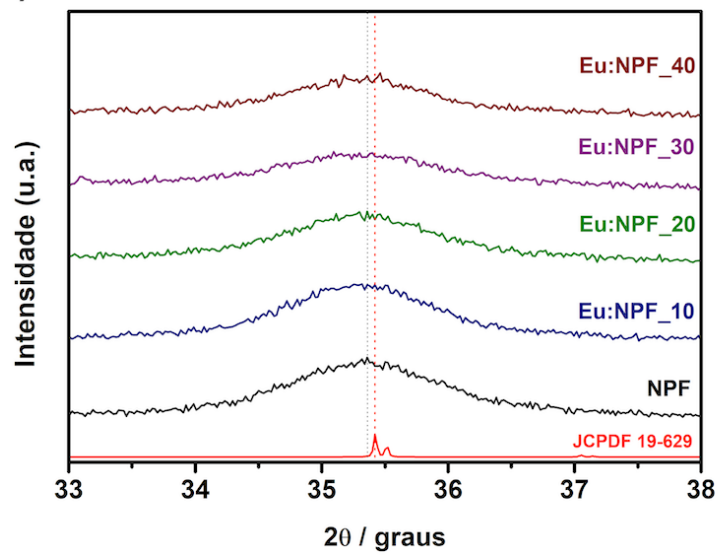

Fonte: Autoria própria.

O espectro FTIR referente à amostra Eu:NPF_20 na Figura 45 apresenta banda de vibração em $580 \mathrm{~cm}^{-1}$, característica de ligações Fe-O em sítios octaédricos e tetraédricos da estrutura cúbica de espinélio invertida da magnetita.(81) Assim como o espectro FTIR da ferrita pura, o espectro da amostra dopada com európio também apresenta bandas referentes à produtos de oxidação e degradação do solvente adsorvidos na superfície da partícula, que podem ser atribuídas a estiramentos de ligações do tipo $\mathrm{C}=\mathrm{O}, \mathrm{C}=\mathrm{C}, \mathrm{C}-\mathrm{O}$ e deformações $\mathrm{C}-\mathrm{H}$, presentes na região em destaque na Figura 45.(68, 84, 85, 86) As bandas presentes na região de 3600 a $3900 \mathrm{~cm}^{-1}$ podem ser atribuídas à substituição de átomos de $\mathrm{O}$ ligados aos cátions metálicos por grupos $\mathrm{OH}$. Essa substituição leva à ao aparecimento de diversos picos referentes ao estiramento dos grupos $\mathrm{OH}$ na região indicada. A diferença na frequência de estiramento das bandas pode estar relacionada à presença de diferentes arranjos entre os cátions metálicos e os grupos $\mathrm{OH} .(87)$ 
Figura 45 - Espectro FTIR da amostra Eu:NPF_20. A área em destaque apresenta bandas referentes à derivados da síntese ligados à superfície das NPF.

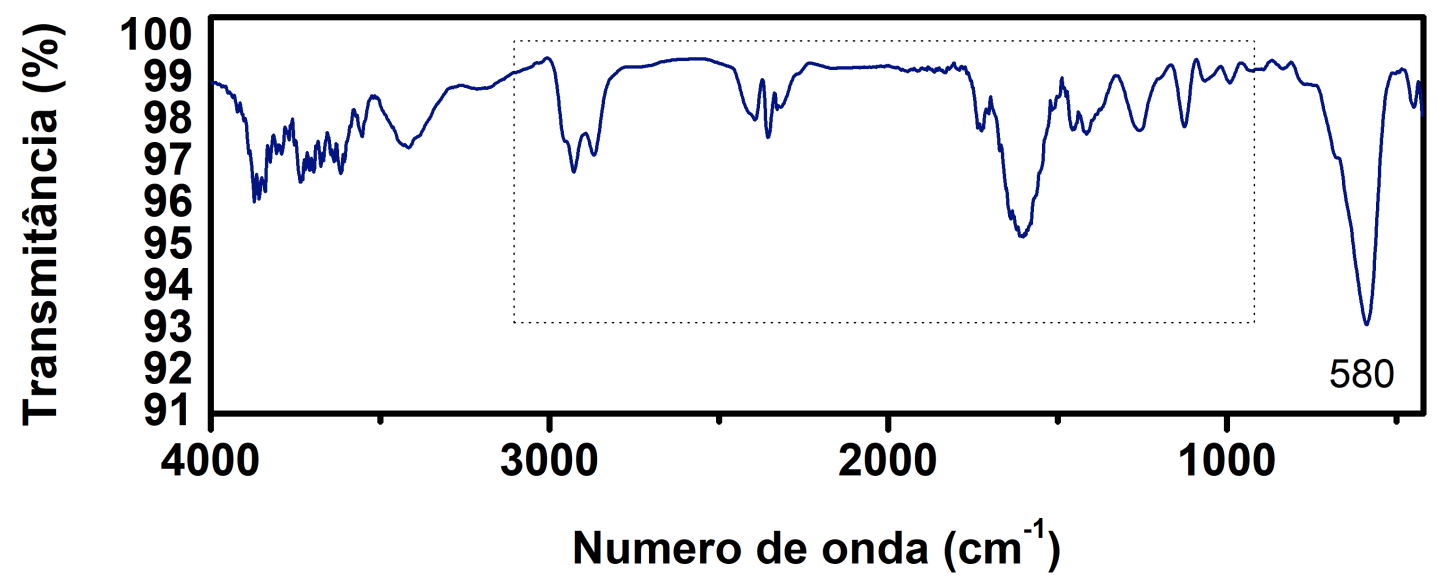

Fonte: Autoria própria.

A Tabela 12 apresenta os valores de tamanho de cristalito calculados a partir do difratograma $\left(D_{h k l}\right)$ e os valores medidos a partir das micrografias obtidas por microscopia eletrônica de transmissão (D).

Tabela 12 - Comparação entre os valores de diâmetro médio (D) e tamanho de cristalito $\left(\mathrm{D}_{h k l}\right)$ para as amostras de magnetita dopadas com európio (Eu:NPF).

\begin{tabular}{ccc}
\hline Amostra & $\mathrm{D}_{h k l}(\mathrm{~nm})$ & $\mathrm{D}(\mathrm{nm})$ \\
\hline Eu:NPF_10 & 6,94 & 6,27 \\
\hline Eu:NPF_20 & 6,83 & 7,92 \\
\hline Eu:NPF_30 & 6,66 & 5,89 \\
\hline Eu:NPF_40 & 7,56 & 6,97 \\
\hline
\end{tabular}

Fonte: Autoria própria.

A Figura 46 apresenta as micrografias e os histogramas de distribuição de tamanho referentes a cada uma das amostras. Assim como no caso da dopagem com neodímio, a amostra com maior índice de polidispersividade é a amostra em que foi utilizada a maior concentração de európio. Uma possível explicação para esse fato envolve os processos de nucleação e crescimento de NP. Devido à lenta degradação térmica do $\mathrm{Eu}(\mathrm{acac})_{3}$, em sínteses com um grande excesso deste precursor, diversos núcleos vão sendo formados no decorrer da reação, fazendo com que a etapa de nucleação seja lenta e ocorra concomitantemente à etapa de crescimento das NP.(108) Conforme descrito anteriormente (verificar Figura 11), a ocorrência simultânea dos processos de nucleação e crescimento faz com que o sistema apresente NP de tamanhos variados. $(25,26,71)$ Ao comparar a amostra Eu:NPF_20 com a amostra Eu:NPF_TTA_3 (obtidas sob mesmo tempo de refluxo e com a mesma proporção Eu/Fe), é possível observar que a substituição do precursor levou à formação de NP mais homo- 
gêneas e com menor diâmetro médio.

Figura 46 - Imagens de MET obtidas para as amostras sintetizadas utilizando proporções de Eu/Fe iguais a 1/10 (Eu:NPF_10) (a), 2/10 (Eu:NPF_20) (b), 3/10 (Eu:NPF_30) (c), 4/10 (Eu:NPF_40) (d) e histogramas de distribuição dos tamanhos das nanopartículas medidas (e).
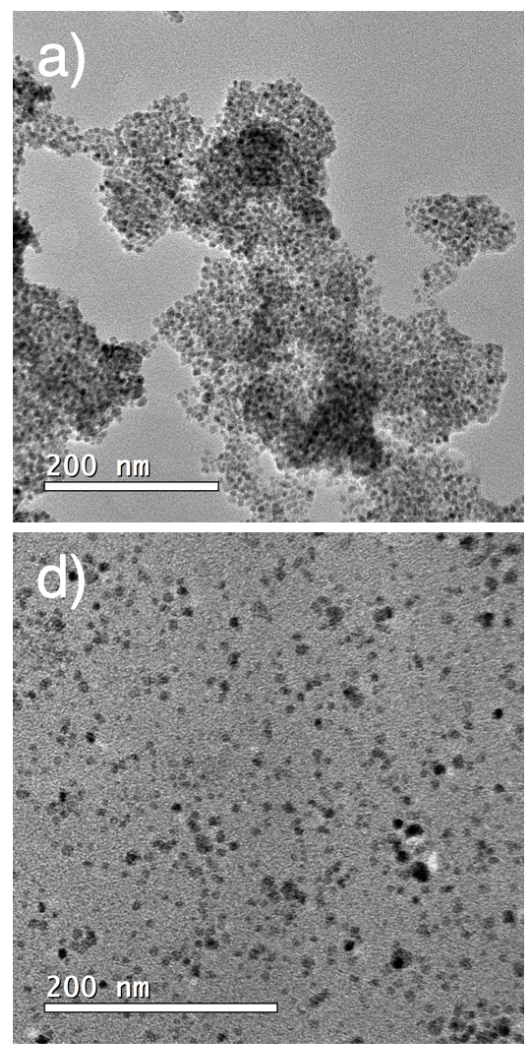

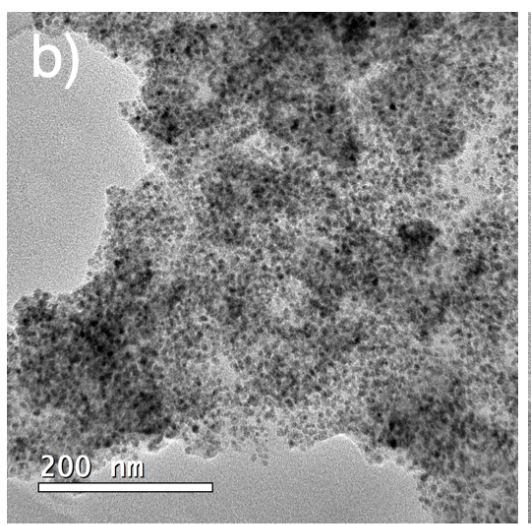

e)
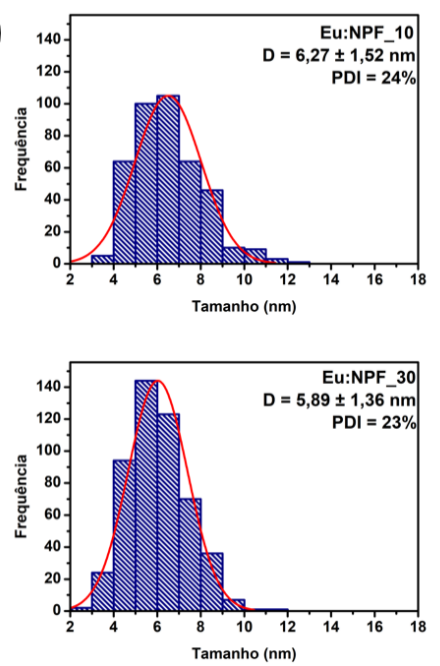

Fonte: Autoria própria.
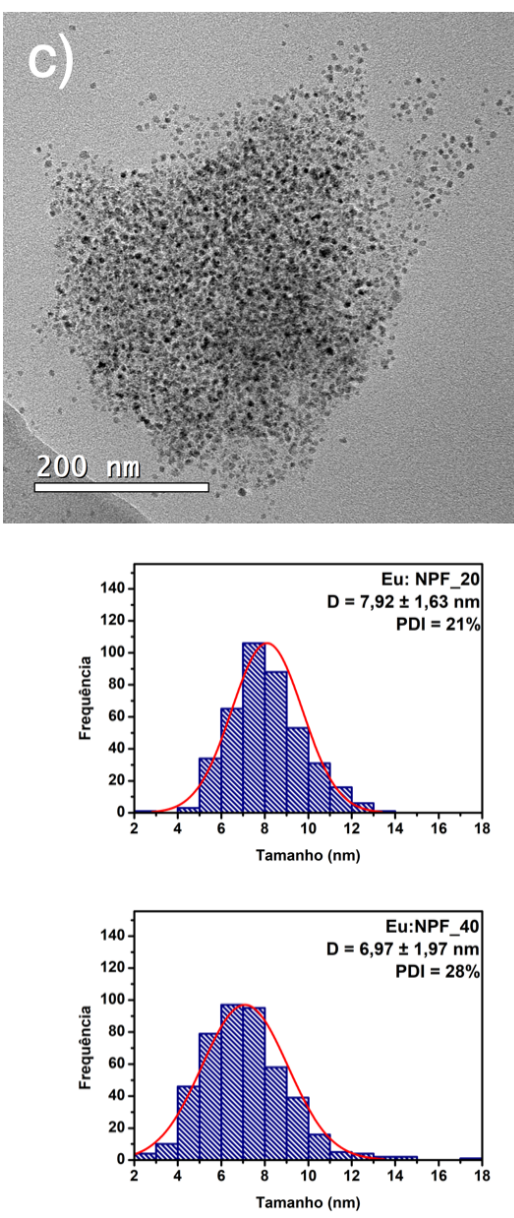

As análises de energia dispersiva de raios $X$ apresentadas pela Figura 47 mostram que de fato ocorreu um aumento na concentração de európio nas amostras conforme o aumento na proporção de $\mathrm{Eu}(\mathrm{acac})_{3}$ utilizada nas sínteses. A porcentagem de Eu calculada para as amostras Eu:NPF_10, Eu:NPF_20 e Eu:NPF_30, em relação ao Fe, foi de 3,7\%, 11,5\% e 21,9\%, respectivamente. A análise de EDX indica a presença do TR nas amostras, no entanto, não é possível afirmar a quantidade de Eu de fato incorporada na estrutura da magnetita. 
Figura 47 - Espectro EDX das amostras Eu:NPF_10, Eu:NPF_20 e Eu:NPF_30.

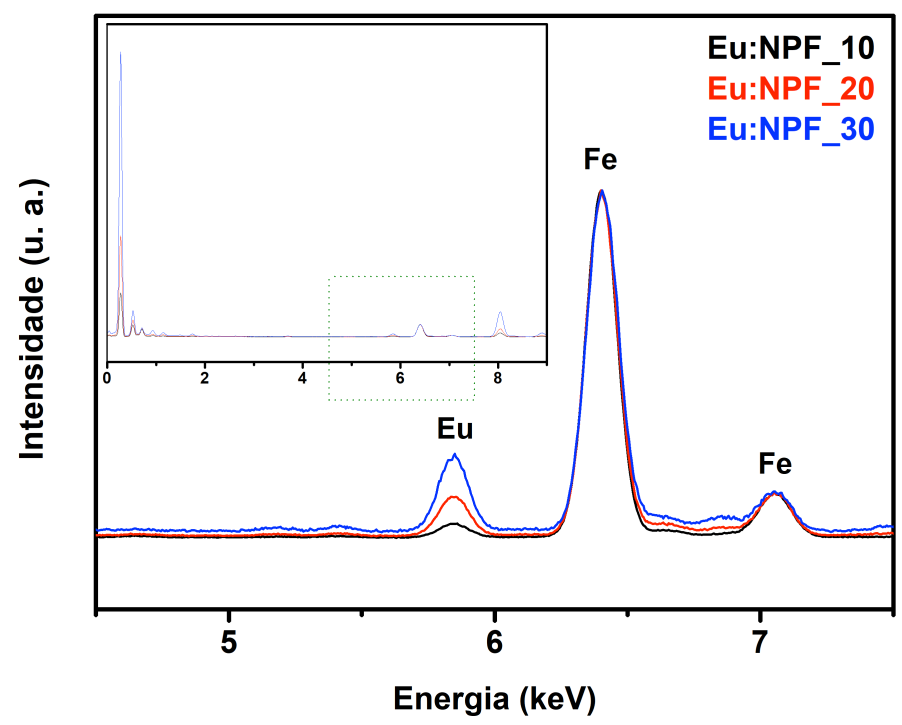

Fonte: Autoria própria.

As curvas de magnetização das amostras dopadas com európio são apresentadas pela Figura 48 e os valores de coercividade $(\mathrm{Hc})$ e magnetização de saturação (Ms) são dados pela Tabela 13. As amostras analisadas apresentam comportamento próximo ao superparamagnético e menores valores de Ms em comparação à magnetita não dopada $(52,8$ emu/g).

Figura 48 - Curva de magnetização das amostras de magnetita dopadas com európio (Eu:NPF) em diferentes proporções. Região em destaque na figura mostra o deslocamento das curvas de histerese devido ao efeito de exchange bias negativo.

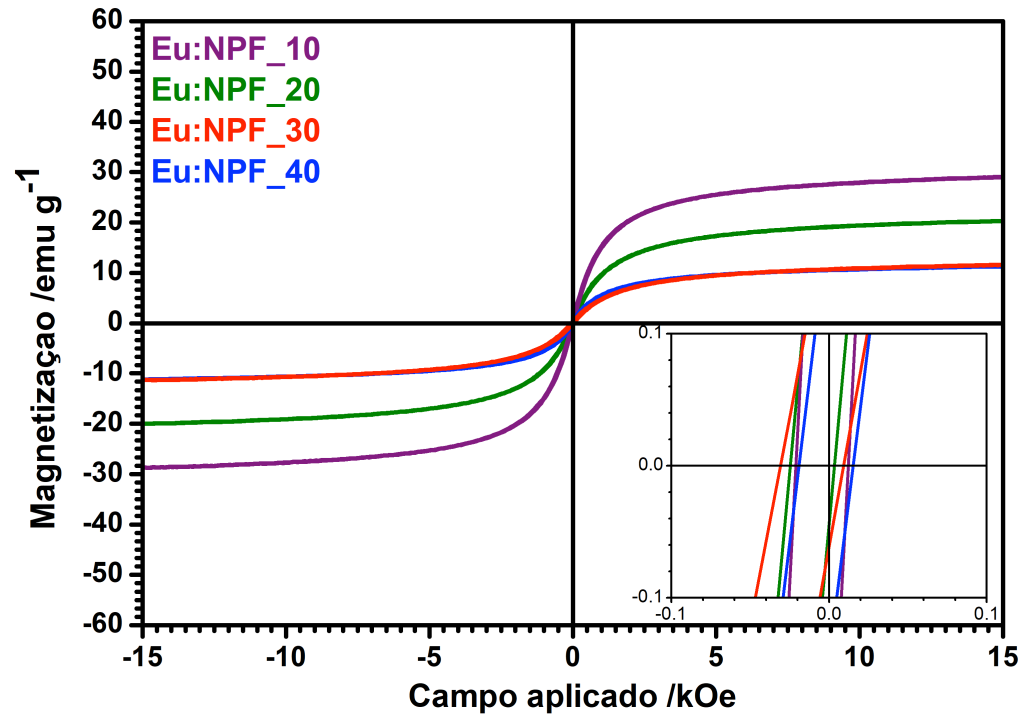

Fonte: Autoria própria. 
Tabela 13 - Valores de magnetização de saturação (Ms), coercividade (Hc) e campo de exchange bias (Heb) das amostras de magnetita dopadas com európio (Eu:NPF).

\begin{tabular}{cccccc}
\hline Amostra & Ms (kOe) & Hc1 (Oe) & Hc2 (Oe) & Heb (Oe) \\
\hline Eu:NPF_10 & 28,9 & $-21,2$ & 12,1 & $-4,6$ \\
\hline Eu:NPF_20 & 20,3 & $-24,3$ & 3,6 & $-10,4$ \\
\hline Eu:NPF_30 & 11,5 & $-30,4$ & 10,4 & -10 \\
\hline Eu:NPF_40 & 11,3 & $-19,4$ & 15,1 & $-2,2$ \\
\hline
\end{tabular}

Fonte: Autoria própria.

A diminuição na Ms ocorre devido à desestruturação da rede cristalina e ao enfraquecimento de interações de supertroca magnéticas entre os sítios $A$ e $B$ nas ferritas, acarretados pela substituição dos íons $\mathrm{Fe}^{3+}$ por íons $\mathrm{Eu}^{3+}$ na estrutura. A diminuição na Ms das amostras com o aumento na proporção de TR indica um aumento na dopagem, causando uma maior desestruturação no sistema e consequente aumento na anisotropia magnética. A similaridade no valor de Ms entre as amostras Eu:NPF_30 e Eu:NPF_40 é um indicativo de que a concentração crítica de dopagem foi atingida com a proporção de $\mathrm{Eu}^{3+}$ e $\mathrm{Fe}^{3+}$ igual a 3:10 e que o subsequente aumento na concentração de $\mathrm{Eu}(\mathrm{acac})_{3}$ não tem efeito na magnetização da amostra. A abertura da curva de histerese para a amostra Eu:NPF_30 indica a ocorrência de uma melhor estruturação na rede cristalina em comparação às demais amostras $(93,99)$, o que sugere que as condições empregadas são melhores em termos de manutenção da estrutura espinélio. O mesmo comportamento foi observado para a amostra Nd:NPF_30, o que sugere que a proporção 3:10 é melhor em termos de manutenção da estrutura espinélio.

Como é possível observar pelos valores de coercividade apresentados na Tabela 13, as curvas de magnetização se encontram deslocadas para valores de campo magnético negativos, indicando novamente a ocorrência de exchange bias. A presença deste efeito pode estar relacionada à existência de defeitos, assim como ao efeito de spin canting. $(11,15,98)$ As bandas referentes ao estiramento $\mathrm{OH}$ estrutural presentes na análise de FTIR mostram a formação de ligações do tipo $\mathrm{Me}-\mathrm{OH}$ (Me= Fe, Eu) na superfície, o que sugere a formação de uma camada de superfície diferente do núcleo da partícula. Essa diferença de composição pode fazer com que haja diferença no ordenamento dos spins do núcleo e da superfície, fazendo com que essas camadas tenham comportamento magnético diferentes, agindo como um sistema de duas fases magnéticas distintas (spins do núcleo e spins de superfície), que podem acoplar magneticamente. $(11,15)$ No entanto, análises aprofundadas acerca da estrutura cristalina das amostras não foram realizadas em decorrência da pandemia de Covid-19. Desta forma, não é possível afirmar a origem do efeito de exchange bias nas amostras. 
sentados pela Figura 49. Os espectros de excitação foram obtidos monitorando a emissão em $612 \mathrm{~nm}$, correspondente à transição hipersensitiva ${ }^{5} D_{0} \rightarrow{ }^{7} F_{2}$ do $E u^{3+}$.(52) É possível observar uma banda na região de 290 a 320 nm, com valor máximo em 307 $\mathrm{nm}$. Essa banda pode ser atribuída à transferência de carga entre os íons $\mathrm{Eu}^{3+} \mathrm{e} \mathrm{O}^{2-}$, devido à transições eletrônicas do orbital $2 p$ do $\mathrm{O}^{2-}$ para o orbital $4 f$ do $\mathrm{Eu}^{3+}$.(109) Em contrapartida, os espectros de emissão da Figura 49b (excitados a $280 \mathrm{~nm}$ ) mostram a ausência de emissão nessas amostras.

Figura 49 - Espectros de excitação (monitorada em 615nm) (a) e emissão (b) das amostras dopadas com európio em diferentes proporções de Eu/Fe (excitadas a $280 \mathrm{~nm}$ ).
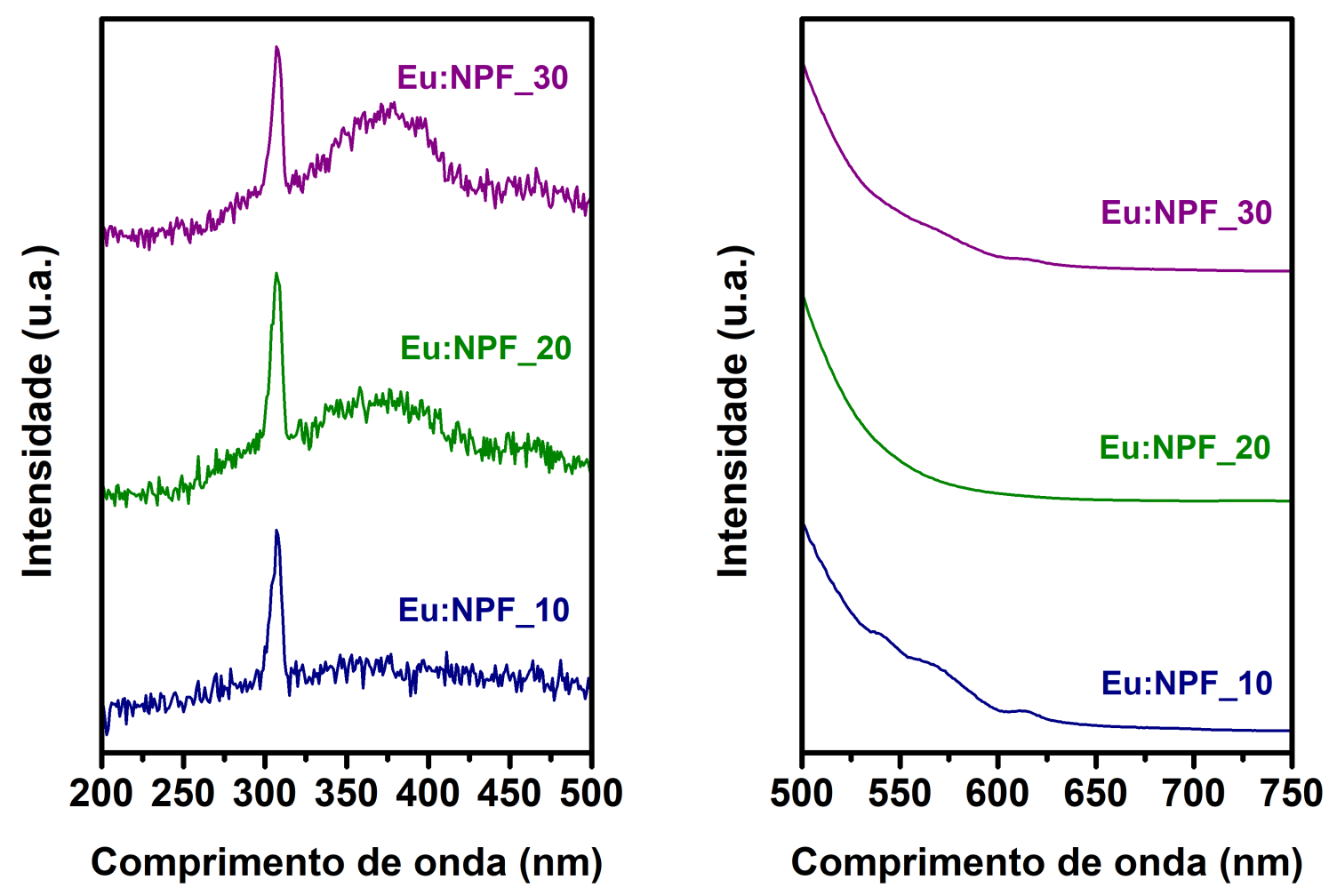

Fonte: Autoria própria.

Embora alguns estudos apontem a existência de propriedade luminescente em magnetitas dopadas com íons terras raras obtidas em condições de síntese muito similares às empregadas neste trabalho $(73,74,75,76)$, a ausência de emissão é esperada, uma vez que a literatura mostra que diversos compostos luminescentes têm sua emissão diminuída ou até mesmo suprimida quando em contato direto com materiais magnéticos. $(110,111,112)$ O mecanismo de desativação da propriedade luminescente, embora não estabelecido completamente, está relacionado ao acoplamento magnético com os elétrons dos orbitais de fronteira, diminuindo a passagem para estados excitados.(110, 112) 
Nesses experimentos, o európio atua como sonda espectroscópica, pois sua emissão característica $\left({ }^{5} D_{0} \rightarrow{ }^{7} F_{2}\right)$ é altamente sensível à simetria da estrutura e ao sítio em que está localizado. $(45,52,112)$ A presença de excitação e ausência de emissão nas amostras indica que a supressão da luminescência está ocorrendo e o mesmo pode estar acontecendo nas amostras dopadas com neodímio. No entanto, estudos aprofundados acerca da propriedade óptica dos materiais não puderam ser realizados em decorrência da pandemia de Covid-19.

De modo geral, a troca do precursor $\mathrm{Eu}(\mathrm{TTA})_{3}$ pelo $\mathrm{Eu}(\mathrm{acac})_{3}$ levou à mudanças positivas nos resultados, obtendo-se NP mais homogêneas, com fortes indícios de dopagem e extinção da formação de fases secundárias, conforme o esperado. Os resultados são encorajadores, uma vez que a dopagem promove uma forma de modificar a anisotropia dos materiais, fazendo com que eles apresentem o comportamento magnético adequado à aplicação de interesse. 


\section{Conclusão}

Os resultados demonstram que, de modo geral, o objetivo de obter nanopartículas de magnetita dopadas com íons de terras raras foi alcançado. O método poliol se mostrou eficiente tanto para a obtenção de nanopartículas de magnetita pura quanto para NP de magnetita dopadas, proporcionando um considerável controle de forma e tamanho.

Análises de difração de raios X (DRX) e espectroscopia de infravermelho com transformada de Fourier (FTIR) confirmaram a formação da estrutura da magnetita e apresentaram indícios da substituição de íons $\mathrm{Fe}^{3+}$ por íons $\mathrm{Ln}^{3+}$. A microscopia eletrônica de transmissão (TEM) mostrou nanopartículas esferoidais com distribuição de tamanho estreita e tamanho médio da ordem de $7 \mathrm{~nm}$. A presença dos elementos terras raras foi confirmada por espectroscopia de energia dispersiva de raios $X$ (EDX) e por mapeamento por STEM (scanning-transmission electron microscopy).

Foi possível observar que o precursor de íons de terras tem um grande impacto na formação de fases secundárias, assim como no tamanho das nanopartículas, dispersividade e propriedades magnéticas. Os resultados mostraram que o complexo TTA induz a formação de fases secundárias em todas as condições analisadas, o que não foi observado para os complexos com acetilacetonato.

As amostras apresentaram comportamento superparamagnético e efeito de exchange bias condizentes com o tamanho das NP e com efeitos de defeitos estruturais induzidos pela formação de fases hidroxiladas na superfície das NP e/ou da presença do dopante. Os valores de magnetização de saturação (Ms) são condizentes com a literatura tanto para as NP de magnetita dopadas quanto não dopadas.

Devido à pandemia de Covid-19, análises de luminescência e análises aprofundadas acerca da composição e da estrutura cristalina das amostras não foram realizadas. No entanto, os deslocamentos apresentados pelos picos principais nos difratogramas, assim como a diminuição da magnetização de saturação das amostras dopadas em relação à magnetita pura, são indícios da substituição dos íons $\mathrm{Fe}^{3+}$ por íons de terras raras.

É importante ressaltar que este trabalho permitiu a determinação de um tempo ótimo de reação para a dopagem igual a 3h, promovendo maior controle dos processos de nucleação e crescimento das NP, e um valor crítico de dopagem em torno de 15$20 \%$. 


\section{Perspectivas para trabalhos futuros}

Devido à impossibilidade de realizar a caracterização completa dos materiais obtidos neste trabalho em decorrência da pandemia de Covid-19, algumas das análises permanecem como perspectivas para futuros trabalhos, assim como o estudo de possíveis aplicações em sistemas biológicos. Desta forma, para trabalhos futuros, espera-se:

i Dar continuidade à caracterização estrutural dos materiais obtidos utilizando acac como precursor de TR por meio de medidas de espectroscopia Mossbauer, espectroscopia de fotoelétrons excitados por raios X (XPS) e análises de EDX quantitativas utilizando o FEG-SEM recentemente adquirido;

ii Realizar as caracterizações ópticas dos materiais, uma vez que as análises foram impossibilitadas pela pandemia e pela quebra do fluorímetro onde seriam realizadas;

iii Realizar ensaios de relaxividade magnética a fim de avaliar os efeitos do dopante nos tempos de relaxação e avaliar o uso destes materiais como agentes de contraste duplo em imageamento por ressonância magnética (MRI);

iv Realizar ensaios de hipertermia magnética com as dispersões em hexano para avaliação preliminar do potencial de aplicação em hipertermia magnética e, de acordo com os resultados, iniciar a troca de ligantes para promover a dispersão dos sistemas em meio aquoso. 


\section{Referências}

1 SENGUPTA, A.; SARKAR, C. K. Introduction to Nano: Basics to Nanoscience and Nanotechnology. 2015. 226 p.

2 LINDSAY, S. M. Introduction to Nanoscience. Oxford: Oxford University Press, 2010. $457 \mathrm{p}$.

3 HORNYAK, G. L. et al. Introduction to Nanoscience. Taylor \& Francis Group, 2008. $815 \mathrm{p}$.

4 KULKARNI, S. K. Nanotechnology : Principles and Practices. 3 ed. Springer, 2015. $403 \mathrm{p}$.

5 BINNS, C. Introduction to Nanoscience and Nanotechnology. Wiley, 2010. $301 \mathrm{p}$.

6 GUIMARÃES, A. P. Principles of Nanomagnetism. Springer, 2009. 224 p.

7 LU, A.-h.; SALABAS, E. L.; SCHÜTH, F. Magnetic Nanoparticles : Synthesis, Protection, Functionalization, and Application. Angewandte Chemie International Edition, v. 46, p. 1222-1244, 2007.

8 CULLITY, B. D.; GRAHAM, C. D. Introduction to magnetic materials. 2 ed. Wiley, 2009. 544 p.

9 SUN, S. Recent Advances in Chemical Synthesis, Self-Assembly, and Applications of FePt Nanoparticles. Advanced Materials, v. 18, p. 393-403, 2006.

10 MEIKLEJOHN, W. H.; BEAN, C. P. New magnetic anisotropy. Physical Review B, v. 102, p. 1413-1414, 1956.

11 NOGUÉS, J. et al. Exchange bias in nanostructures. Physics Reports, v. 422, p. 65-117, 2005.

12 CHANDRA, S. et al. Exchange bias effect in Au-Fe3O4 nanocomposites. Nanotechnology, v. 25, p. 1-10, 2014.

13 HONG, F. et al. Positive and negative exchange bias effects in the simple perovskite manganite NdMnO3. Applied Physics Letters, v. 101, p. 1-5, 2012.

14 RADU, F.; ZABEL, H. Exchange Bias Effect of Ferro- / Antiferromagnetic Heterostructures. In: ZABEL, H.; BADER, S. D. Magnetic Heterostructures:

Advances and Perspectives in Spinstructures and Spintransport. Springer, 2007. v. 227, p. 97-184.

15 MANNA, P. K.; YUSUF, S. M. Two interface effects : Exchange bias and magnetic proximity. Physics Reports, v. 535, n. 2, p. 61-99, 2014.

16 INDRA, A. et al. Magnetoelectric coupling and exchange bias effects in multiferroic NdCrO3. Journal of Physics: Condensed Matter, v. 28, p. 1-8, 2016.

17 STAMPS, R. L. Mechanisms for exchange bias. Journal of Physics D: Applied Physics, v. 33, p. 247-268, 2000. 
18 SOARES, M. M. Observação de vórtices magnéticos em calotas tridimensionais submicrométricas. 149 p. (Dissertação (Mestrado)) - Universidade Estadual de Campinas, 2008.

19 NOGUES, J. et al. Positive Exchange Bias in FeF2-Fe Bilayers. Physical Review Letters, v. 76, p. 4624-4627, 1996.

20 NOGUÉS, J.; SCHULLER, I. K. Exchange bias. Journal of Magnetism and Magnetic Materials, v. 192, p. 203-232, 1999.

21 NOGUÉS, J.; LEIGHTON, C.; SCHULLER, I. K. Correlation between antiferromagnetic interface coupling and positive exchange bias. Physical Review B, v. 61 , p. $1315-1317,2000$.

22 MIGLIORINI, A. et al. Spontaneous exchange bias formation driven by a structural phase transition in the antiferromagnetic material. Nature Materials, v. 17, p. 28-35, 2018.

23 DIMITRIADIS, V. et al. Shape-dependent exchange bias effect in magnetic nanoparticles with core-shell morphology. Physical Review B, v. 92, p. 1-6, 2015.

24 KAKADE, S. G. et al. Dielectric, electrical transport and magnetic properties of Er3+substituted nanocrystalline cobalt ferrite. Journal of Physics and Chemistry of Solids, v. 98, p. 20-27, 2016.

25 VARANDA, L. C.; JAFELICCI, M.; BECK, W. Magnetic and Multifunctional Magnetic Nanoparticles in Nanomedicine : Challenges and Trends in Synthesis and Surface Engineering for Diagnostic and Therapy Applications. Biomedical Engineering, Trends in Materials Science. Intech, 2011. p. 397-424.

26 VARANDA, L. C. et al. Size and shape-controlled nanomaterials based on modified polyol and thermal decomposition approaches . A brief review. Anais da Academia Brasileira de Ciências, v. 91, p. 1-32, 2019.

27 REICHEL, V. et al. Single crystalline superstructured stable single domain magnetite nanoparticles. Scientific Reports, v. 7, p. 1-8, 2017.

28 WU, X. et al. Effect of the rare-earth substitution on the structural, magnetic and adsorption properties in cobalt ferrite nanoparticles. Ceramics International, v. 42, n. 3, p. 4246-4255, 2016.

29 VALENZUELA, R. Novel applications of ferrites. Physics Research International, v. 2012, 2012.

30 MAHALAKSHMI, S.; SRINIVASAMANJA, K.; NITHIYANANTHAM, S. Electrical Properties of Nanophase Ferrites Doped with Rare Earth lons. Journal of Superconductivity and Novel Magnetism, v. 27, n. 9, p. 2083-2088, 2014.

31 DOUGLAS, F. J. et al. Gadolinium-doped magnetite nanoparticles from a single-source precursor. RSC Advances, v. 6, p. 74500-74505, 2016.

32 LEVIN, C. S. et al. Magnetic-Plasmonic Core-Shell Nanoparticles. ACS Nano, v. 3, n. 6, p. 1379-1388, jun 2009. 
$33 \mathrm{ZHU}, \mathrm{H}$. et al. Magnetic, fluorescent, and thermo-responsive Fe3O4/rare earth incorporated poly(St-NIPAM) core-shell colloidal nanoparticles in multimodal optical/magnetic resonance imaging probes. Biomaterials, v. 34, n. 9, p. 2296-2306, 2013.

34 LOUIE, A. Multimodality Imaging Probes: Design and Challenges. Chem. Rev., v. 110, n. 5, p. 3146-3195, 2010.

35 ABDESSELEM, M. et al. Multifunctional Rare-Earth Vanadate Nanoparticles: Luminescent Labels, Oxidant Sensors, and MRI Contrast Agents. ACS Nano, v. 8, n. 11, p. 11126-11137, nov 2014.

36 SOUZA, C. G.; BECK, W.; VARANDA, L. C. Multifunctional luminomagnetic FePt@Fe3O4/SiO2/Rhodamine B/SiO2nanoparticles with high magnetic emanation for biomedical applications. Journal of Nanoparticle Research, v. 15, n. 4, 2013.

37 XIA, A. et al. Core-shell NaYF4:Yb3+,Tm3+@FexOynanocrystals for dualmodality T2-enhanced magnetic resonance and NIR-to-NIR upconversion luminescent imaging of small-animal lymphatic node. Biomaterials, v. 32, n. 29, p. 7200-7208, 2011.

38 DAS, G. K. et al. Gadolinium Oxide Ultranarrow Nanorods as Multimodal Contrast Agents for Optical and Magnetic Resonance Imaging. Langmuir, v. 26, n. 11, p. 8959-8965, jun 2010.

39 LOUIS, C. et al. Nanosized Hybrid Particles with Double Luminescence for Biological Labeling. Chemistry of Materials, v. 17, n. 7, p. 1673-1682, apr 2005.

40 VARANDA, L. C. et al. Iron oxide versus Fe55Pt55/Fe3O4: Improved properties of core/shell nanoparticles for biomedical applications. IEEE Transactions on Magnetics, v. 44, n. 11, p. 4448-4451, 2008.

41 PETORAL, R. M. et al. Synthesis and Characterization of Tb 3+ -Doped Gd2O3 Nanocrystals: A Bifunctional Material with Combined Fluorescent Labeling and MRI Contrast Agent Properties. The Journal of Physical Chemistry C, v. 113, n. 17, p. 6913-6920, 2009.

42 WANG, F. et al. Simultaneous phase and size control of upconversion nanocrystals through lanthanide doping. Nature, v. 463, n. 7284, p. 1061-1065, 2010.

43 GORDON, W. O.; CARTER, J. A.; TISSUE, B. M. Long-lifetime luminescence of lanthanide-doped gadolinium oxide nanoparticles for immunoassays. Journal of Luminescence, v. 108, n. 1-4, p. 339-342, 2004.

44 CHATTERJEE, D. K.; RUFAIHAH, A. J.; ZHANG, Y. Upconversion fluorescence imaging of cells and small animals using lanthanide doped nanocrystals. Biomaterials, v. 29 , n. 7, p. 937-943, 2008.

45 ANDRES, J.; CHAUVIN, A. S. Luminescence. In: ATWOOD, D. A. (Ed.). The Rare Earth Elements: Fundamentals and Applications. Wiley, 2012.

46 BETTENCOURT-DIAS, A. The Electronic Structure of the Lanthanides. In: ATWOOD, D. A. (Ed.). The Rare Earth Elements: Fundamentals and Applications. Wiley, 2012. 
47 MARTINS, T. S.; ISOLANI, P. C. Terras raras: aplicações industriais e biológicas. Química Nova, v. 28, p. 111-117, 2005.

48 WEN, H.; WANG, F. Lanthanide-Doped Nanoparticles: Synthesis, Property, and Application. In: Nanocrystalline Materials. 2 ed. Elsevier, 2014. p. 121-160.

49 SHAHALIZAD, A. et al. Near infrared electroluminescence from $\mathrm{Nd}(\mathrm{TTA}) 3 p h e n$ in solution-processed small molecule organic light-emitting diodes. Organic Electronics, v. 44 , p. 50-58, 2017.

50 WAWRZYNCZYK, D. et al. Neodymium(III) doped fluoride nanoparticles as non-contact optical temperature sensors. Nanoscale, v. 4, p. 6959-6961, 2012.

51 VICENTINI, G. et al. Luminescence and structure of europium compounds. Coordination Chemistry Reviews, v. 196, p. 353-382, 2000.

52 BINNEMANS, K. Interpretation of europium(III) spectra. Coordination Chemistry Reviews, v. 295, p. 1-45, 2015.

53 COTTON, S. A. Lanthanides in Living Systems. In: ATWOOD, D. A. (Ed.). The Rare Earth Elements: Fundamentals and Applications. Wiley, 2012.

54 ANDRES, J.; CHAUVIN, A.-S. Lanthanides: Luminescence Applications. In: ATWOOD, D. A. (Ed.). The Rare Earth Elements: Fundamentals and Applications. Wiley, 2012.

55 ROCHA, U. et al. Neodymium-Doped LaF3 Nanoparticles for Fluorescence Bioimaging in the Second Biological Window. Small, v. 10, p. 1141-1154, 2014.

56 SKRIPKA, A. et al. Advancing neodymium single-band nanothermometry. Nanoscale, v. 11, p. 11322-11330, 2019.

57 SINHA, S. P. Spectroscopic investigations of some neodymium complexes. Spectrochimica Acta, v. 22, p. 57-62, 1966.

58 SPRECHER, B.; KLEIJN, R.; KRAMER, G. J. Recycling Potential of Neodymium : The Case of Computer Hard Disk Drives. Environmental Science \& Technology, v. 48, p. 9506-9513, 2014.

59 WANG, B.-W.; GAO, S. Magnetism. In: ATWOOD, D. A. (Ed.). The Rare Earth Elements: Fundamentals and Applications. Wiley, 2012.

60 CROZALS, G. D. et al. Nano Today Nanoparticles with multiple properties for biomedical applications : A strategic guide. Nano Today, v. 11, p. 435-463, 2016.

61 TAHAR, L. B. et al. Magnetic properties of CoFe1.9RE0.1O4nanoparticles $(\mathrm{RE}=\mathrm{La}, \mathrm{Ce}, \mathrm{Nd}, \mathrm{Sm}, \mathrm{Eu}, \mathrm{Gd}, \mathrm{Tb}, \mathrm{Ho}$ ) prepared in polyol. Journal of Magnetism and Magnetic Materials, v. 320, n. 23, p. 3242-3250, 2008.

62 ZHAO, L. et al. Magnetic properties of CoFe2O4ferrite doped with rare earth ion. Materials Letters, v. 60, n. 1, p. 1-6, 2006.

63 ZUBAIR, A. et al. Structural, morphological and magnetic properties of Eu-doped CoFe2O4nano-ferrites. Results in Physics, v. 7, p. 3203-3208, 2017. 
64 NIKUMBH, A. K. et al. Structural, electrical, magnetic and dielectric properties of rare-earth substituted cobalt ferrites nanoparticles synthesized by the co-precipitation method. Journal of Magnetism and Magnetic Materials, v. 355, p. 201-209, 2014.

65 FLORES-MARTINEZ, N. et al. Giant Exchange-Bias in Polyol-Made CoFe2O4CoO Core-Shell Like Nanoparticles. Particle and Particle Systems Characterization, p. 1-8, 2018.

$66 \mathrm{BECK}, \mathrm{W}$. et al. Formation mechanism via a heterocoagulation approach of FePt nanoparticles using the modified polyol process. Journal of Physical Chemistry C, v. 115, p. 10475-10482, 2011.

67 FIEVET, F.; LAGIER, J. P.; BLIN, B. Homogeneous and Heterogeneous Nucleations In The Poliol Process For The Preparation Of Micron And Submicron Size Metal Particles. Solid States Ionic, v. 32, p. 198-205, 1989.

68 FIÉVET, F. et al. The polyol process: a unique method for easy access to metal nanoparticles with tailored sizes, shapes and compositions. Chemical Society Reviews, p. 1-47, 2018.

69 SUN, S. et al. Monodisperse FePt Nanoparticles and Ferromagnetic FePt Nanocrystal Superlattices. Science, v. 287, p. 1989-1992, 2000.

70 VARANDA, L. C. et al. Structural and magnetic transformation of monodispersed iron oxide particles in a reducing atmosphere Structural and magnetic transformation of monodispersed iron oxide particles in a reducing atmosphere. Journal of Applied Physics, v. 92, p. 2079-2085, 2002.

71 LAMER, V. K.; DINEGAR, R. JOURNAL OF THE. Journal of American Chemical Society, v. 72, p. 4847-4854, 1950.

72 VOORHEES, P. W. The Theory of Ostwald Ripening. Journal of Statistical Physics, v. 38, p. 231-252, 1985.

73 KANNA, R. et al. Doping effect of rare-earth ( lanthanum, neodymium and gadolinium ) ions on structural, optical, dielectric and magnetic properties of copper nanoferrites. Journal of Rare Earths, v. 36, p. 1299-1309, 2018.

74 HUAN, W. et al. Preparation, Characterization of High-Luminescent and Magnetic Eu3+, Dy3+ Doped Superparamagnetic Nano-Fe3O4. Journal of Nanoscience and Nanotechnology, v. 15, p. 1780-1788, 2015.

75 HUAN, W. et al. A Study on the Magnetic and Photoluminescence Properties of Eu $\mathrm{n}+$ and Sm 3 + Doped Fe 3 O 4 Nanoparticles. Journal of Nanoscience and Nanotechnology, v. 12, p. 4621-4634, 2012.

76 KOBAYASHI, Y. et al. Europium doping of superparamagnetic iron oxide nanoparticles enables their detection by fluorescence microscopy and for quantitative analytics. Technology and Health Care, v. 1, p. 1-14, 2016.

77 CHARLES, R.; OHLMANN, R. Europium thenoyltrifluoroacetonate, preparation and fluorescence properties. Journal of Inorganic Nuclear Chemistry, v. 27, n. 1, p. 255-259, 1965. 
78 STITES, J. G.; MCCARTY, C.; QUILL, L. The rare earth metals and their compounds. VIII. An improved method for the synthesis of some rare earth acetylacetonates. J. Am. Chem. Soc., v. 70, p. 3142-3143, 1948.

79 CULLITY, B. D.; STOCK, S. R. Elements of X-Ray Diffraction. 3 Ed. Pearson Education Limited, 2014. 649 p.

80 BAALOUSHA, M.; LEAD, J. R. Nanoparticle dispersity in toxicology. Nature Nanotechnology, v. 8, p. 308 EP -, 2013.

81 CORNELL, R. M.; SCHWERTMANN, U. The Iron Oxides: Structure, Properties, Reactions, Occurence and Uses. Wiley, 2003.

82 PRATHAPANI, S. et al. Effect of Er doping on the structural and magnetic properties of cobalt-ferrite. Journal of Applied Physics, v. 115, p. 1-4, 2014.

83 CALLISTER, W.; RETHWISCH, D. Materials Science and Engeneering: An Introduction. 8 ed. Wiley, Inc., 2010.

84 NUNES, S. et al. Characterization of tetraethylene glycol passivated iron nanoparticles. Applied Surface Science, v. 315, p. 337-345, 2014.

85 CHOUKOUROV, A. et al. Vacuum Thermal Degradation of Poly(ethylene oxide). J. Phys. Chem. B, v. 113, p. 2984-2989, 2009.

86 PAVIA, D. L. et al. Introduction to Spectroscopy. 4th. ed. Cengace Learning, 2008. $752 \mathrm{p}$.

87 CHUKANOV, N. V.; CHERVONNYI, A. D. Infrared Spectroscopy of Minerals and Related Compounds. 1 ed. Springer, 2016. 1109 p.

88 MEDINA-VELAZQUEZ, D. Y. et al. Influence of Synthesis Parameters on Luminescence of Thenoyltrifluoroacetone Europium Powders. Journal of Materials Science and Chemical Engineering, v. 6, p. 1-8, 2018.

89 SHAHI, P. K. et al. Revelation of the Technological Versatility of the Eu(TTA)3 Phen Complex by Demonstrating Energy Harvesting, Ultraviolet Light Detection , Temperature Sensing, and Laser Applications. ACS Applied Materials and Interfaces, v. 7, p. 18231-18239, 2015.

90 CHITNIS, D.; KALYANI, N. T.; DHOBLE, S. J. Portrayal of structural , thermal and optical properties of $\mathrm{pH}$ sensitive $\mathrm{Eu}(\mathrm{TTA}) 3$ bipy hybrid organic complex for OLEDs. Optik, v. 130, p. 237-244, 2017.

$91 \mathrm{HE}, \mathrm{G}$. et al. A Color-Tunable Europium Complex Emitting Three Primary Colors and White Light. Angewandte Chemie International Edition, v. 48, p. 6132-6135, 2009.

92 SILVA, C. R. D. et al. Lanthanide ( III ) - Doped Magnetite Nanoparticles. Journal of American Chemical Society, v. 131, p. 6336-6337, 2009.

93 JAIN, R.; LUTHRA, V.; GOKHALE, S. Probing influence of rare earth ions ( Er3+,Dy3+ and Gd3+) on structural, magnetic and optical properties of magnetite nanoparticles. Journal of Magnetism and Magnetic Materials, v. 456, p. 179-185, 2018. 
94 ROUTRAY, K. L.; SAHA, S.; SANYAL, D. Role of rare-earth (Nd3+) ions on structural, dielectric , magnetic and Mossbauer properties of nano-sized CoFe2O4: useful for high frequency application. Materials Research Express, v. 6, p. 1-16, 2019.

95 MCLENNAN, S. M. Geology, Geochemistry, and Natural Abundances of the Rare Earth Elements. In: ATWOOD, D. A. (Ed.). The Rare Earth Elements: Fundamentals and Applications. Wiley, 2012. p. 2-19.

96 ZHANG, H. et al. Synthesis and characterization of Gd-doped magnetite nanoparticles. Journal of Magnetism and Magnetic Materials, v. 423, p. 386-394, 2017.

97 DHIMAN, M. et al. Augmenting the photocatalytic performance of cobalt ferrite via change in structural and optical properties with the introduction of different rare earth metal ions. Ceramics International, v. 45, n. 3, p. 3698-3709, 2019.

98 PETRAN, A. et al. Effects of rare earth doping on multi-core iron oxide nanoparticles properties. Applied Surface Science, v. 428, p. 492-499, 2018.

99 POUDEL, T. P. et al. The effect of gadolinium substitution in inverse spinel nickel ferrite: Structural, Magnetic , and Mossbauer study. Journal of Alloys and Compounds, v. 802, p. 609-619, 2019.

100 UGENDAR, K. et al. Cationic ordering and magnetic properties of rare-earth doped NiFe2O4 probed by Mössbauer and X-ray spectroscopies. Journal of Magnetism and Magnetic Materials, v. 484, p. 291-297, 2019.

101 LYUBUTIN, I. S. et al. Canted spin structure and the first order magnetic transition in CoFe2O4 nanoparticles coated by amorphous silica. Journal of Magnetism and Magnetic Materials, v. 416, p. 1-10, 2016.

102 CHEN, Y. et al. Ion Doping Effects on the Lattice Distortion and Interlayer Mismatch of Aurivillius-Type Bismuth Titanate Compounds. Materials, v. 11, p. 2-15, 2018.

103 ZOLFAGHARI, M.; CHIREH, M. Effect of Mn Dopant on Lattice Parameters and Band Gap Energy of Semiconductor ZnO Nanoparticles. Advanced Materials Research, v. 829, p. 784-789, 2014.

104 MARX, J. et al. Spin canting in ferrite nanoparticles. Hyperfine interact, v. 237, p. 13-18, 2016.

105 KERIM, F. M. A.; ALY, H. F.; EL-AGRAMY, A. Infrared absorption spectra of some lanthanide acetylacetonate complexes. Proc. Indian Acad. Sci., v. 85, n. 6, p. 559-566, 1977.

106 MISUMI, S.; IWASAKI, N. The Infrared Spectra and Some Properties of Tris- ( acetylacetonato ) Lanthanide ( III ) Complexes. Bulletin of the Chemical Society of Japan, v. 40, n. 3, p. 550-554, 1967.

107 TANDON, S. P.; MEHTA, P. C.; KAPOOR, R. N. The Infrared Absorption Spectra of Some Samarium Ethylbenzoyl Acetate Complexes. Z. Naturforsch, v. 25, p.

142-145, 1970. 
108 PARK, J. et al. Synthesis of Monodisperse Spherical Nanocrystals Angewandte. Angewandte Chemie International Edition, v. 46, n. 25, p. 4630-4660, 2007.

109 KAUR, J. et al. Synthesis, characterization and luminescence behaviour of ZrO2:Eu3+, Dy3+ with variable concentration of Eu and Dy doped Phosphor. Superlattices and Microstructures, v. 73, p. 38-53, 2014.

110 CORR, S. A.; RAKOVICH, Y. P.; GUN'KO, Y. K. Copyright @ 2008 The Authors Multifunctional Magnetic-fluorescent Nanocomposites for Biomedical Applications. Nanoscale Research Letter, v. 3, p. 87-104, 2008.

111 DUAN, $\mathrm{H}$. et al. Beating the exclusion rule against the coexistence of robust luminescence and ferromagnetism in chalcogenide monolayers. Nature Communications, v. 10, p. 1-9, 2019.

112 JIANG, W. et al. Influence of high magnetic field on the luminescence of Eu3 + doped glass ceramics. Journal of Applied Physics, v. 116, p. 1-5, 2014. 